\title{
TECNOLOGÍA LÍTICA DEL SITIO DE MODO TÉCNICO 3 DE LA DESEMBOCADURA DEL RÍO GUADALMESÍ (TARIFA, CÁDIZ) Y SU CONTEXTUALIZACIÓN HISTÓRICA EN EL SUR DE LA PENÍNSULA IBÉRICA
}

\section{Mode 3 lithic technology at the mouth of the Guadalmesi River (Tarifa, Cádiz) and its historical context in the South of the Iberian Peninsula}

\author{
Luis Pérez Ramos ${ }^{1}$
}

Recibido el 7 de mayo de 2012. Aceptado el 6 de agosto de 2012

\begin{abstract}
Resumen. Presentamos el análisis morfotécnico del conjunto lítico del sitio de modo técnico 3 de la desembocadura del río Guadalmesi (Tarifa, Cádiz). Exponemos las distintas estrategias de reducción de soportes y configuración de los artefactos líticos, prestamos especial atención a las diferentes estrategias y métodos de talla, con el objetivo de plantear la variabilidad, tanto sincrónica como diacrónica, de los conjuntos líticos del Paleolítico Medio en el sur peninsular, en su contexto histórico.

Palabras claves: Paleolítico Medio, Estrecho de Gibraltar, Musteriense, modo 3, tecnología lítica, Tarifa.

Abstract. This paper presents a morphotechnical analysis of the mode 3 lithic assemblages at the mouth of the Guadalmesi river (Tarifa, Cádiz). We expose the distinct lithic reduction strategies and configuration of tools. We pay special attention to the diversity of reduction sequences and knapping methods with the aim of raising the variability of the Middle Paleolithic assemblages in the South of the Iberian Peninsula in its historical context, both in a synchronic and diachronic level.
\end{abstract}

Key words: Middle Palaeolithic, Strait of Gibraltar, Mousterian, mode 3, lithic technology, Tarifa.

\section{INTRODUCCIÓN}

Este trabajo se incluye en los estudios de tecnología lítica. Entendemos la tecnología lítica como un medio complementario, que nos facilitará la consecución del objetivo que nos planteamos como historiadores, que no es otro que acercarnos a la forma de vida concreta de una sociedad determinada. Para alcanzar esta meta precisamos de la realización de distintas analíticas, como las derivadas de la antracología, arqueozoología, tafonomía, dataciones absolutas, etc., con las que no contamos en este momento, por lo que asumimos las limitaciones que supone el registro analizado, donde únicamente disponemos de evidencias líticas materiales. A pesar de ello consideramos relevante su puesta en valor.

El sitio prehistórico de la desembocadura del río Guadalmesí se localizó en el año 1999 durante la campaña de prospección del término municipal de Tarifa. En su recogida no existió criterio discriminatorio de selección en cuanto a materia prima o tipometría, presentamos por tanto muestras totales de un conjunto lítico de superficie, pero que se

(1) Miembro del Grupo de Investigación Primeras ocupaciones humanas y sus inferencias socioeconómicas en el extremo Sur de la Península Ibérica. (PAI. HUM-831).Universidad de Cádiz.primerasocupacioneshumanas@uca.es 
encuentra íntimamente relacionado con el depósito sobre el que aparece, incluso localizándose numerosas piezas en conexión estratigráfica, como veremos en el apartado geológico y geomorfológico.

Fue identificado en ese momento como uno de los sitios que se sitúan entre "Arroyo de la Viña y Río Guadalmesí" (Ramos 2008:120). El conjunto lítico ha permanecido inédito hasta la realización de la memoria de investigación del autor ${ }^{2}$.

\section{METODOLOGÍA}

En el análisis morfotécnico de los artefactos líticos empleamos la metodología desarrollada por el Sistema Lógico Analítico (SLA) (Carbonell et al. 1983; Carbonell et al. 1992).

El corpus teórico del SLA es una derivación no tipológica de la línea marcada por George Laplace (1972), conservando su espíritu analítico y estructural, pero eliminando el componente tipológico (Carbonell et al. 1983) y la perspectiva culturalista de la realidad histórica (Carbonell et al. 2005), al tiempo que le influye el enfoque analítico y sistémico (Clarke 1968) y se alimenta de la lógica histórica (Thompson 1981; Carbonell et al. 2006), recogiendo también la perspectiva procesual que plantea el estudio de cadenas operativas líticas (Carbonell 2005), al introducir los factores espacio y tiempo en el análisis de los objetos (Carbonell et al. 1997), de lo que se desprende un marcado carácter de ruptura con el empirismo y subjetivismo tradicional y aporta el método analítico, la propia lógica histórica y la dialéctica a la investigación prehistórica (Carbonell et al. 1999).

EI SLA se ha demostrado especialmente eficaz en el análisis de los conjuntos líticos adscritos a los modos técni$\cos 1,2$ y 3 y lo consideramos el más oportuno con nuestra posición teórica ${ }^{3}$ de partida, así como el más apropiado para este tipo de conjuntos.

Se ha aplicado con éxito en amplias zonas de la Península lbérica, principalmente en la redacción de tesis doctorales, como ha sido en los distintos yacimientos de la
Sierra de Atapuerca y la Meseta Norte de España (Menéndez 2009; Mosquera 1995; Navazo 2006; Rodríguez 1997; Terradillos 2010), en la cuenca Media-Baja del Tajo (Mejías 2009), en el nordeste de la Península Ibérica y sudeste de Francia (García 2005; Chacón 2009).

Valoramos el SLA como un método de clasificación tipológico abierto, por ello hemos incorporado algunas aportaciones que al mismo se realizan desde las tesis doctorales mencionadas, que hemos expuesto en otras ocasiones (Pérez 2010) y que pasamos a desarrollar en las siguientes líneas.

Al aplicar los conceptos de la fase constructiva, cada artefacto ha sido clasificado e integrado en la Categoria Estructural correspondiente, situándolo así de manera espacio-temporal en el momento que le corresponde dentro de la secuencia de producción.

Para el análisis tipométrico se han tomado medidas de longitud, anchura y espesor de todo el conjunto lítico, al objeto de determinar el formato y volumen de cada artefacto. Las Bases Positivas (lascas) y las Bases Negativas de Explotación (núcleos), ya sean en primera o segunda generación, se han clasificado tipométricamente según lo establecido por Xose Pedro Rodríguez (1997), cuyo criterio está basado en la anatomía de la mano y las características tipométricas de los objetos, correspondiéndose con:

- Gran formato: más de $100 \mathrm{~mm}$.

- Medio formato: entre 61 y $100 \mathrm{~mm}$.

- Pequeño formato: entre 31 y $60 \mathrm{~mm}$.

- Formato muy pequeño: menos de $30 \mathrm{~mm}$.

Para establecer el formato de las Bases Negativas de Segunda Generación de Configuración (objetos retocados) se ha seguido el criterio establecidos por el SLA y que Joan García i Garriga (2005) aplica en su tesis doctoral:

- Formato Macro: entre 80 y $175 \mathrm{~mm}$.

- Gran formato: entre 55 y $80 \mathrm{~mm}$.

- Formato medio: entre 55 y $30 \mathrm{~mm}$.

- Pequeño formato: entre 10 y $30 \mathrm{~mm}$.

(2) En este artículo se presenta uno de los aspectos desarrollados en la memoria de investigación para la obtención del Diploma de Estudios Avanzados (DEA), concretamente el de la tecnología lítica, que el autor defendió en la sede central de la UNED (Madrid), el día 15/12/2010, con el título "El yacimiento de modo técnico 3 de la desembocadura del río Guadalmesí (Tarifa, Cádiz) y su contextualización histórica en el Sur de la Península lbérica", y que contó con la codirección de los Profs. Martí Mas (UNED) y Vicente Castañeda (UCA).

$\left({ }^{3}\right)$ Entendemos la posición teórica (Gándara 1993) como un compromiso a nivel personal y profesional. En nuestro caso nos posicionamos de manera genérica del lado de las corrientes materialistas frente a las idealistas y concretamente de la llamada Arqueología social, cuya teoria sustantiva es el Materialismo Histórico no dogmático, entendido como la aplicación a la historia y la economía del materialismo dialectico de Marx, siendo su objetivo la explicación de la realidad como totalidad histórica concreta y su finalidad generar nuevo conocimiento de la manera más objetiva posible para ayudarnos a entender el presente. Desde este posicionamiento se procura la transformación de la realidad a través de la praxis, se entiende la Arqueología como una disciplina de la ciencia social que deberá conocer procesos sociales, inferir relaciones sociales a partir de componentes materiales e inferir el contenido de las formaciones socioeconómicas a través de sus formas culturales para alcanzar los objetivos definidos (Bate 1998). Por ello desde este posicionamiento el arqueólogo no debe conformarse con el ordenamiento y descripción de los materiales, deberá huir del reduccionismo tipológico propio del historicismo cultural, pues "son las relaciones sociales y no las manifestaciones culturales las que traducen en el espacio y en el tiempo los procesos que llamamos históricos" (Arteaga 1992). En este sentido el investigador debe establecer el nivel de desarrollo de las fuerzas productivas que le permitirá reconstruir las relaciones sociales de producción y en definitiva el modo de producción (Lumbreras 1974). 
Para orientar los objetos nos hemos basado en el concepto de rectángulo minimal establecido por G. Laplace (1977), una vez orientado tendremos en cuenta que la arista más tallada se situará en la parte distal y la cara más tallada será la cara horizontal superior (Rodríguez 1997). Para orientar las BNE utilizamos el criterio de volumen minimal (Guilbaud 1985), variación del rectángulo minimal (Laplace 1977; Carbonell et al. 1987).

En cuanto a las fracturas, hemos diferenciado entre BPF (Bases Positivas Fracturadas), en las que la fractura es longitudinal u oblicua al plano horizontal, permitiendo conservar el talón y con ello su estudio y análisis morfotécnico y FBP (Fracturas de Bases Positivas) en las que ha desaparecido el talón, por lo que han sido descritas e incluidas en el cómputo general, pero no se tendrán en cuenta para el estudio estadístico de las BP (García 2005).

El SLA clasifica las Bases naturales ( $\mathrm{Bn}$ ) en función de si presentan estigmas de percusión (Bnb) o no (Bna) y fracturas (Bnc), nosotros hemos tenido en cuenta las bases naturales con estigmas de percusión (Bnb), ya que al tratarse de una recogida de superficie son las únicas evidencias líticas de esta categoría que no plantean dudas sobre su aportación antrópica al yacimiento.

La metodología empleada en el análisis de las Bases Negativas de Explotación (BNE) (núcleos), independientemente de que sean en primera o segunda generación, se ha realizado en base a los siguientes criterios:

- El carácter facial, que nos informa del número de caras talladas y que jerarquiza al resto: Unifacial (U), Bifacial (B), Trifacial (T) y Multifacial (M). Este concepto se encuentra intimamente relacionado con el de estrategia de talla que veremos a continuación.

- El carácter centrípeto, que nos informa del porcentaje de zona tallada respecto a no tallada del perímetro, hemos aplicado cuatro criterios (Chacón. 2009), en lugar de los cinco descritos por el SLA, dividiéndose entre: tendencia centrípeta (1C) con menos del 25\% del perímetro, poco centripeto (2C) entre el 25 y el $50 \%$, centrípeto (3C) entre el 50 y el $75 \%$ y totalmente centrípeto (4C) con todo el perímetro retocado.

- En el carácter de oblicuidad, que indica la inclinación de las extracciones en relación con el plano de orientación del objeto se distinguen cinco modalidades: Plano (p) entre $0^{\circ}$ y $15^{\circ}$, semiplano (sp) entre $15^{\circ}$ y $35^{\circ}$, simple (s) entre $35^{\circ}$ y $55^{\circ}$, semiabrupto (sa) entre $55^{\circ}$ y $75^{\circ}$ y abrupto (a) entre $75^{\circ}$ y $90^{\circ}$.

- El carácter de profundidad, indica la longitud de la extracción más profunda en relación con el cortex, distinguiéndose: Muy marginal $(\mathrm{mm})$, marginal $(\mathrm{m})$, profundo $(p)$, muy profundo $(m p)$ y total $(t)$.
- El carácter de la arista frontal, que nos informa de la forma del filo bajo una visión superior del plano horizontal y se distinguen las formas genéricas de: Convexo (cx), recto $(r)$ y cóncavo $(c)$, aunque existen otras formas como oval (0), uniangular (1a) y biangular (2a).

- El carácter de la arista sagital, se corresponde con la forma del filo visto desde el plano octogonal al plano bisector de la arista, o dicho de otra forma, es la morfología de la arista de intersección entre el plano de intervención y el plano de configuración. Existen tres modalidades: incurvada (inc), recta ( $r$ ) y sinuosa (sin). La arista sagital puede ser simétrica (si) o asimétrica (nsi), así como se podría valorar su continuidad o discontinuidad cuando nos encontramos varios planos de intervención (Chacón 2009).

- Debido a la importancia cuantitativa y cualitativa que adquieren en el conjunto los sistemas de explotación predeterminados, incluimos los criterios que aplican D. Leticia Menéndez (2009) y M. Gema Chacón (2009) en lo que se refiere a la Fase de la Secuencia Productiva, y que han sido tomados de Marina Mosquera (1995) y Manuel Vaquero (1997), entendiendo ésta como el momento de la cadena operativa en la que se encuentran las BNE cuando han sido abandonadas, distinguiendo los estadios de Inicialización (I), que es cuando se procede al descortezado del núcleo y que por una u otra causa ha sido abandonado; Explotación (E), en la que se presenta un modelo de configuración plenamente identificado para la producción de BP y Terminal (T), cuando el objeto ha agotado su capacidad productiva.

- Aplicamos los criterios de Testado (TEST), a aquellas BNE que han sido testadas y abandonadas y Preparación $(P)$, que son las $B N E$ que han sido abandonadas en el momento de preparación de las caras horizontal superior e inferior (Menéndez 2009).

- Igualmente nos ha parecido que aporta valiosa información los conceptos de Estrategia de Talla y Método de Talla. La estrategia de talla se describe a través de los criterios de facialidad, planos de intervención y dirección de las extracciones y el método de talla sería el esquema o sistema operativo aplicado en la producción de BP (Chacón 2009).

- En la misma línea de obtener la máxima información de los sistemas de explotación predeterminados, hemos aplicado el criterio de jerarquización de las superficies, distinguiendo entre superficie horizontal superior y superficie horizontal inferior (Menéndez 2009). De la cara horizontal superior hemos analizado: la dirección de los negativos, morfología, ángulo de los levantamientos y grado de prepara- 
ción y de la cara horizontal inferior: el número de levantamientos, localización, ángulo de los levantamientos y grado de preparación, así como la simetria o asimetria que presentan.

- Finalmente hemos decidido realizar un estudio complementario de las BNE predeterminadas aplicando los criterios establecidos por E. Boëda (1988, 1990, 1993, 1994 y 1995) y L. Slimak (1998-1999).

Las Bases Positivas (BP) (lascas) son los objetos desprendidos de la matriz en el proceso de configuración o explotación. Para su análisis morfotécnico hemos tenido en cuenta los criterios descriptivos expuestos por X. P. Rodríguez (1997):

- Cara talonar, donde se ha descrito el talón en base al tipo; plataforma (PLA), lineal (LIN), puntiforme (PNT), roto $(R T)$ y abatido (ABAT). Delineación; recto $(\mathrm{RT})$, convexo (CX), cóncavo (CC), sinuoso (SIN), uniangular (1a). Facetado; no facetado (NF), unifacetado (UF), bifacetado (BF) y multifacetado (MF). Corticalidad; cortical (CO), cortical/no cortical (CO/ NCO), no cortical/cortical (NCO/CO) y no cortical (NCO). Morfología; triangular (TRG), trapezoidal (TRP), cuadrangular (CDR), pentagonal (PENT), polígono indeterminado (PI), oval (OV).

- Cara dorsal, donde se ha tenido en cuenta la corticalidad, clasificándose en primer lugar en función del porcentaje de cortex que presenten, resultando cortical (CO), cortical/no cortical (CO/NCO), no cortical/cortical (NCO/CO) y no cortical (NCO). El número de levantamientos, la delineación y la oblicuidad de las extracciones.

- Cara ventral, donde se ha descrito el tipo de bulbo (marcado o difuso) y la delineación.

- Morfología de la BP, desde un punto de vista frontal, sagital y transversal.

Hemos valorado cualitativa y cuantitativamente el porcentaje de BP procedentes de sistemas de explotación predeterminados, independientemente de la subcategoría (CO, $\mathrm{CO}-\mathrm{NCO}, \mathrm{NCO}-\mathrm{CO}, \mathrm{NCO}$ ) a la que pertenezca, relacionando este dato con las BNE predeterminadas.

En cuanto a las Bases Negativas de Segunda Generación de Configuración (BN2GC) (objetos retocados), hemos sido muy estrictos en su clasificación al proceder de una prospección superficial que ha sufrido las alteraciones propias de los agentes erosivos, pisoteo, etc.

Las BN2GC, como BP que han sido, se estudian utilizando los mismos criterios analíticos, en cuanto a cara ventral, cara talonar y cara dorsal que se vieron para las BP, que completamos con la asignación de orden, grupo y análisis del retoque según la tipología analítica (Laplace 1972).
Al aplicar los conceptos descriptivos analíticos, somos conscientes de que un conjunto lítico debe ser estudiado desde las tres perspectivas, análisis Morfotécnico, Morfopotencial y Morfofuncional. Nosotros hemos realizado un detallado análisis morfotécnico en base a los parámetros que acabamos de explicar, así como en los casos específicos de BN2GC se ha realizado un análisis Morfopotencial, valorando la capacidad de intervención sobre la materia en base a unos modelos geométricos (diedro, triedro, semitriedro, pirámide) a los que se asocia la arista de los objetos (Rodríguez 1997), pero no sae ha realizado un análisis Morfofuncional al tratarse de artefactos líticos de superficie sometidos a procesos erosivos y alteraciones físico-químicas. Somos conscientes de las limitaciones que supone un estudio morfotécnico sin su complementación traceológica.

Entendemos la "tecnología prehistórica" no sólo como la disciplina que analiza la forma de los objetos, sino que pretende conocer la selección de las materias primas, su proceso de fabricación, utilización y posterior abandono (Carbonell 2005), por ello hemos realizado al conjunto lítico un análisis morfotécnico y morfopotencial, así como un estudio descriptivo de las alteraciones que presentan en forma de pátina y rodamiento, identificación macroscópica litológica y realización de láminas delgadas, a fin de intentar proponer las posibles áreas fuente. Con ello obtendremos una valiosa información sobre la movilidad de estos grupos y el uso social que realizan del espacio, lo que nos permitirá proponer una explicación socioeconómica del pasado.

Relacionado con estos conceptos nos interesa analizar el primer nivel de la cadena operativa, es decir, conocer la selección de las materias primas, planteándonos alcanzar los siguientes objetivos:

- Identificar las distintas estrategias de reducción de soportes y configuración de las herramientas líticas por parte de las sociedades cazadoras-recolectoras adscritas al modo técnico 3, y concretamente las utilizadas en el yacimiento de la desembocadura del río Guadalmesí.

- Determinar la movilidad de estos grupos, la articulación del territorio y el uso social que realizan del espacio.

- Desde la Arqueología Social no debemos conformarnos con la explicación analítica y porcentual derivada del análisis litológico, sino que éste debe ir más allá y servirnos para intentar una explicación socioeconómica del pasado a partir de la gestión practicada sobre los recursos minerales. Pues éstos no pueden ser desvinculados del resto de procesos productivos, con lo que nos aproximaremos al nivel de desarrollo de las fuerzas productivas (Terradas 2001). 
La metodología empleada ha seguido diferentes líneas de trabajo:

- Se ha prospectado de manera intensiva las inmediaciones del yacimiento en un radio de unos $20 \mathrm{Km}$, con el objetivo de localizar e identificar las principales rocas de la comarca y las posibles áreas de captación de materias primas.

- Se ha realizado una recogida de muestras, en forma de bases naturales de los principales tipos litológicos que afloran en la zona prospectada, con el objetivo de realizar láminas delgadas y análisis mediante microscopía óptica con luz doblemente polarizada a los distintos tipos de rocas que han sufrido modificación antrópica, para determinar sus características petrológicas y el tipo de selección de materias primas minerales llevada a cabo en la elaboración del conjunto lítico.

- Con la información obtenida se ha generado una base de datos, cuyo fin es la obtención de una litoteca que engrosará la que se encuentra en elaboración para el Campo de Gibraltar por el Grupo de Investigación PAI-HUM 831.

- Hemos realizado un estudio mineralógico y una clasificación petrológica a visu del conjunto lítico objeto de estudio.

- Se han elaborado una serie de láminas delgadas a determinadas piezas de los tipos litológicos más re-

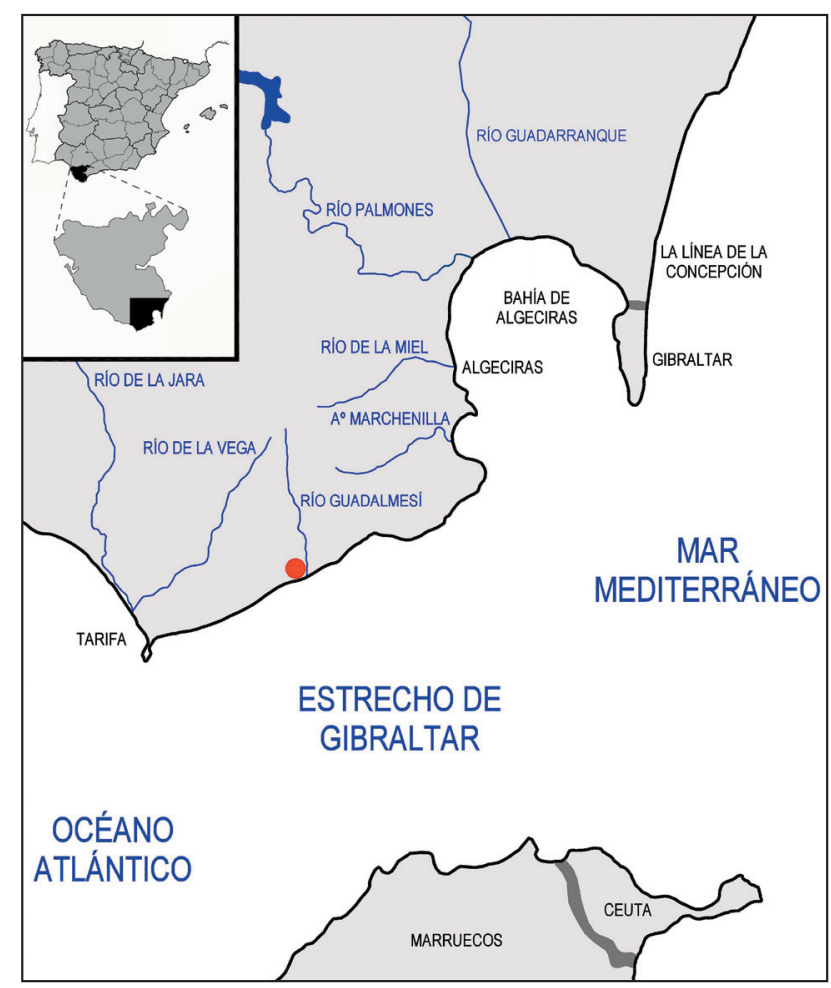

A Figura 1. Localización geográfica del sitio de la desembocadura del río Guadalmesí. presentativos, para su estudio microscópico con luz doblemente polarizada.

La técnica empleada para la confección de la descriptiva litológica ha sido:

- Establecimiento de las características texturales y mineralógicas a visu, con lupa de 10 aumentos, a fin de adjudicar cada pieza a un grupo litológico.

- Determinación del color utilizando la tabla de colores Munsell.

- Finalmente se ha realizado la comparación mediante el microscopio petrográfico de los tipos litológicos presentes en el conjunto lítico con las principales rocas de la comarca que han sido utilizadas como bases naturales, para proponer posibles áreas fuente de las materias primas minerales utilizadas, lo que nos permitirá inferir la movilidad de estos grupos.

Somos conscientes de las limitaciones que supone la identificación macroscópica y el análisis petrológico mediante microscopía óptica, sin la aplicación de otras técnicas de análisis propias de la petroarqueología, como son la difracción de rayos $X(X R D)$, las distintas espectometrías: de fluorescencia de rayos $X$, de masas, de emisión, la microscopía electrónica de barrido, etc, pero consideramos que pueden resultar válidas e interesantes las inferencias obtenidas para la identificación de áreas de aprovisionamiento y alcanzar los objetivos planteados al inicio.

\section{LOCALIZACIÓN GEOGRÁFICA Y RESEÑA GEOLÓGICA}

Estamos en la línea de las tesis que asocian las tareas de selección y aprovisionamiento de materias primas líticas por parte de grupos neandertales a un nivel eminentemente local (Geneste 1992; Turq 1996), lo que requiere por nuestra parte de un conocimiento geológico, geográfico y físico del medio en el que desarrollaron sus actividades, en definitiva donde materializaron su modo de vida.

El sitio prehistórico de la desembocadura del río Guadalmesí se localiza en la orilla norte del Estrecho de Gibraltar, en la comarca del Campo de Gibraltar, en el término municipal de Tarifa (Cádiz) y concretamente en el Cortijo de la Cañada de Guadalmesí (Figs. 1, 2a y 2b).

La cuenca del río Guadalmesí y el sitio arqueológico localizado en su desembocadura se sitúan en el extremo occidental de la Cordillera Bética, en el conocido como Arco de Gibraltar, gran estructura mediante la que se conectan los orógenos de ambos lados del Mediterráneo occidental. En ella afloran principalmente sedimentos tipo Flysch, deposi- 


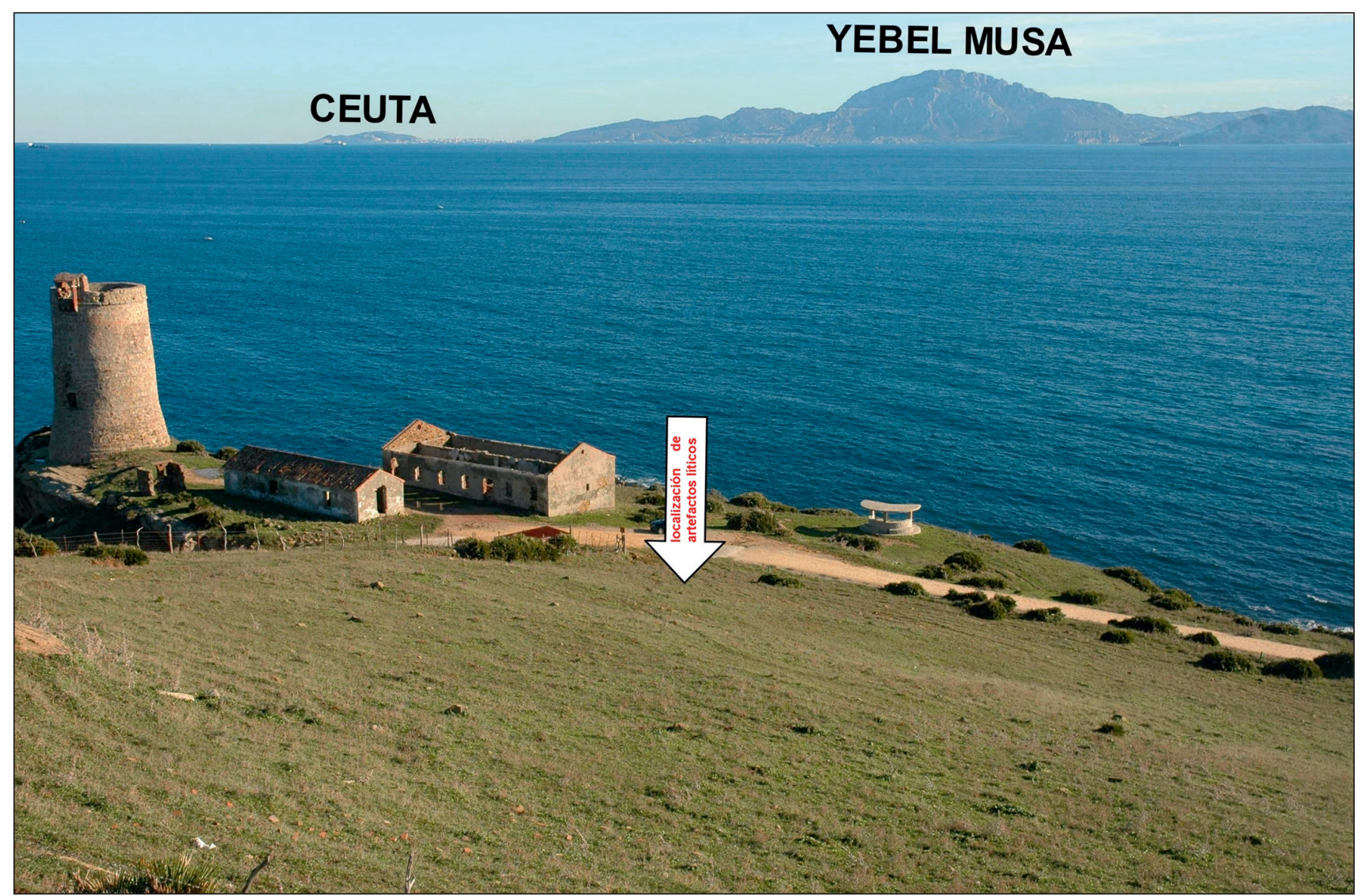

ه Figura 2A. Situación sobre el acantilado costero, situado entre la desembocadura del río Guadalmesí y la del arroyo Cañada de los Alhelíes, más próximo a la primera, y junto a la torre almenara que domina el lugar.

tados en ambientes de abanico submarino profundo durante el Cretácico superior-Mioceno inferior, y pertenecientes a las unidades paleogeográficas de la Cordillera Bética denominadas Complejo del Campo de Gibraltar (CCG).

El tramo alto del río está ocupado por afloramientos de Arenisca del Aljibe, pertenecientes a la Unidad del Aljibe, contenidos en cuarzo en torno al $90 \%$ y tamaños de grano que van desde muy fino a microconglomerado. Son las rocas que originan los principales relieves del Campo de Gibraltar y la materia prima de la gran mayoría del conjunto lítico analizado.

Los tramos medio y bajo discurren encajados entre las Sierras del Bujeo y del Cabrito, conformadas por materiales pertenecientes a la Unidad de Algeciras-Los Nogales. En el cambio de pendiente que se origina en el contacto entre los relieves de Arenisca del Aljibe y los materiales más blandos de la Unidad de Algeciras-Los Nogales afloran extensos depósitos aluviales correspondientes a deslizamientos de ladera y conos de derrubios, de edad Cuaternario s.l., que sirvieron de área fuente a los depósitos fluviales de la desembocadura del río.

Además, el estar situados en el contacto entre las placas litosféricas africana y euroasiática, que tienden a converger, ha provocado un levantamiento generalizado de la orilla Norte del Estrecho, que junto con las oscilaciones glacioeus- táticas del nivel del mar ocurridas durante el Cuaternario, con fuertes descensos durante los periodos glaciales, y excavación de plataformas de abrasión, durante las altas paradas del nivel del mar (highstand) ocurridas en los óptimos interglaciares, ha conformado para nuestra zona unidades morfosedimentarias escalonadas que hemos identificado como terrazas marinas correspondientes a épocas interglaciares en las que el mar estaba a alturas similares o pocos metros por encima del nivel actual. Una de estas terrazas guarda estrecha relación con el sitio arqueológico que aquí exponemos.

La desembocadura del Guadalmesí se sitúa en la divisoria de las cuencas hidrográficas atlántica y mediterránea, donde la característica costa acantilada, forma el frente norte del Estrecho de Gibraltar, con dirección ENE-WSW y un trazado fundamentalmente rectilíneo, lo que indica un claro control tectónico de este tramo de litoral.

El río Guadalmesí, de dirección N-S, con una longitud de $8 \mathrm{Km}$ y una pendiente media del 15\% (Valenzuela 1995), es un río pluvial que lleva agua durante todo el año, nace en la Sierra de la Luna a 786 m.s.n.m, en el Tajo de la Corza, cuya base geológica forma parte de la Unidad del Aljibe, a la que pertenece la Arenisca del Aljibe (Gavala 1924), de edad Aquitaniense.

El yacimiento (Fig. 3) ha sido puesto de manifiesto por el abarrancamiento producido en el carril que parte del ca- 


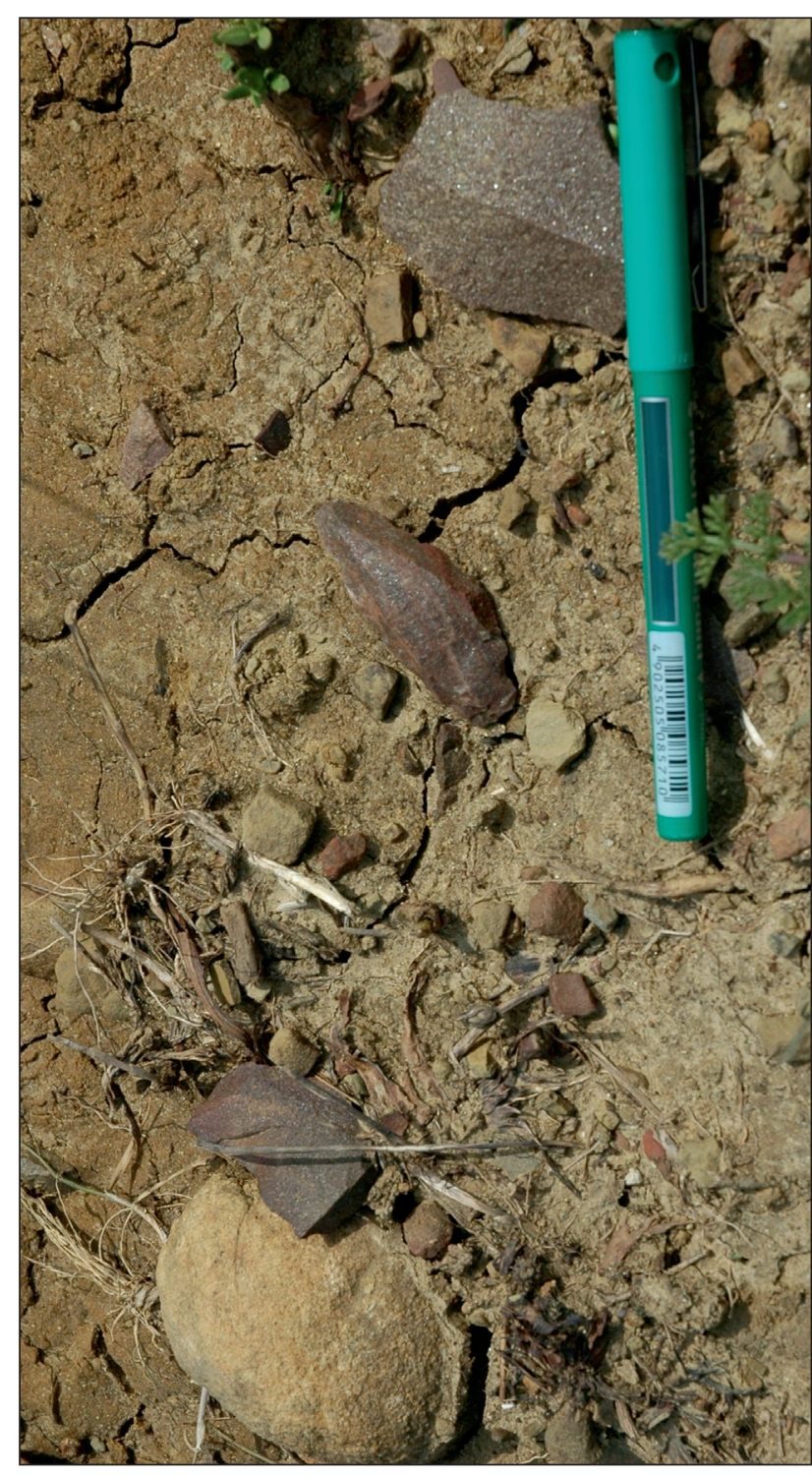

$\Delta$ Figura 2в. Imagen de detalle de localización de artefactos líticos en superficie.

mino paralelo a la costa y va hacia el $\mathrm{N}$ para dar acceso al Cortijo Costa.

Sobre el acantilado de la margen derecha de la desembocadura del Guadalmesí, y a cota $+15 \mathrm{~m}$, hemos localizado un contacto plano entre los materiales terciarios de la Unidad de Algeciras y depósitos fluviales pleistocenos, que interpretamos, basándonos en las bioerosiones localizadas y en los estudios geomorfológicos regionales llevados a cabo por el Grupo PAI. HUM-831, como la plataforma de abrasión de una terraza marina correspondiente a una de las altas paradas del nivel del mar del estadio isotópico 5.

Sobre esta rasa aflora un paquete de conglomerados con cantos muy redondeados, de claro origen fluvial, que se corresponderian con los depósitos de la desembocadura del Paleo-Guadalmesí. En la desembocadura actual se puede observar un proceso similar al que originó la serie descrita, con el depósito de un potente paquete de conglomerados, aportados por el río, sobre la plataforma de abrasión marina actual. El levantamiento tectónico de toda esta parte de la costa, elevó la plataforma de abrasión del OIS 5 y los sedimentos fluviales que se depositaron sobre ella a la cota en que actualmente los encontramos.

Discordantes sobre la parte más proximal de los sedimentos fluviales y sobre los materiales de la Unidad de Algeciras que ocupan la pendiente anexa, aparecen unos depósitos de ladera de poca potencia consistentes en arenas limo-arcillosas de color 10YR 5/4, con cantos angulosos dispersos de entre 0,5 y $30 \mathrm{~cm}$ de diámetro, y origen aluvialcoluvial. Gran parte de las piezas recogidas se localizan a techo de estos depósitos de ladera (Fig. 4), seguramente depositados durante el levantamiento tectónico de la costa.

\section{ESTRATEGIAS DE SELECCIÓN, APROVISIONAMIENTO E IDENTIFICACIÓN DE ÁREAS FUENTE}

En el proceso de captación de materias primas líticas durante la Prehistoria se han definido dos mecanismos principalmente; la explotación directa del territorio y el intercambio, que a la vez se generan a partir de unos sistemas de explotación determinados, interesándonos en este trabajo el conocido como "laboreo superficial", que es el sistema recolector que se realiza seleccionando cantos rodados de las cuencas, los bordes de las playas, o cualquier otro depósito sedimentario desde sus fuentes originales, correspondiéndose con afloramientos en posición secundaria (Mangado 2006).

La materia prima (tabla 1) seleccionada en la elaboración de los 1321 artefactos líticos analizados ha sido en un 92,66\% arenisca del Aljibe $(n=1224$ en arenisca, $\mathrm{n}=88$ en sílex, $\mathrm{n}=6$ en metacuarcita, $\mathrm{n}=2$ en radiolarita $\mathrm{y}$ $\mathrm{n}=1$ roca ígnea) (Fig. 5).

La arenisca fue seleccionada en forma de canto redondeado, en posición secundaria, depositados por el río Guadalmesí en las inmediaciones del yacimiento (Fig. 6), procede de la erosión de la Sierra del Cabrito y Sierra del Bujeo, nos encontramos ante una arenisca silícea en más de un $90 \%$, compacta, muy cementada, capaz de producir filos diedros activos ante los procesos de talla (Torres et al. 2012).

La identificación macroscópica de la arenisca ha permitido diferenciar distintos tipos de tamaño de grano, que ha sido confirmado posteriormente con la serie de láminas delgadas, así tenemos: $(n=160$ arenisca de grano muy fino con el $13,1 \%, n=273$ en arenisca de grano fino con el 22,3\%, $n=527$ en arenisca de grano medio con el $43,1 \%, n=245$ en arenisca de grano grueso con el $20 \%$ y $n=19$ en arenisca muy gruesa con el 1,6\%).

La presencia de arenisca de grano muy grueso (Fig. 7, arriba izda.), es prácticamente anecdótica, hecho que tene- 


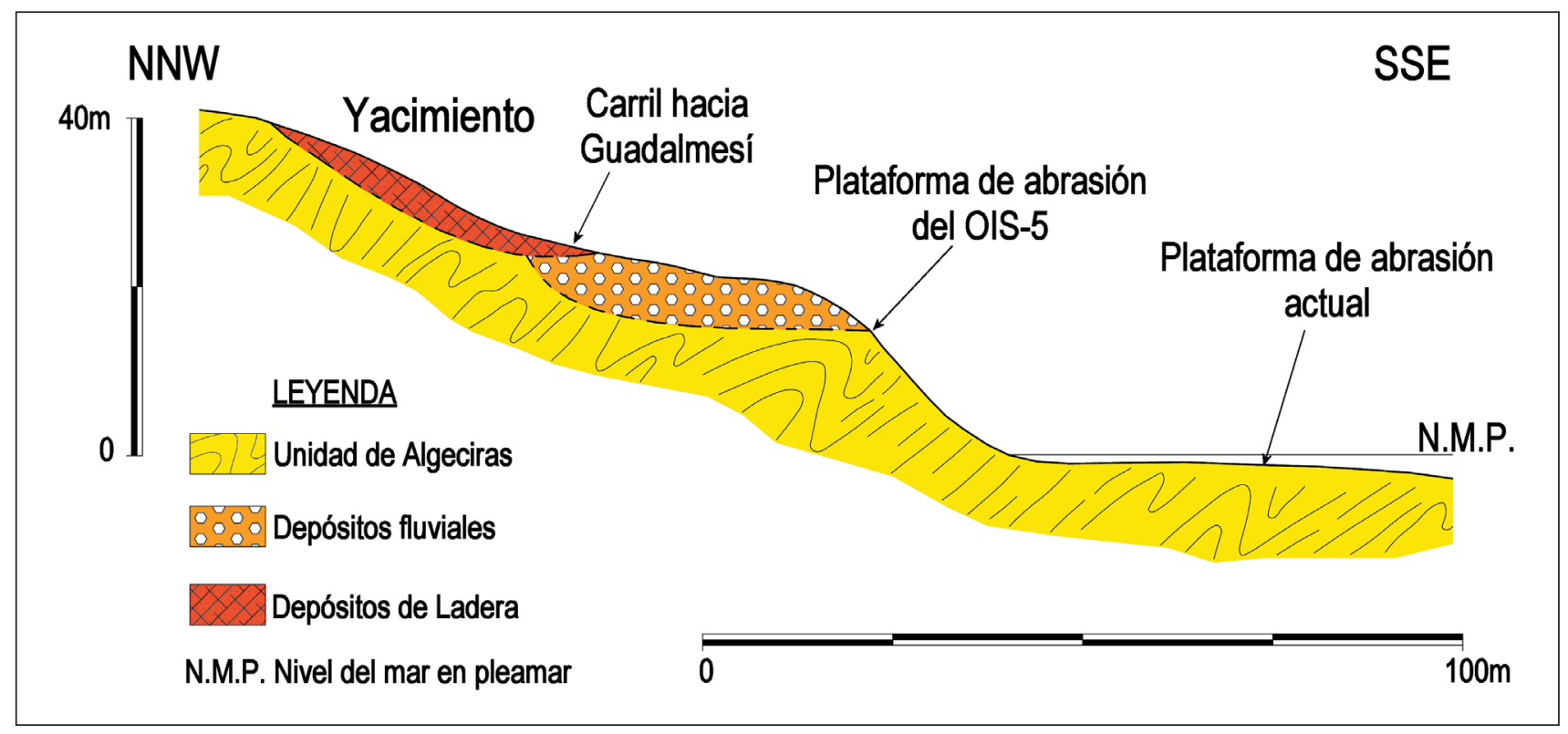

A Figura 3. Corte geológico del yacimiento de la desembocadura del río Guadalmesí (Autor F. Torres, digitalización J. M. Tomassetti).

mos contrastado a nivel diacrónico para la zona del Campo de Gibraltar, donde se evidencia una disminución en el tamaño de grano de la arenisca seleccionada en relación con sitios del modo 2, como el yacimiento de Algetares en Algeciras (Cádiz) (Castañeda et al. 2009), así como de los sitios en tránsito desde el modo 2 al modo 3 (Castañeda et al. 2010a y 2010b), disminución que tendrá su continuidad en sitios de modo 4, como Ventorrillo de la Trocha 1 y 2 en Algeciras (Cádiz) (Castañeda et al. 2011).

El segundo tipo de roca representado en el yacimiento es el silex, con un total de 88 artefactos, lo que supone un $6,7 \%$, que a pesar de ser escaso, triplica el porcentaje en sílex para los sitios del modo 2 en el Campo de Gibraltar.

Los distintos tipos de sílex presentes en el yacimiento son: sílex masivo opaco (Fig. 7, arriba derecha), con un total de 41 artefactos líticos, identificándose los colores amarillo, beige, gris, marrón, rojo y verde, sílex masivo translúcido, con un total de 11, identificándose los colores beige, gris, marrón y verde, tratándose de un sílex de facies subbética que puede encontrarse en sitios del Campo de Gibraltar como la cantera de la Coracha, cantera de los Pastores o en el mismo Peñón de Gibraltar, localizándose además en forma de cantos e incluso bloques en las terrazas marinas situadas entre la desembocadura del río Guadiaro y Gibraltar (Torres et al. 2003); sílex oolítico $(n=30)$ (Fig. 7, abajo izda.) de colores beige, blanco, gris, marrón, así como sílex oolítico laminado y sílex oolítico poroso, cuya composición a nivel microscópico la forman oolitos, identificándose en el mapa geológico de Tarifa complejos que se denominan "Complejo Tectosedimentario Mioceno con bloques diversos", que ocupan grandes extensiones en el Campo de Gibraltar, existiendo bloques desde escala centimétrica a kilométrica de las más diversas litologías y edades, locali- zándolos de edad Jurásica y Cretácica que a veces contienen sílex, como lo que han sido localizados en el cerro de Agua de Enmedio (Tarifa).

Otros tipos de sílex, como sílex arcilloso $(n=2)$ (Fig. 7, abajo derecha.), sílex bandeado $(n=2)$, sílex brechoide beige $(n=1)$, silex hidratado $(n=1)$, con una mínima representación en el yacimiento tienen un origen autóctono, ya que como ocurre con la radiolarita $(n=2)$, pueden encontrarse entre las formaciones arcillosas de la Unidades geológicas del Campo de Gibraltar.

El tercer grupo lo componen 6 artefactos realizados en metacuarcita, que suponen el $0,45 \%$ del total, es una roca metamórfica compacta, cuyo afloramiento más próximo se localiza en la cuenca fluvial del río Guadiaro, el cual, por erosión lo transporta a la costa, donde la dinámica litoral lo redeposita y distribuye por las distintas terrazas marinas del Campo de Gibraltar. Hemos localizado cantos de metacuarcita en las terrazas marinas situadas entre Algeciras y Tarifa. Un origen similar proponemos para el único objeto que ha sido identificado en roca ígnea.

Se trata por tanto de materias primas autóctonas que se localizan en el propio yacimiento, o el entorno inmediato (Fig. 8), aunque observamos mayor movilidad que en sitios adscritos a modos técnicos anteriores.

\section{ANÁLISIS MORFOTÉCNICO}

El registro lítico analizado lo componen un total de 1321 artefactos líticos (tabla 1), de los cuales, 145 (11\%) se corresponden con Bases Negativas de Explotación (BNE), 943 $(71,4 \%)$ son Bases Positivas (BP) y $233(17,6 \%)$ Bases Negativas de Segunda Generación de Configuración (BN2GC). 

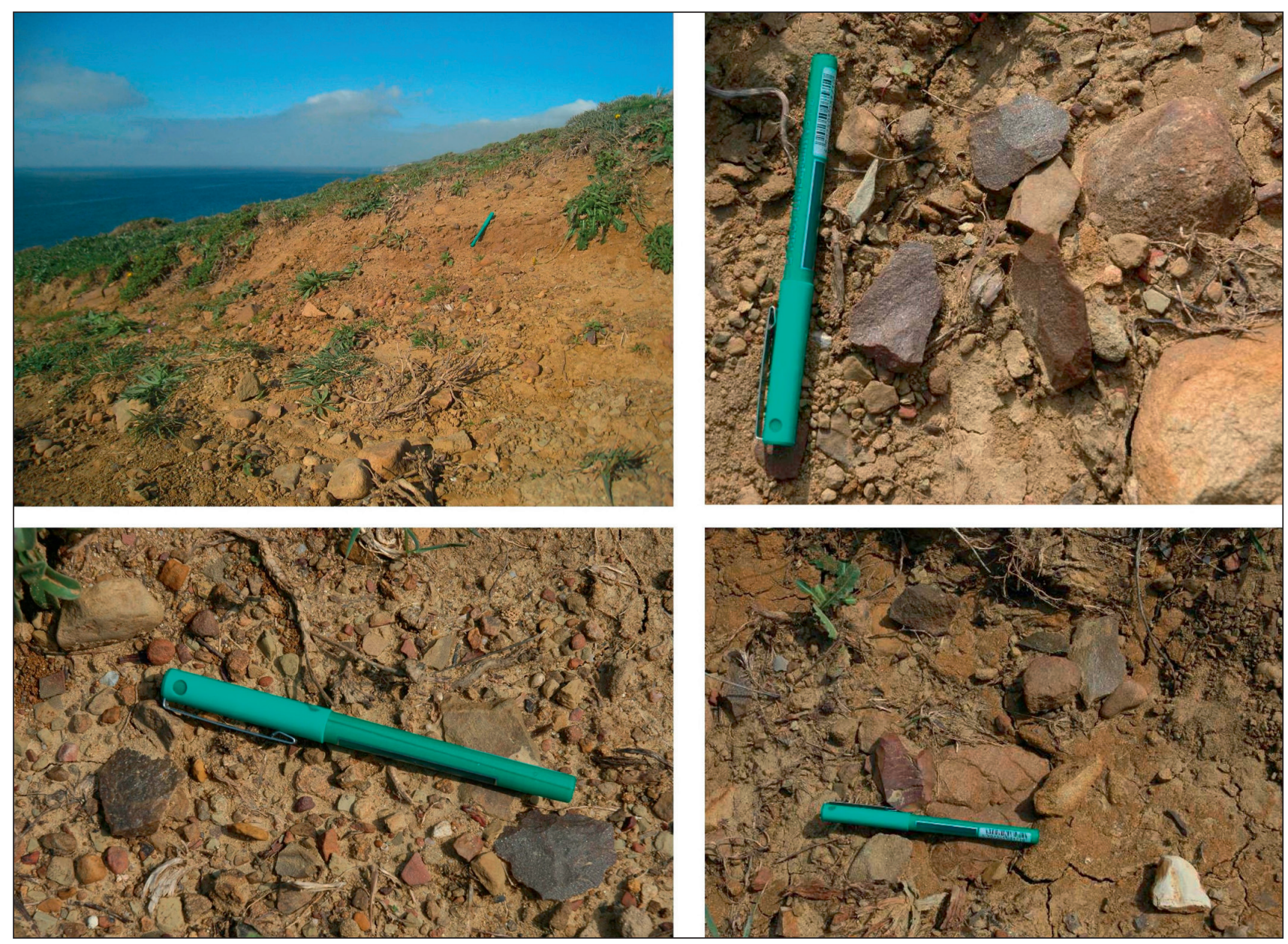

ム Figura 4. Depósitos de ladera e imágenes de localización de artefactos líticos.

Las aristas vivas y los planos de fractura frescos aún en la actualidad, nos indica un grado de rodamiento nulo, lo que interpretamos como resultado del escaso movimiento que ha sufrido el conjunto lítico desde su abandono.

Presentan pátina el 100\% de los casos, como consecuencia de los agentes físico-químicos que les han afectado.

\subsection{Análisis de las Bases Negativas \\ de Explotación (núcleos)}

De las 145 BNE, 13 presentan un índice de fractura que imposibilita su adscripción a una estrategia de talla determinada, por lo que son desechadas. Presentamos el análisis morfotécnico de un total de $132 \mathrm{BNE}$, lo que supone el 10\% del registro.

De ellas $107(81,1 \%)$ se corresponde con Bases Negativas de Primera Generación de Explotación y 25 (18,9\%) con Bases Negativas de Segunda Generación de Explotación.

La materia prima seleccionada para su reducción ha sido en más del 90\% la arenisca del Aljibe, seguido del sílex, predomina la elección de una arenisca de grano fino y medio (tabla 1).

Las BNE fueron abandonadas en un $78,8 \%$ de los casos, con tamaños (tabla 2) entre 31 y $60 \mathrm{~mm}$, se incluyen por tanto en un rango tipométrico de pequeño formato, seguido de lejos por el formato medio y escasamente representado el muy pequeño y el gran. El valor tipométrico medio se sitúa en $52,2 \times 57,4 \times 29,5 \mathrm{~mm}$.

A continuación presentamos al análisis morfotécnico de las BNE (tabla 3), debiendo precisar que el número de superficies totales analizadas debe ser superior al número de $B N E$, debido al aporte cuantitativo de las estrategias de talla bifaciales.

- El carácter facial dominante es el bifacial, seguido del unifacial y finalmente el trifacial.

- El carácter centrípeto tenemos que ponerlo en relación con la estrategia de talla, ya que el criterio 4C dominante, se corresponde con la superficie de explotación o cara horizontal superior de los bifaciales multipolares centrípetos (levallois recurrente y levallois de lasca preferente), mientras que el criterio $2 \mathrm{C}$, se relaciona con la superficie de preparación o cara horizontal inferior. Están escasamente representados los criterios $1 \mathrm{C}$ y $3 \mathrm{C}$.

- El carácter de oblicuidad está intimamente relacionado con la estrategia de talla, ya que los levanta- 


\begin{tabular}{|c|c|c|c|c|c|c|c|c|c|c|c|c|c|c|c|c|}
\hline \multirow{3}{*}{$\begin{array}{l}\text { MATERIA } \\
\text { PRIMA }\end{array}$} & \multicolumn{14}{|c|}{ CATEGORÍAS ESTRUCTURALES } & \multirow{2}{*}{\multicolumn{2}{|c|}{ TOTAL }} \\
\hline & \multicolumn{2}{|c|}{ BNE } & \multicolumn{2}{|c|}{$\begin{array}{l}\text { BNE } \\
\text { FRAC }\end{array}$} & \multicolumn{2}{|c|}{ BN2GC } & \multicolumn{2}{|c|}{$\begin{array}{c}\text { BN2GC } \\
\text { FRAC }\end{array}$} & \multicolumn{2}{|c|}{ BP } & \multicolumn{2}{|c|}{ BPF } & \multicolumn{2}{|c|}{ FBP } & & \\
\hline & N..$^{\circ}$ & $\%$ & $\mathrm{~N} .^{\circ}$ & $\%$ & $\mathrm{~N} .^{\circ}$ & $\%$ & $\mathrm{~N} .^{\circ}$ & $\%$ & $\mathrm{~N}$ & $\%$ & $\mathrm{~N} .^{\circ}$ & $\%$ & N..$^{\circ}$ & $\%$ & $\mathrm{~N} .^{\circ}$ & $\%$ \\
\hline AMF & 18 & 11,3 & 0 & 0,0 & 22 & 13,8 & 11 & 6,9 & 62 & 38,8 & 27 & 16,9 & 20 & 12,5 & 160 & 12,1 \\
\hline $\mathrm{AF}$ & 38 & 13,9 & 4 & 1,5 & 32 & 11,7 & 16 & 5,9 & 104 & 38,1 & 38 & 13,9 & 41 & 15,0 & 273 & 20,7 \\
\hline AM & 57 & 10,8 & 7 & 1,3 & 60 & 11,4 & 20 & 3,8 & 216 & 41,0 & 92 & 17,5 & 75 & 14,2 & 527 & 39,9 \\
\hline$A G$ & 13 & 5,3 & 2 & 0,8 & 38 & 15,5 & 8 & 3,3 & 120 & 49,0 & 39 & 15,9 & 25 & 10,2 & 245 & 18,5 \\
\hline AMG & 1 & 5,3 & 0 & 0,0 & 3 & 15,8 & 1 & 5,3 & 9 & 47,4 & 2 & 10,5 & 3 & 15,8 & 19 & 1,4 \\
\hline MT & 0 & 0,0 & 0 & 0,0 & 0 & 0,0 & 1 & 16,7 & 5 & 83,3 & 0 & 0,0 & 0 & 0,0 & 6 & 0,5 \\
\hline $\mathrm{RD}$ & 0 & 0,0 & 0 & 0,0 & 0 & 0,0 & 0 & 0,0 & 1 & 50,0 & 0 & 0,0 & 1 & 50,0 & 2 & 0,2 \\
\hline $\mathrm{RI}$ & 0 & 0,0 & 0 & 0,0 & 0 & 0,0 & 0 & 0,0 & 0 & 0,0 & 1 & 100 & 0 & 0,0 & 1 & 0,1 \\
\hline $\mathrm{SA} / \mathrm{SB} / \mathrm{SBB} / \mathrm{SH}$ & 1 & 16,7 & 0 & 0,0 & 1 & 16,7 & 0 & 0,0 & 4 & 66,7 & 0 & 0,0 & 0 & 0,0 & 6 & 0,5 \\
\hline SMO & 2 & 4,9 & 0 & 0,0 & 7 & 17,1 & 3 & 7,3 & 16 & 39,0 & 8 & 19,5 & 5 & 12,2 & 41 & 3,1 \\
\hline SMT & 0 & 0,0 & 0 & 0,0 & 2 & 18,2 & 0 & 0,0 & 4 & 36 & 3 & 27,3 & 2 & 18,2 & 11 & 0,8 \\
\hline so & 2 & 6,7 & 0 & 0,0 & 4 & 13,3 & 4 & 13,3 & 10 & 33,3 & 6 & 20,0 & 4 & 13,3 & 30 & 2,3 \\
\hline TOTAL & 132 & 10,0 & 13 & 1,0 & 169 & 12,8 & 64 & 4,8 & 551 & 41,7 & 216 & 16,4 & 176 & 13,3 & 1321 & 100 \\
\hline
\end{tabular}

- TABla 1. Distribución del conjunto lítico en relación con las Categorías Estructurales, materia prima e índice de fracturación. AMF (arenisca grano muy fino), AF (arenisca grano fino), AM (arenisca grano medio), AG (arenisca grano grueso), AMG (arenisca grano muy grueso), MT (metacuarcita), RD (radiolarita), RI (roca ígnea), SA (sílex arcilloso), SB (sílex bandeado), SBB (sílex brechoide beige), SH (sílex hidratado), SMO (sílex masivo opaco), SMT (sílex masivo translúcido), SO (sílex oolítico).

mientos planos $(n=112)$ se corresponden con la cara horizontal superior de las BNE bifaciales multipolares centrípetas, jerarquizadas asimétricas (levallois), mientras que los levantamientos simples $(n=75)$ se relacionan con las BNE bifaciales multipolares centrípetas no jerarquizadas simétricas (discoides) y las extracciones abruptas $(n=69)$ con la configuración tendente a preparar las convexidades que servirá de plano de percusión recurrente y la cara horizontal inferior de las BNE bifaciales multipolares centripetas jerarquizadas asimétricas (levallois).

- $\quad$ El carácter de profundidad, representado por 155 totales, 54 marginales, 35 profundos, 8 muy marginales y 5 muy profundos, en relación con el carácter centrípeto nos pone de manifiesto el grado de explotación terminal al que se han sometido las BNE.

- La delineación de la arista frontal se divide de manera más o menos equitativa entre recta, convexa y sinuosa, se encuentra escasamente representado el criterio cóncavo y el criterio 1a. Como vemos destaca el criterio convexo que se corresponde con el perímetro de la estrategia de talla bifacial multipolar centrípeta y los métodos de talla levallois y discoides.
- En la delineación de la arista sagital, domina la sinuosa asimétrica continua, lo que se encuentra en relación con la estrategia de talla bifacial multipolar centrípeta, jerarquizada asimétrica (levallois), le sigue la sinuosa simétrica y la recta asimétrica, se encuentra mínimamente presente el resto de criterios.

- El aprovechamiento intensivo al que hicimos referencia al desarrollar los criterios centrípeto y de profundidad, se pone de manifiesto al realizar el análisis del grado de explotación, donde los criterios de plena explotación y fase terminal alcanzan un índice superior al 90\%, que en ningún caso parece estar relacionado con la falta de materia prima en las inmediaciones del lugar de intervención, ya que se encuentra de manera natural en el sitio como quedó desarrollado.

- La estrategia de talla dominante es la bifacial multipolar centrípeta (Fig. 9a y 9b), pero están presentes otras estrategias de talla como la unipolar longitudinal, unipolar circular, bipolar opuesta, bipolar ortogonal y por último con una pieza multifacial multipolar.

- El grado de explotación terminal en relación con la estrategia de talla multipolar centrípeta nos aporta unos índices de 98,6\%. 


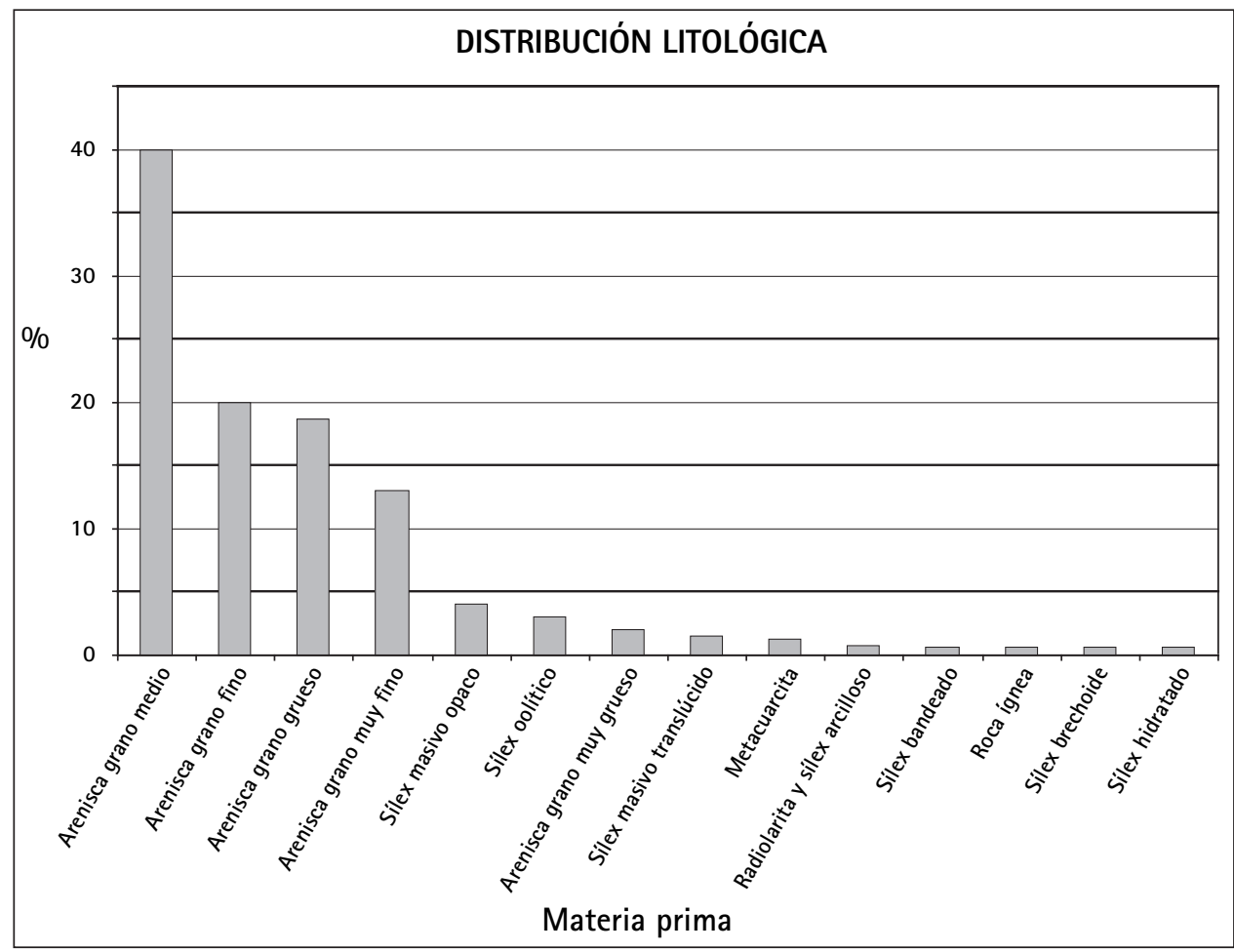

A Figura 5. Distribución litológica por grupos.

- El método de talla dominante empleado en la estrategia de talla bifacial multipolar centripeta es el predeterminado recurrente con dos superficies jerarquizadas asimétricas (Figs. 9, 10 y 11), seguido del discoide (Fig. 12), donde dominan las superficies no jerarquizadas simétricas y finalmente el predeterminado de lasca preferente, con estrategia de talla bifacial multipolar y bipolar (Fig. 13), representados por sistemas jerarquizados asimétricos.

- En los sistemas de explotación con dos superficies, sean jerarquizadas o no, hemos realizado el análisis individualizado de ambas superficies, de una parte la cara horizontal superior o superficie de explotación y de otra la cara horizontal inferior o superficie de preparación, para los métodos de talla levallois, ya que en la mayoría de los discoides no existe diferencia entre planos, al no tener las superficies jerarquizadas.

En la Cara horizontal Superior (superficie de explotación) domina la dirección de los negativos centrípeta con 98 piezas, siendo anecdótico el ortogonal con 6, multipolar con 2, bipolar con 1, cordal con 1 y longitudinal con 1. La morfología de la cara horizontal superior está representada por 31 circulares, 26 ovales, 21 cuadrangulares, 21 rectangulares, 9 triangulares y 1 poligonal, la mayoría irregulares. De nuevo podemos relacionar las morfologías circulares, ovales, rectangulares y cuadrangulares con la estrategia de talla bifacial multipolar cen- trípeta y concretamente con los métodos de talla levallois, tanto predeterminado recurrente como de lasca preferente, y el método de talla discoide. El modo plano y semiplano impera en el ángulo de los levantamientos, seguido del simple, semiabrupto y abrupto. El grado de preparación está representado por 62 no observables, en relación con el grado de explotación terminal que presentan las $B N E_{1} 41$ de preparación sumaria, relacionado con la escasa preparación necesaria en los sistemas de explotación levallois al seleccionar cantos que en su forma natural presentan contornos convexos, 5 de preparación y 1 no preparado.

En la Cara Horizontal Inferior (superficie de preparación), se han analizado el número de levantamientos, 23 artefactos con 7 levantamientos, seguido de 19 con 6 levantamientos, 16 con 5 levantamientos, 13 piezas con 8 levantamientos, siendo el resto anecdótico. La localización de estos levantamientos se sitúa en la periferia de los núcleos e incluso en toda la superficie de la cara inferior. A pesar de ello es habitual observar BNE multipolares centripetas, predeterminadas recurrentes, con superficies jerarquizadas y grado de explotación terminal con cortex en la zona mesial central de la cara horizontal inferior. El grado de preparación cuenta con 71 de preparación sumaria, 19 de preparación, 17 no observable y 2 no preparado. 


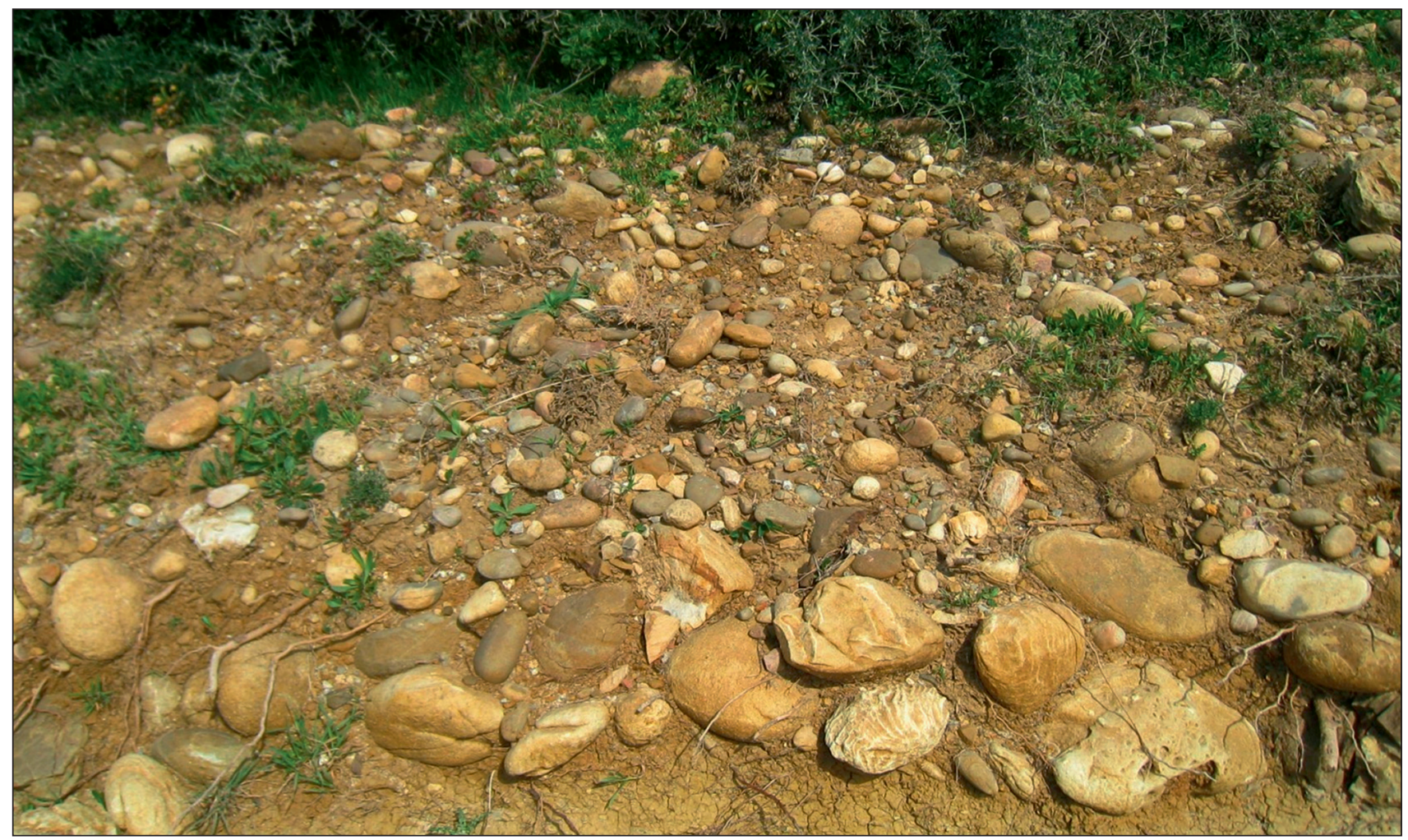

ム Figura 6. Cantos rodados de arenisca, depositados por la desembocadura del paleo-Guadalmesí en las inmediaciones del yacimiento.

\subsection{Análisis de las Bases Positivas (lascas)}

De las 943 Bases Positivas (BP) identificadas, 216 presentan algún tipo de fractura que no afecta al talón (Bases Positivas Fracturadas-BPF) y 176 son fracturas de bases positivas (FBP), en las que el talón se encuentra roto o suprimido, por lo que no han sido tenidas en cuenta en el análisis de la superficie talonar, aunque se han incluido en el análisis del resto de caracteres (tabla 1).

Las 943 BP (análisis estadístico en tablas 4 y 5), que suponen el $71,4 \%$ del conjunto, son por tanto la categoria estructural mejor representada ( $n=873$ en arenisca, $n=62$ en sílex, $n=5$ en metacuarcita, $n=2$ radiolarita y $n=1$ roca ígnea).

No se han tenido en cuenta las BP que presentan fracturas, en función de su necesidad o no para el criterio descrito en cada momento, es decir, en las fracturas proximales no se ha podido analizar el talón, en las fracturas totales no se ha podido tomar medida de la longitud o la anchura, etc..., hecho que debemos tener en cuenta a la hora de contrastar porcentajes y cantidades totales.

- El rango tipométrico de las BP (tabla 2) se encuentra entre pequeño y muy pequeño formato. Los valores de gran formato y formato medio son anecdóticos. El valor medio de las BP se sitúa en 40,3 x 31 × 9,98 $\mathrm{mm}$ y el volumen nos aporta un índice ligeramente superior para el formato largo/plano 58,4\%, frente al espeso/plano con un 41,6\%.
- Los índices tipométricos y de volumen nos indican que se trata de un conjunto poco espeso, en consonancia con el espesor medio de 9,98 $\mathrm{mm}$, para nada carenado, donde tan sólo 50 BP $(5,30 \%)$ reúnen el requisito tipométrico exigible del doble de longitud respecto a la anchura, propio de una lámina, aunque analizado individualmente, el 100\% de los casos se corresponde con el resultado accidental de la dinámica de talla, ya que no se ha identificado la pertenencia a estrategias de explotación laminares.

- En relación con el porcentaje laminar se han identificado 4 cuchillos de dorso natural (Bordes 1961), elaborados sobre BP no corticales dominantes, en cuyo filo diedro activo se aprecian trazas de utilización, aunque somos conscientes del tipo de afirmación que sólo es posible tras los análisis morfofuncionales.

- De la cara ventral de las BP se han analizado el bulbo, con un dominio del tipo difuso frente al marcado y la delineación, con un dominio de la forma recta, seguida de la cóncava, sinuosa y convexa, lo que nos indica la escasa flexibilidad de las piezas, posiblemente relacionado con la materia prima utilizada (arenisca).

- El análisis de la cara dorsal nos muestra la secuencia operativa completa de los distintos tipos de BP en arenisca (Fig. 14), desde las que presentan el $100 \%$ de superficie dorsal cortical, hasta las que 


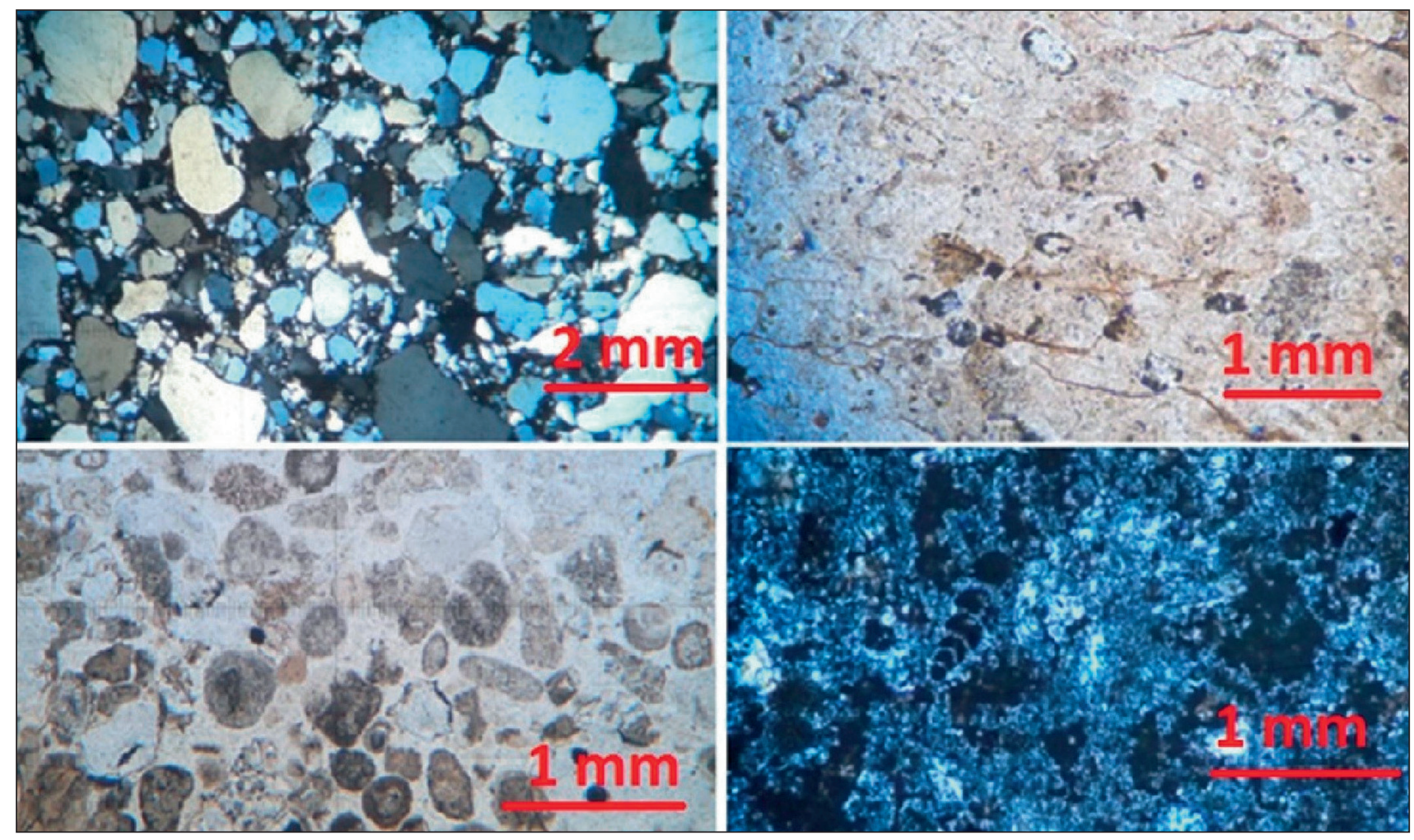

\ Figura 7. (Arriba izda.). Imagen mediante microscopía óptica de una lámina delgada de una BP NCO/CO, en arenisca de grano muy grueso. Luz doblemente polarizada. (Arriba derecha). Lámina delgada de una BP NCO/CO, en sílex masivo opaco gris. Luz polarizada. (Abajo izda.). Lámina delgada de una BP NCO, realizada en sílex oolítico beige. Luz polarizada. (Abajo derecha). Lámina delgada, en sílex arcilloso. Se aprecian orbitolinas y gasterópodos. Luz doblemente polarizada.

son completamente no corticales, pasando por las corticales/no corticales y no corticales/corticales. Este hecho, unido al porcentaje cualitativo y cuantitativo de las BNE nos permite inferir que el aporte de este tipo de materia prima (arenisca) al lugar se realizó en forma de canto, practicándose en el centro de intervención todos los gestos expeditivos necesarios para su reducción.

El sílex carece prácticamente de representación cortical y cortical dominante, lo que unido al bajísimo $3,8 \%$ de BNE en esta roca, nos indica que el aporte al lugar se realizó una vez desbastado, como consecuencia de la mayor distancia que había que recorrer desde el área de aprovisionamiento, lo que indica un importante ahorro energético para la comunidad.

- Al contrastar con los sistemas de clasificación tradicionales, la secuencia operativa se muestra completa, al estar presentes las lascas de descortezado, semidescortezado, internas y las BP procedentes de métodos de talla estandarizados (levallois) (Fig. 15). En la elaboración de BP levallois seleccionan una arenisca de grano muy fino y fino en un $50,8 \%$ de los casos. A este índice de producción levallois tenemos que sumar las 110 BN2GC cuyo soporte ha sido una BP procedente de método de talla predeterminado.
- El análisis de la cara dorsal evidencia un dominio de entre 3 y 5 levantamientos, aunque se encuentra bien representado las piezas que cuentan entre 0 y 2 levantamientos y mínimamente las que tienen 6 o más, en clara sintonía con los tipos de BP que acabamos de describir, conformando una oblicuidad en relación con el plano de lascado, en general plana o simple, aunque se encuentran bien representados otros modos como el abrupto, con delineaciones rectas y convexas, que se complementan con sinuosas, uniangulares $1 a$, cóncavas y finalmente biangulares 2a.

- La morfología de las secciones frontal, sagital y transversal no se han presentado en la tabla 4, por lo que expondremos brevemente algunos datos. En la sección frontal domina la forma trapezoidal y rectangular, seguida de triangular, pentagonal y polígono irregular, estando escasamente representadas otras formas como circular, cuadrangular y oval.

- En la morfología de la sección sagital observamos un desequilibrio a favor de la forma triangular $(n=320,41,8 \%)$, seguida de trapezoidal ( $n=166$, $21,7 \%)$, rectangular $(n=115,15 \%)$, polígono irregular $(n=28,3,7 \%)$, y otras formas meramente testimoniales como pentagonal, en segmento u oval. 
- La morfología de la sección transversal presenta dominio de la forma triangular $(n=452,52,5 \%)$, seguida de trapezoidal ( $n=211,24,5 \%)$, en segmento $(n=94,10,9 \%)$, rectangular $(n=38,4,4 \%)$, mientras que las formas romboidal, oval y polígono irregular son anecdóticas.

- Los criterios analíticos de la superficie talonar se exponen en la tabla 5, donde podemos contrastar la información estadística, pero se hace necesario desarrollar brevemente algunas especificidades dentro de las generalidades; en primer lugar evidenciamos una representación de más del $12 \%$ de superficies talonares con cortex y que como decíamos al desarrollar los tipos de BP se corresponden con piezas en arenisca; en segundo lugar existe un porcentaje importante de superficies convexas, que unidas a las uniangulares, biangulares y sinuosas, representan el 29,8\%, lo que se encuentra en relación con las estrategias de talla multipolares centripetas, concretamente con los métodos levallois y discoide; en tercer lugar las superficies bifacetadas y multifacetadas suponen el 20,2\%, muy en consonancia con el 23,3\% de BP procedentes de métodos de explotación estandarizados; finalmente analizados los tipos de superficie talonar lineal y puntiforme con un 5,4\%, podemos decir que ninguno de ellos se corresponde con métodos de talla leptolíticos, sino que se trata del resultado accidental de la propia dinámica del proceso de talla.

5.3 Análisis de las Bases Negativas de Segunda Generación de Configuración (objetos retocados)

En la descripción de los caracteres propios del retoque, hemos utilizado la metodología analítica desarrollada por G. Laplace (1972), pero consideramos que ésta debe servirnos de guía, ya que el criterio básico de clasificación que utiliza es el de modo de retoque y sabemos que las diferencias entre uno y otro modo cuando superan un determinado ángulo son muy sutiles, a la par que subjetivas, ya que depende en gran medida de la vida útil que haya tenido el artefacto, su uso intensivo, la variabilidad técnica sincrónica que resulta de la explotación de bases naturales de distinta composición para su configuración, distinta composición granulométrica..., por ello somos conscientes de que aunque algunos tipos pueden clasificarse como raederas, muescas o denticulados, que pertenecen al orden de los simples y sobreelevados, son susceptibles de presentar retoques semiabruptos o abruptos, en función de las causas expuestas. En relación con este

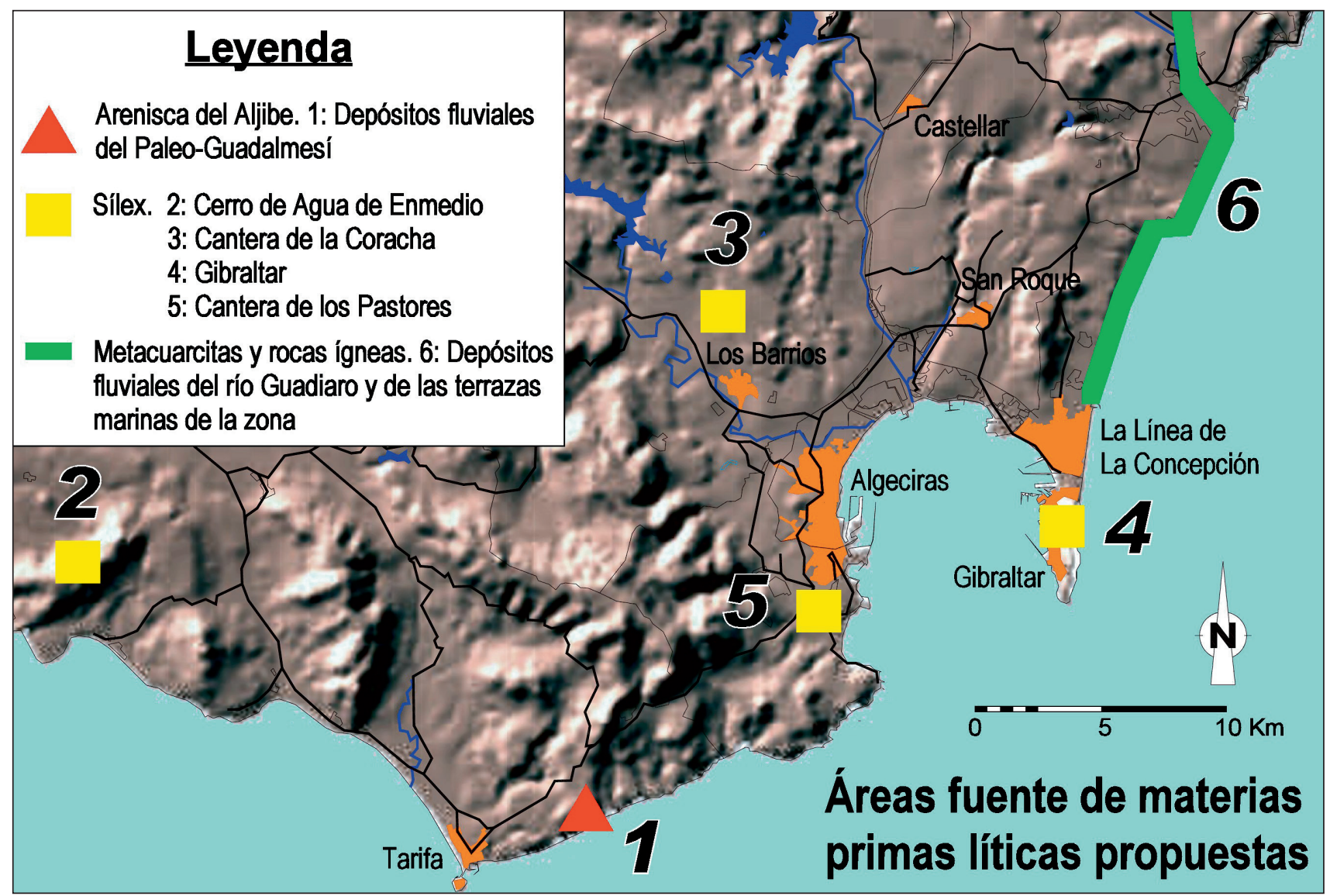

A Figura 8. Mapa de localización de las fuentes de aprovisionamiento de las diferentes materias primas líticas identificadas. 


\begin{tabular}{|c|c|c|c|c|c|c|c|c|c|c|}
\hline \multirow{3}{*}{ MATERIA PRIMA } & \multicolumn{8}{|c|}{ TIPOMETRÍA BNE } & \multirow{2}{*}{\multicolumn{2}{|c|}{$\begin{array}{c}\text { TOTAL } \\
\text { BNE }\end{array}$}} \\
\hline & \multicolumn{2}{|c|}{ GRAN FORMATO } & \multicolumn{2}{|c|}{$\begin{array}{l}\text { MEDIO } \\
\text { FORMATO }\end{array}$} & \multicolumn{2}{|c|}{$\begin{array}{l}\text { PEQUEÑO } \\
\text { FORMATO }\end{array}$} & \multicolumn{2}{|c|}{$\begin{array}{l}\text { MUY PEQUEÑO } \\
\text { FORMATO }\end{array}$} & & \\
\hline & N. ${ }^{\circ}$ & $\%$ & $\mathrm{~N} .^{\circ}$ & $\%$ & $\mathrm{~N} .^{\circ}$ & $\%$ & N. ${ }^{\circ}$ & $\%$ & $\mathrm{~N} .^{\circ}$ & $\%$ \\
\hline ARENISCA GRANO MUY FINO & 2 & 11,1 & 0 & 0,0 & 15 & 83,3 & 1 & 5,6 & 18 & 13,6 \\
\hline ARENISCA GRANO FINO & 0 & 0,0 & 8 & 21,1 & 29 & 76,3 & 1 & 2,6 & 38 & 28,8 \\
\hline ARENISCA GRANO MEDIO & 3 & 5,3 & 10 & 17,5 & 44 & 77,2 & 0 & 0,0 & 57 & 43,2 \\
\hline ARENISCA GRANO GRUESO & 0 & 0,0 & 2 & 15,4 & 11 & 84,6 & 0 & 0,0 & 13 & 9,8 \\
\hline ARENISCA GRANO MUY GRUESO & 0 & 0,0 & 0 & 0,0 & 1 & 100 & 0 & 0,0 & 1 & 0,8 \\
\hline SÍLEX ARCILLOSO & 0 & 0,0 & 0 & 0,0 & 1 & 100 & 0 & 0,0 & 1 & 0,8 \\
\hline SÍLEX MASIVO OPACO & 0 & 0,0 & 0 & 0,0 & 1 & 50,0 & 1 & 50,0 & 2 & 1,5 \\
\hline SÍLEX OOLITICO & 0 & 0,0 & 0 & 0,0 & 2 & 100 & 0 & 0,0 & 2 & 1,5 \\
\hline TOTAL & 5 & 3,8 & 20 & 15,2 & 104 & 78,8 & 3 & 2,3 & 132 & 100 \\
\hline
\end{tabular}

\begin{tabular}{|c|c|c|c|c|c|c|c|c|c|c|}
\hline \multirow{3}{*}{ MATERIA PRIMA } & \multicolumn{8}{|c|}{ TIPOMETRÍA BP } & \multirow{2}{*}{\multicolumn{2}{|c|}{$\begin{array}{l}\text { TOTAL } \\
\text { BP }\end{array}$}} \\
\hline & \multicolumn{2}{|c|}{ GRAN FORMATO } & \multicolumn{2}{|c|}{$\begin{array}{c}\text { MEDIO } \\
\text { FORMATO }\end{array}$} & \multicolumn{2}{|c|}{$\begin{array}{l}\text { PEQUEÑO } \\
\text { FORMATO }\end{array}$} & \multicolumn{2}{|c|}{$\begin{array}{l}\text { MUY PEQUEÑO } \\
\text { FORMATO }\end{array}$} & & \\
\hline & N. ${ }^{\circ}$ & $\%$ & $\mathrm{~N} .^{\circ}$ & $\%$ & N. ${ }^{\circ}$ & $\%$ & N. ${ }^{\circ}$ & $\%$ & $\mathrm{~N} .^{\circ}$ & $\%$ \\
\hline ARENISCA GRANO MUY FINO & 0 & 0,0 & 5 & 7,8 & 38 & 59,4 & 21 & 32,8 & 64 & 11,1 \\
\hline ARENISCA GRANO FINO & 1 & 0,9 & 9 & 8,0 & 82 & 73,2 & 20 & 17,9 & 112 & 19,5 \\
\hline ARENISCA GRANO MEDIO & 2 & 0,9 & 18 & 8,0 & 142 & 63,1 & 63 & 28,0 & 225 & 39,2 \\
\hline ARENISCA GRANO GRUESO & 1 & 0,8 & 17 & 14,0 & 87 & 71,9 & 16 & 13,2 & 121 & 21,1 \\
\hline ARENISCA GRANO MUY GRUESO & 0 & 0,0 & 1 & 11,1 & 8 & 88,9 & 0 & 0,0 & 9 & 1,6 \\
\hline METACUARCITA & 0 & 0,0 & 0 & 0,0 & 0 & 0,0 & 5 & 100 & 5 & 0,9 \\
\hline RADIOLARITA & 0 & 0,0 & 0 & 0,0 & 0 & 0,0 & 1 & 100 & 1 & 0,2 \\
\hline ROCA ÍGNEA & 0 & 0,0 & 0 & 0,0 & 0 & 0,0 & 1 & 100 & 1 & 0,2 \\
\hline $\mathrm{SA} / \mathrm{SB} / \mathrm{SBB} / \mathrm{SH}$ & 0 & 0,0 & 0 & 0,0 & 3 & 50,0 & 1 & 16,7 & 6 & 1,0 \\
\hline SÍLEX MASIVO OPACO & 0 & 0,0 & 0 & 0,0 & 4 & 23,5 & 13 & 76,5 & 17 & 3,0 \\
\hline SÍLEX MASIVO TRANSLÚCIDO & 0 & 0,0 & 0 & 0,0 & 1 & 20,0 & 4 & 80,0 & 5 & 0,9 \\
\hline SÍLEX OOLITICO & 0 & 0,0 & 0 & 0,0 & 3 & 30,0 & 7 & 70,0 & 10 & 1,7 \\
\hline TOTAL & 4 & 0,7 & 50 & 8,7 & 368 & 64,1 & 152 & 26,5 & 574 & 100 \\
\hline
\end{tabular}

\begin{tabular}{|c|c|c|c|c|c|c|c|c|c|c|}
\hline \multirow{3}{*}{ MATERIA PRIMA } & \multicolumn{8}{|c|}{ TIPOMETRÍA BN2GC } & \multirow{2}{*}{\multicolumn{2}{|c|}{$\begin{array}{c}\text { TOTAL } \\
\text { BN2GC }\end{array}$}} \\
\hline & \multicolumn{2}{|c|}{$\begin{array}{c}\text { FORMATO } \\
\text { MACRO }\end{array}$} & \multicolumn{2}{|c|}{$\begin{array}{c}\text { GRAN } \\
\text { FORMATO }\end{array}$} & \multicolumn{2}{|c|}{$\begin{array}{c}\text { FORMATO } \\
\text { MEDIO }\end{array}$} & \multicolumn{2}{|c|}{$\begin{array}{l}\text { PEQUEÑO } \\
\text { FORMATO }\end{array}$} & & \\
\hline & N. ${ }^{\circ}$ & $\%$ & N. ${ }^{\circ}$ & $\%$ & $\mathrm{~N} .^{\circ}$ & $\%$ & N. ${ }^{\circ}$ & $\%$ & $\mathrm{~N} .^{\circ}$ & $\%$ \\
\hline ARENISCA GRANO MUY FINO & 0 & 0,0 & 5 & 21,7 & 16 & 69,6 & 2 & 8,7 & 23 & 12,6 \\
\hline ARENISCA GRANO FINO & 1 & 2,9 & 11 & 31,4 & 21 & 60,0 & 2 & 5,7 & 35 & 19,2 \\
\hline ARENISCA GRANO MEDIO & 2 & 3,1 & 10 & 15,4 & 51 & 78,5 & 2 & 3,1 & 65 & 35,7 \\
\hline ARENISCA GRANO GRUESO & 1 & 2,4 & 14 & 34,1 & 26 & 63,4 & 0 & 0,0 & 41 & 22,5 \\
\hline ARENISCA GRANO MUY GRUESO & 0 & 0,0 & 2 & 66,7 & 1 & 33,3 & 0 & 0,0 & 3 & 1,6 \\
\hline SÍLEX BANDEADO & 0 & 0,0 & 0 & 0,0 & 1 & 100 & 0 & 0,0 & 1 & 0,5 \\
\hline SÍLEX MASIVO OPACO & 0 & 0,0 & 0 & 0,0 & 7 & 87,5 & 1 & 12,5 & 8 & 4,4 \\
\hline SÍLEX MASIVO TRANSLÚCIDO & 0 & 0,0 & 0 & 0,0 & 2 & 100 & 0 & 0,0 & 2 & 1,1 \\
\hline SILEX OOLITICO & 0 & 0,0 & 0 & 0,0 & 4 & 100 & 0 & 0,0 & 4 & 2,2 \\
\hline TOTAL & 4 & 2,2 & 42 & 23,1 & 129 & 70,9 & 7 & 3,8 & 182 & 100 \\
\hline
\end{tabular}

ム TABLA 2. Tipometría de las BNE, BP y BN2GC en base a los criterios expuestos en el apartado metodológico. 


\begin{tabular}{|c|c|c|c|c|c|c|c|c|c|c|c|c|c|c|c|c|c|c|c|}
\hline & & \multicolumn{16}{|c|}{ MATERIA PRIMA } & \multirow{2}{*}{\multicolumn{2}{|c|}{$\begin{array}{c}\text { TOTAL } \\
\text { BNE/CARAS } \\
\text { TALLADAS }\end{array}$}} \\
\hline \multicolumn{2}{|c|}{ CRITERIOS ANALÍTICOS } & \multicolumn{2}{|c|}{ AMF } & \multicolumn{2}{|c|}{$\mathrm{AF}$} & \multicolumn{2}{|c|}{ AM } & \multicolumn{2}{|c|}{$A G$} & \multicolumn{2}{|c|}{ AMG } & \multicolumn{2}{|c|}{ SA } & \multicolumn{2}{|c|}{ SMO } & \multicolumn{2}{|c|}{ SO } & & \\
\hline & & N..$^{\circ}$ & $\%$ & N. ${ }^{\circ}$ & $\%$ & N..$^{\circ}$ & $\%$ & N. ${ }^{\circ}$ & $\%$ & N. ${ }^{\circ}$ & $\%$ & N. ${ }^{\circ}$ & $\%$ & N. ${ }^{\circ}$ & $\%$ & N. ${ }^{\circ}$ & $\%$ & N. ${ }^{\circ}$ & $\%$ \\
\hline \multirow{4}{*}{$\begin{array}{l}\text { CARÁCTER } \\
\text { FACIAL }\end{array}$} & UNIFACIAL & 1 & 5,6 & 6 & 15,8 & 4 & 7,0 & 0 & 0,0 & 0 & 0,0 & 0 & 0,0 & 0 & 0,0 & 0 & 0,0 & 11 & 8,3 \\
\hline & BIFACIAL & 17 & 94,4 & 32 & 84,2 & 51 & 89,5 & 11 & 84,6 & 1 & 100 & 1 & 100 & 2 & 100 & 2 & 100 & 117 & 88,6 \\
\hline & TRIFACIAL & 0 & 0,0 & 0 & 0,0 & 2 & 3,5 & 2 & 15,4 & 0 & 0,0 & 0 & 0,0 & 0 & 0,0 & 0 & 0,0 & 4 & 3,0 \\
\hline & TOTAL & 18 & 100 & 38 & 100 & 57 & 100 & 13 & 100 & 1 & 100 & 1 & 100 & 2 & 100 & 2 & 100 & 132 & 100 \\
\hline \multirow{5}{*}{$\begin{array}{l}\text { CARÁCTER } \\
\text { CENTRÍPETO }\end{array}$} & $1 \mathrm{C}$ & 5 & 14,3 & 5 & 7,1 & 11 & 9,9 & 4 & 14,3 & 0 & 0,0 & 0 & 0,0 & 1 & 20,0 & 0 & 0,0 & 26 & 10,2 \\
\hline & $2 C$ & 12 & 34,3 & 16 & 22,9 & 21 & 18,9 & 3 & 10,7 & 1 & 50,0 & 0 & 0,0 & 2 & 40,0 & 0 & 0,0 & 55 & 21,5 \\
\hline & $3 C$ & 1 & 2,9 & 8 & 11,4 & 9 & 8,1 & 3 & 10,7 & 1 & 50,0 & 0 & 0,0 & 0 & 0,0 & 1 & 33,3 & 23 & 9,0 \\
\hline & $4 C$ & 17 & 48,6 & 41 & 58,6 & 70 & 63,1 & 18 & 64,3 & 0 & 0,0 & 2 & 100 & 2 & 40,0 & 2 & 66,7 & 152 & 59,4 \\
\hline & TOTAL & 35 & 100 & 70 & 100 & 111 & 100 & 28 & 100 & 2 & 100 & 2 & 100 & 5 & 100 & 3 & 100 & 256 & 100 \\
\hline \multirow{6}{*}{$\begin{array}{c}\text { ARISTA } \\
\text { FRONTAL }\end{array}$} & RECTA & 8 & 44,4 & 11 & 28,9 & 7 & 12,3 & 4 & 30,8 & 0 & 0,0 & 0 & 0,0 & 0 & 0,0 & 1 & 50,0 & 31 & 23,5 \\
\hline & CONVEXA & 6 & 33,3 & 17 & 44,7 & 24 & 42,1 & 6 & 46,2 & 1 & 100 & 0 & 0,0 & 2 & 100 & 1 & 50,0 & 57 & 43,2 \\
\hline & CÓNCAVA & 1 & 5,6 & 1 & 2,6 & 0 & 0,0 & 0 & 0,0 & 0 & 0,0 & 0 & 0,0 & 0 & 0,0 & 0 & 0,0 & 2 & 1,5 \\
\hline & SINUOSA & 2 & 11,1 & 8 & 21,1 & 21 & 36,8 & 2 & 15,4 & 0 & 0,0 & 1 & 100 & 0 & 0,0 & 0 & 0,0 & 34 & 25,8 \\
\hline & $1 .^{a}$ & 1 & 5,6 & 1 & 2,6 & 5 & 8,8 & 1 & 7,7 & 0 & 0,0 & 0 & 0,0 & 0 & 0,0 & 0 & 0,0 & 8 & 6,1 \\
\hline & TOTAL & 18 & 100 & 38 & 100 & 57 & 100 & 13 & 100 & 1 & 100 & 1 & 100 & 2 & 100 & 2 & 100 & 132 & 100 \\
\hline \multirow{6}{*}{$\begin{array}{l}\text { ARISTA } \\
\text { SAGITAL }\end{array}$} & INC/ASI & 1 & 5,6 & 2 & 5,3 & 3 & 5,3 & 0 & 0,0 & 0 & 0,0 & 0 & 0,0 & 0 & 0,0 & 0 & 0,0 & 6 & 4,5 \\
\hline & INC/SI & 0 & 0,0 & 1 & 2,6 & 0 & 0,0 & 0 & 0,0 & 0 & 0,0 & 0 & 0,0 & 0 & 0,0 & 0 & 0,0 & 1 & 0,8 \\
\hline & RT/ASI & 0 & 0,0 & 5 & 13,2 & 6 & 10,5 & 1 & 7,7 & 0 & 0,0 & 1 & 100 & 0 & 0,0 & 1 & 50,0 & 14 & 10,6 \\
\hline & SIN/ASI & 16 & 88,9 & 25 & 65,8 & 37 & 64,9 & 10 & 76,9 & 0 & 0,0 & 0 & 0,0 & 2 & 100 & 1 & 50,0 & 91 & 68,9 \\
\hline & $\mathrm{SIN} / \mathrm{SI}$ & 1 & 5,6 & 5 & 13,2 & 11 & 19,3 & 2 & 15,4 & 1 & 100 & 0 & 0,0 & 0 & 0,0 & 0 & 0,0 & 20 & 15,2 \\
\hline & TOTAL & 18 & 100 & 38 & 100 & 57 & 100 & 13 & 100 & 1 & 100 & 1 & 100 & 2 & 100 & 2 & 100 & 132 & 100 \\
\hline \multirow{4}{*}{$\begin{array}{l}\text { GRADO DE } \\
\text { EXPLOTACIÓN }\end{array}$} & INICIALIZACIÓN & 1 & 5,6 & 2 & 5,3 & 10 & 17,5 & 0 & 0,0 & 0 & 0,0 & 0 & 0,0 & 0 & 0,0 & 0 & 0,0 & 13 & 9,8 \\
\hline & EXPLOTACIÓN & 4 & 22,2 & 13 & 34,2 & 20 & 35,1 & 7 & 53,8 & 1 & 100 & 0 & 0,0 & 0 & 0,0 & 1 & 50,0 & 46 & 34,8 \\
\hline & TERMINAL & 13 & 72,2 & 23 & 60,5 & 27 & 47,4 & 6 & 46,2 & 0 & 0,0 & 1 & 100 & 2 & 100 & 1 & 50,0 & 73 & 55,3 \\
\hline & TOTAL & 18 & 100 & 38 & 100 & 57 & 100 & 13 & 100 & 1 & 100 & 1 & 100 & 2 & 100 & 2 & 100 & 132 & 100 \\
\hline \multirow{7}{*}{$\begin{array}{c}\text { ESTRATEGIA } \\
\text { DE TALLA }\end{array}$} & UNIPOLAR LONGITUDINAL & 0 & 0,0 & 3 & 7,9 & 2 & 3,5 & 0 & 0,0 & 0 & 0,0 & 0 & 0,0 & 0 & 0,0 & 0 & 0,0 & 5 & 3,8 \\
\hline & UNIPOLAR CIRCULAR & 0 & 0,0 & 0 & 0,0 & 3 & 5,3 & 2 & 15,4 & 0 & 0,0 & 0 & 0,0 & 0 & 0,0 & 0 & 0,0 & 5 & 3,8 \\
\hline & BIPOLAR OPUESTO & 0 & 0,0 & 1 & 2,6 & 1 & 1,8 & 0 & 0,0 & 0 & 0,0 & 0 & 0,0 & 0 & 0,0 & 0 & 0,0 & 2 & 1,5 \\
\hline & BIPOLAR ORTOGONAL & 2 & 11,1 & 3 & 7,9 & 4 & 7,0 & 1 & 7,7 & 0 & 0,0 & 0 & 0,0 & 0 & 0,0 & 0 & 0,0 & 10 & 7,6 \\
\hline & MULTIPOLAR & 0 & 0,0 & 0 & 0,0 & 1 & 1,8 & 0 & 0,0 & 0 & 0,0 & 0 & 0,0 & 0 & 0,0 & 0 & 0,0 & 1 & 0,8 \\
\hline & MULTIPOLAR CENTRÍPETO & 16 & 88,9 & 31 & 81,6 & 46 & 80,7 & 10 & 76,9 & 1 & 100 & 1 & 100 & 2 & 100 & 2 & 100 & 109 & 82,6 \\
\hline & TOTAL & 18 & 100 & 38 & 100 & 57 & 100 & 13 & 100 & 1 & 100 & 1 & 100 & 2 & 100 & 2 & 100 & 132 & 100 \\
\hline \multirow{5}{*}{$\begin{array}{l}\text { MULTIPOLAR } \\
\text { CENTRÍPETO } \\
\text { (MÉTODO DE } \\
\text { TALLA) }\end{array}$} & SIN PREPARACIÓN & 0 & 0,0 & 1 & 3,2 & 0 & 0,0 & 1 & 10,0 & 0 & 0,0 & 0 & 0,0 & 0 & 0,0 & 0 & 0,0 & 2 & 1,8 \\
\hline & PREDETER. RECURRENTE & 12 & 75,0 & 19 & 61,3 & 33 & 71,7 & 5 & 50,0 & 0 & 0,0 & 0 & 0,0 & 1 & 50,0 & 1 & 50,0 & 71 & 65,1 \\
\hline & PREDETER. PREFERENTE & 4 & 25,0 & 5 & 16,1 & 2 & 4,3 & 1 & 10,0 & 0 & 0,0 & 1 & 100 & 1 & 50,0 & 1 & 50,0 & 15 & 13,8 \\
\hline & DISCOIDE & 0 & 0,0 & 6 & 19,4 & 11 & 23,9 & 3 & 30,0 & 1 & 100 & 0 & 0,0 & 0 & 0,0 & 0 & 0,0 & 21 & 19,3 \\
\hline & TOTAL & 16 & 100 & 31 & 100 & 46 & 100 & 10 & 100 & 1 & 100 & 1 & 100 & 2 & 100 & 2 & 100 & 109 & 100 \\
\hline
\end{tabular}

- Tabla 3. Criterios analíticos de las Bases Negativas de Explotación.

tema, el propio G. Laplace (1972) considera que, en algunos casos, es necesario introducir el concepto de "tendencia" para definir el modo real de amplitud.

Hemos analizado un total de 233 BN2GC, que representa el 17,6\% del conjunto lítico y que suponen $284 \mathrm{seg}-$ mentos retocados.

Identificamos 64 BN2GC con algún tipo de fractura $(27,5 \%)$, de ellas 26 presentan fractura de la zona proximal y 3 tienen el talón abatido, por lo que no han sido incluidas en el análisis de los criterios del talón, pero sí se han tenido en cuenta en el análisis del resto de criterios descriptivos. Otras 35 presentan fractura que no afecta al talón, pero sí a las medidas, por lo que se han descartado para el análisis tipométrico.

En cuanto a la materia prima en la que han sido elaboradas ( $n=211$ en arenisca con un 90,57\%, $n=21$ en sílex con un $9,01 \%$ y $n=1$ en metacuarcita $0,42 \%$ ), se observa un incremento importante de la selección de sílex en la configuración de BN2G, en relación con las BNE que suponían un $3,8 \%$ y las BP con un 6,6\%. Un incremento similar se observa en la selección de una arenisca de grano fino y muy fino.
En el análisis de los soportes, entendidos como las BP que han sufrido modificación por retoque en segunda generación, utilizados para configurar los 233 artefactos, nos detendremos exclusivamente en aquellos criterios que supongan una diferencia significativa con lo visto al explicar la Categoria Estructural de BP.

Tras su análisis observamos como las medidas de las BN2GC (tabla 2) se sitúan con un 70,9\% en el rango de formato medio, entre 30 y $55 \mathrm{~mm}$, con unos valores medios de $47 \times 37,9 \times 12,4 \mathrm{~mm}$, que si lo comparamos con los valores obtenidos para las BP, que eran de 40,3 x $31 \times 9,98$ mm, se evidencia una clara selección de las BP con ejes longitudinales y transversales más largos, en definitiva se eligen para su configuración en segunda generación las BP de mayor formato.

El análisis de la cara dorsal nos aporta un porcentaje mínimo de cortex en su superficie, seleccionándose mayoritariamente BP no corticales $(n=179,72,5 \%)$ y no corticales dominantes $(n=48,20,6 \%)$, las corticales $(n=10,4 \%)$ y las corticales dominantes $(n=15)$ el 6,4\%.

Al comparar los tipos de soporte elegidos para la configuración de BN2G según la terminología clásica, observamos 
una selección de BP procedentes de métodos de talla predeterminados (levallois) con un total de 110 artefactos que suponen el $47,2 \%$, porcentaje que duplica al de las BP, las internas con 72 artefactos (30,9\%), de semidescortezado con 50 artefactos líticos con el 21,5\% y de descortezado $(n=1,0,4 \%)$.

Encontramos diferencias importantes en el número de levantamientos de la cara dorsal, con respecto a lo visto para las BP, ya que, en ambas domina el número de levantamientos situados entre 3 y 5 , siendo en el caso de las BN2GC un $66,8 \%$, pero mientras en las BP el número de levantamientos igual o menor a 2 suponían el $34,8 \%$, en las BN2GC suponen el 12,9\% y mientras en las BP el número de levantamientos igual o superior a 6 suponían el 5,9\%, en las BN2GC suponen el 20,3\%. Este hecho nos indica el aumento de soportes levallois seleccionados para la configuración de las herramientas líticas.

La delineación de la cara dorsal, con dominio de las formas rectas y convexas, la oblicuidad de las extracciones, el tipo de bulbo y delineación reproduce los patrones vistos para las BP.

De las 233 BN2GC ha sido posible identificar la morfología frontal de 198, de las cuales 86 , con 43,4\% presentan forma trapezoidal, seguida de la forma triangular $(n=27$, $13,6 \%)$, la rectangular $(n=25,12,6 \%)$ y polígono irregular $(n=21,10,6 \%)$, el resto de formas circulares, cuadrangulares, ovales, están mínimamente representadas.

Con un total de 205 secciones sagitales identificadas se evidencia un dominio de la forma triangular $(n=128$, $62,4 \%$ ), seguida muy de lejos por las forma trapezoidal con 26 y rectangular con 25 . El resto de morfologías tienen una representación anecdótica.

Se han identificado 220 secciones transversales, de las cuales 141 se corresponden con la forma triangular, lo que arroja un índice de $64,1 \%$, seguido de la forma trapezoidal $(n=50,22,7 \%)$, teniendo el resto de formas una representación mínima.

En el análisis de la superficie talonar hemos descrito los criterios de corticalidad, delineación, grado de facetado, tipo de superficie y morfología.

En cuanto a corticalidad, delineación y tipo de superficie reproduce el modelo desarrollado en las BP, pero es preciso detenerse en el análisis del grado de facetado, ya que en las BP los talones bifacetados y multifacetados, sin tener en cuenta los rotos o abatidos, suponían un 20,2\%, en las BN2GC, si descartamos el número de talones rotos o abatidos suponen un 34,35\%. Este incremento debemos relacionarlo con el porcentaje de BP procedentes de métodos de talla predeterminados (levallois), que han sido seleccionadas para su configuración.

Como tuvimos ocasión de ver las 233 BN2GC suponen un total de 284 segmentos retocados, remitimos al lector a la tabla 6 para su cotejo analítico. Domina la serie el retoque simple, profundo, directo, continuo y recto, en clara sinto- nía con el conjunto lítico identificado (raederas, muescas y denticulados).

El análisis por grupo nos ha permitido identificar en el yacimiento 127 raederas, 52 muescas, 48 denticulados, 3 raspadores y 3 buriles, para cuyo elaboración se han utilizado como soporte según la terminología clásica, lascas levallois ( $n=110$, $47,2 \%)$, lascas internas $(n=72,30,9)$, lascas de semidescortezado $(n=50,21,5 \%)$ y lascas de descortezado $(n=1,0,4 \%)$.

En la configuración y tipos de raederas (Fig. 16 y 17) podemos establecer las siguientes conclusiones:

En cuanto a la materia prima, se observa un aumento significativo en la selección de areniscas de grano muy fino $(14,2 \%)$ y fino $(20,6 \%)$

En el tipo de BP elegida como soporte, evidenciamos la elección de las BP que presentan mayores dimensiones de los ejes longitudinales y transversales, no así del espesor que disminuye con respecto a las $\mathrm{BP}$, con valores medios de $46 \times 38 \times 10 \mathrm{~mm}$.

Aumento cuantitativo en el método de talla empleado, pues proceden en un 61,4\% de métodos de talla predeterminados (levallois), lo que significa triplicar el porcentaje aportado en el análisis de las BP.

De otro lado, no desentona la ausencia de raederas carenadas (R3), en sintonía con lo visto para las $\mathrm{BP}$ y con lo desarrollado en la relación tipometría/volumen que nos daba unos índices de soportes planos o muy planos.

Están representados los tipos de raederas (tabla 7) R11, $\mathrm{R} 12, \mathrm{R} 13, \mathrm{R} 21, \mathrm{R} 22$ y $\mathrm{R} 23$, dominan las raederas laterales con retoque profundo, aunque están presentes las raederas transversales y latero-transversales, tanto con retoque marginal como profundo.

Dominan las raederas con retoque profundo respecto a las raederas con retoque marginal $(n=45,35,4 \%)$. En cuanto a la disposición del retoque se cuentan 97 raederas laterales, 18 transversales y 11 latero-transversales. De las 97 raederas laterales, 8 son dobles correspondiéndose con retoques profundos que representamos $n=8$ R21-2. Las 127 raederas arrojan un total de 148 segmentos retocados o filos configurados, cuyo análisis nos aporta los siguientes datos; 144 presentan filos con retoque simple y 4 con tendencia abrupta, en cuanto a la amplitud dominan los retoques profundos con 99 segmentos, respecto a los marginales con 49, la dirección del retoque es directa en 122 segmentos, inversa en 24 y alternante en 2 , con retoques continuos y de morfologías rectas $(n=91)$, convexas $(n=53)$ y sinuosas $(n=4)$.

En el grupo de los denticulados identificamos 15 raederas denticuladas (D23), que cumplen todos los patrones vistos para el grupo de las raederas y que tras su análisis observamos que las denticulaciones que presentan pueden estar relacionadas con su uso intensivo, e incluso con desconchones accidentales, por lo que según nuestro criterio tipológicamente son denticulados, pero realmente la mayoría se corresponden con raederas. 


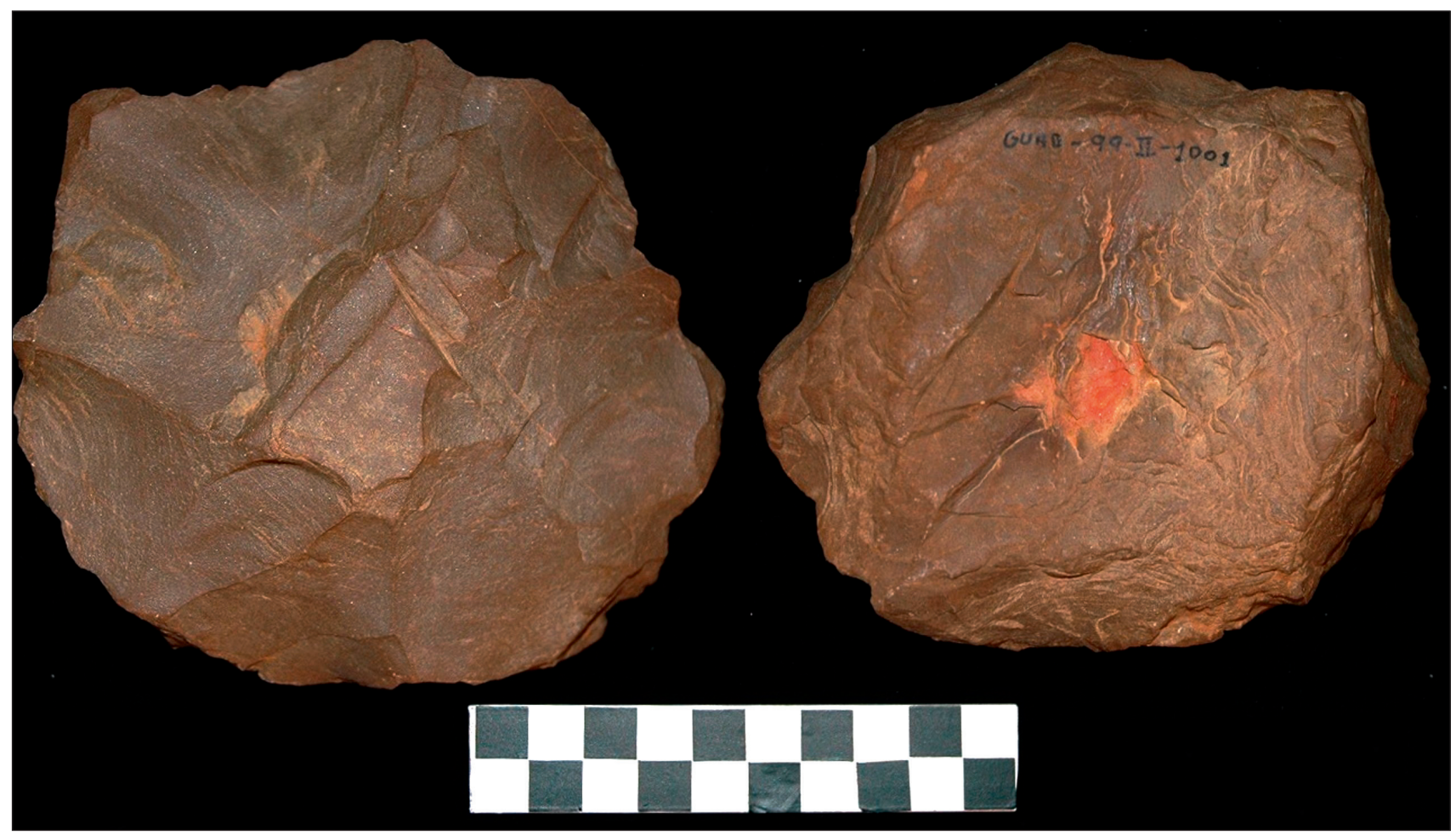

\ FIgURA 9A. Imagen de una Base negativa de Explotación bifacial, multipolar, centrípeta recurrente, jerarquizada asimétrica.

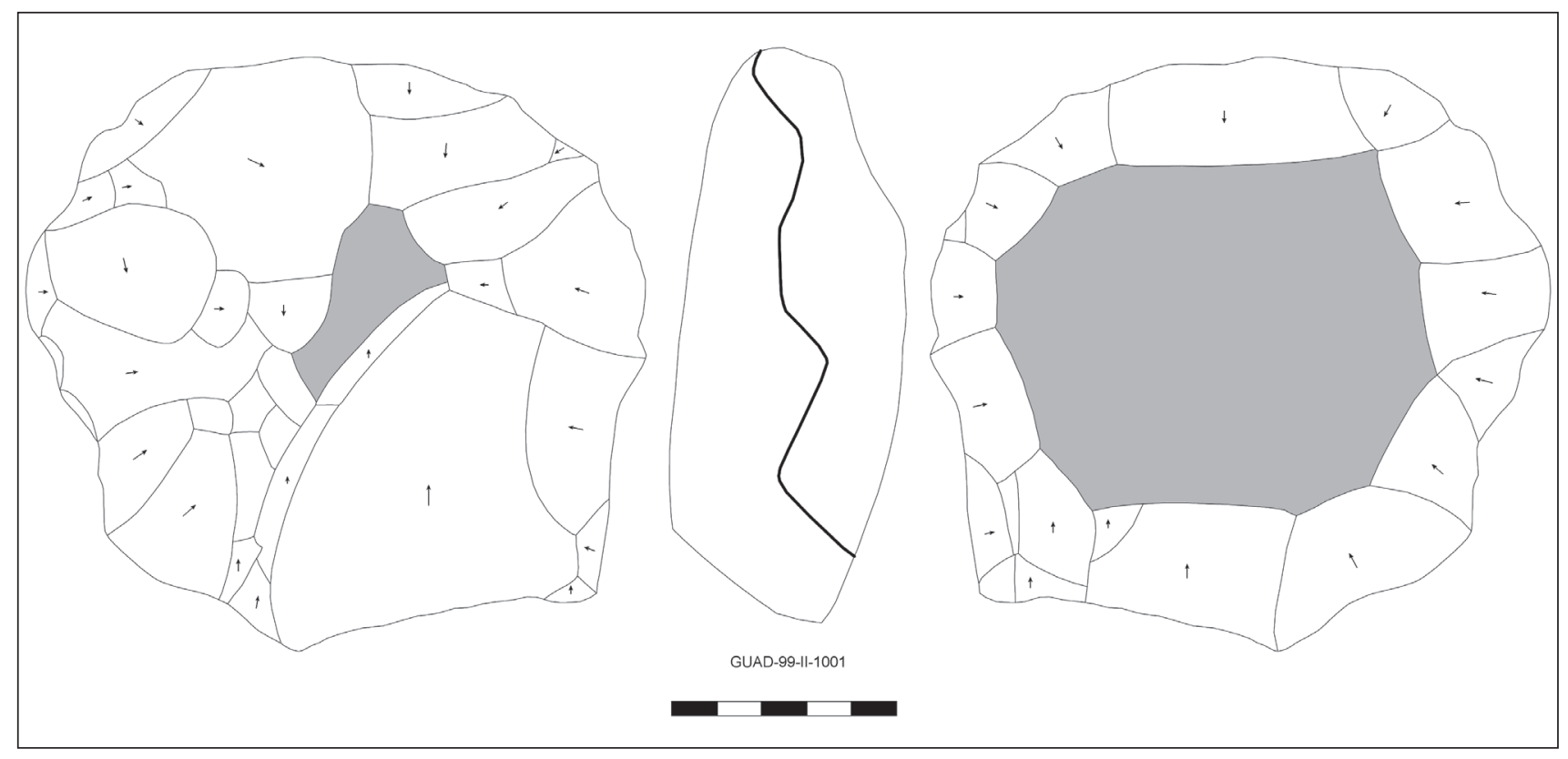

ム Figura 9в. Base negativa de Explotación bifacial multipolar centrípeta recurrente, jerarquizada asimétrica.

En la configuración y tipo de muescas y denticulados (Fig. 18), podemos establecer que:

En cuanto a la materia prima, se observa una disminución importante en la selección de areniscas de grano muy fino y fino si la comparamos con las raederas.

El tipo de muesca presente (tabla 8) se corresponde con D21 de G. Laplace, mientras que los denticulados están representados por los tipos: D22, D23, D24, D25 y D32.
De las 52 muescas, 20 han sido realizadas sobre BP no corticales, otras 20 sobre BP procedentes de métodos de talla predeterminados (levallois), lo que supone un 38,5\% (muy lejos de los indices que presentaban las raederas) y 12 sobre BP que presentan cortex en su superficie; mientras que de los 48 denticulados, 1 se configuró sobre una BP cortical, 19 sobre BP con presencia de cortex, 18 sobre BP no corticales y 10 sobre BP procedentes de métodos de talla predeterminados, lo que supone un $28,8 \%$. 


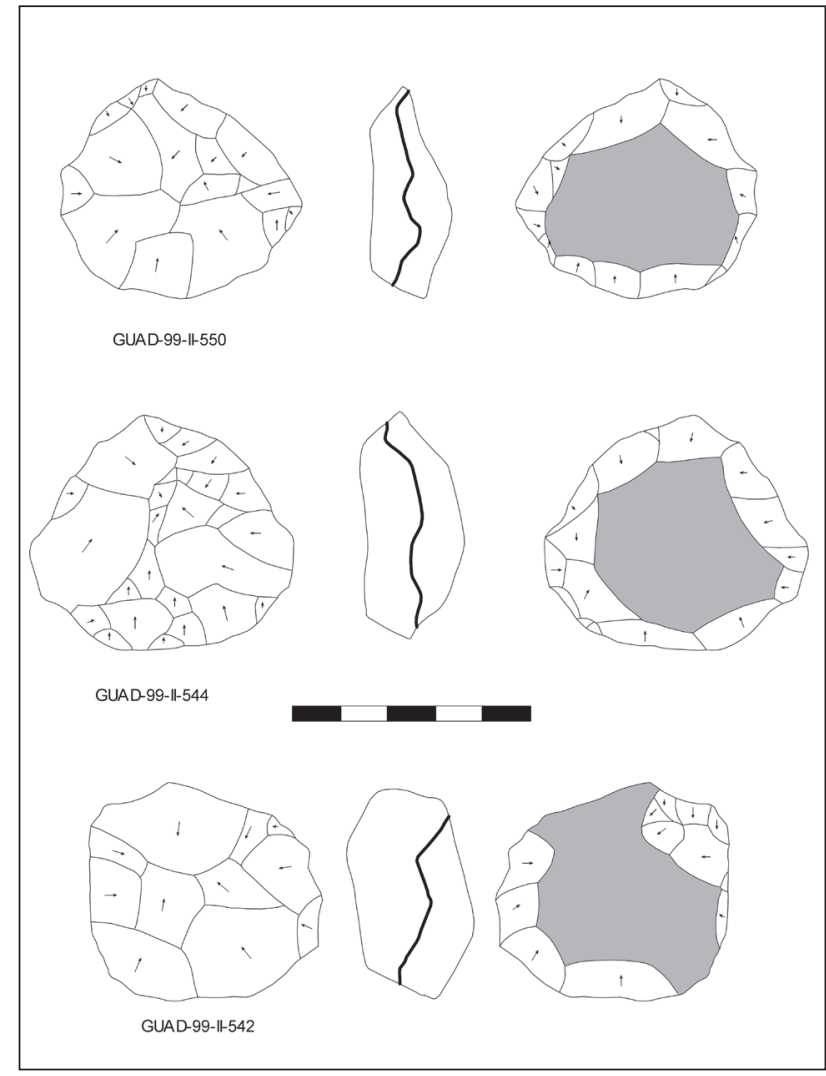

\ Figura 10. Bases negativas de Explotación bifaciales multipolares centrípetas, recurrentes, jerarquizadas.

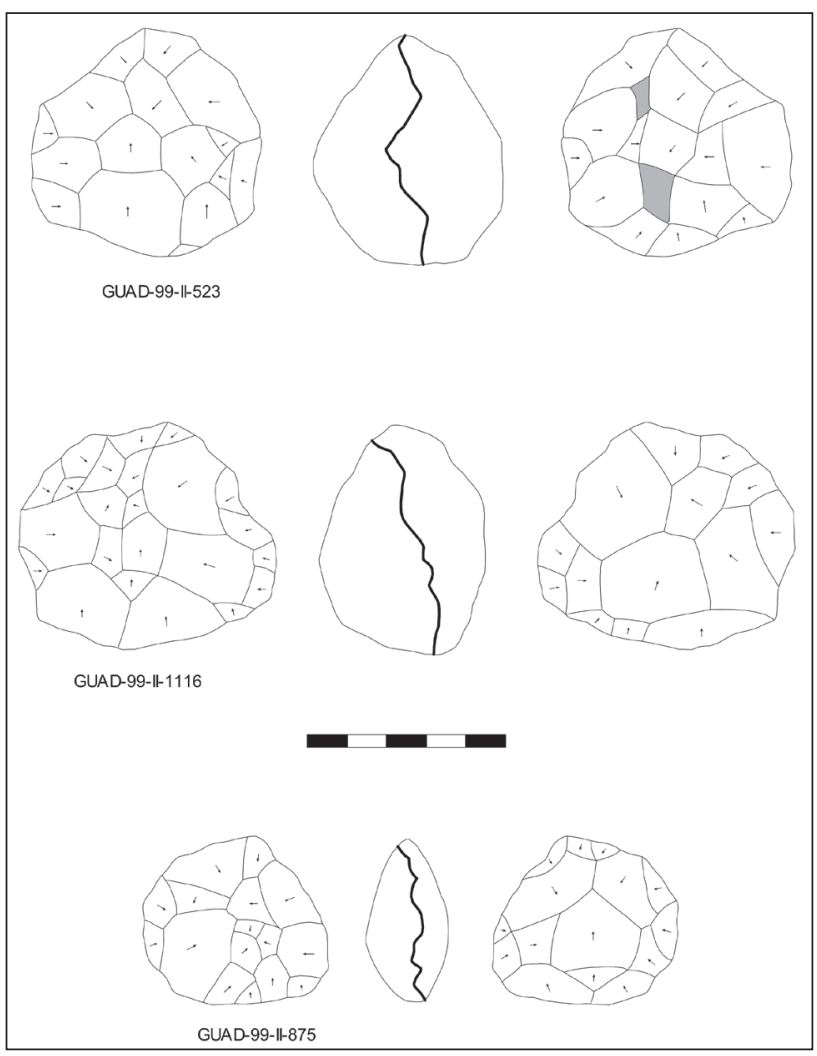

\ FIgURA 12. Bases negativas de Explotación bifaciales multipolares centrípetas, discoides, no jerarquizadas.

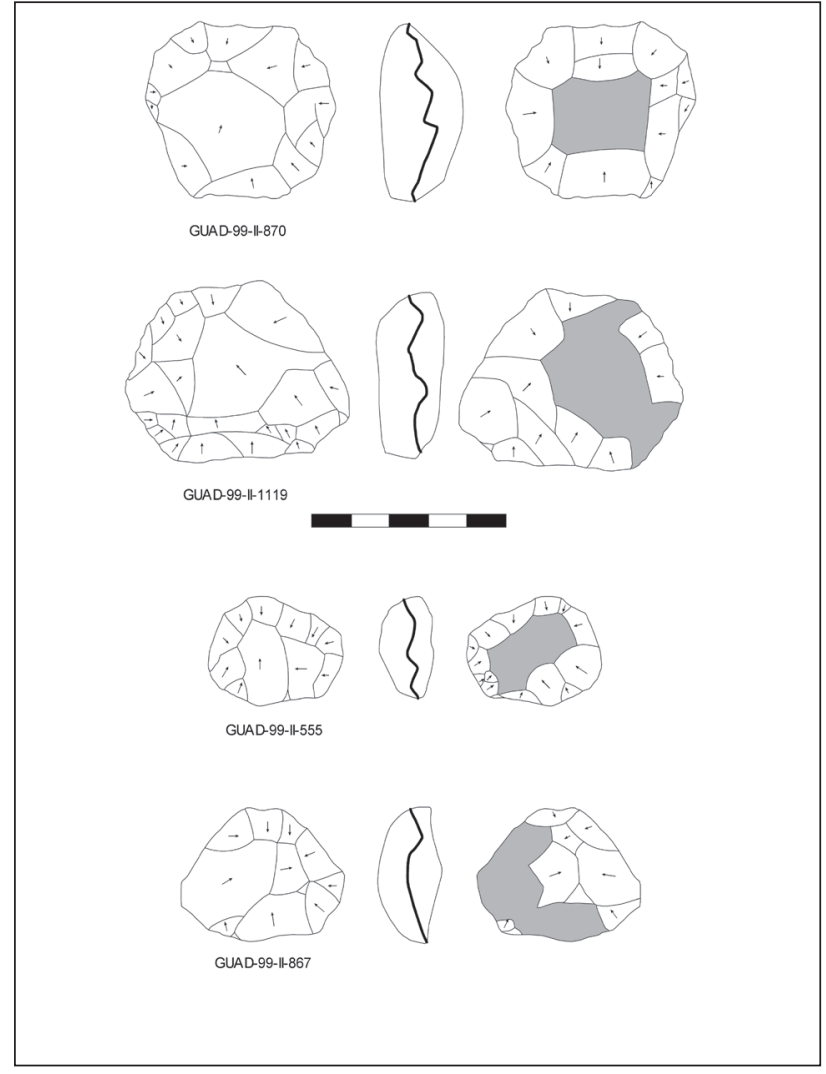

A Figura 11. Bases negativas de Explotación bifaciales multipolares centrípetas, recurrentes, jerarquizadas.

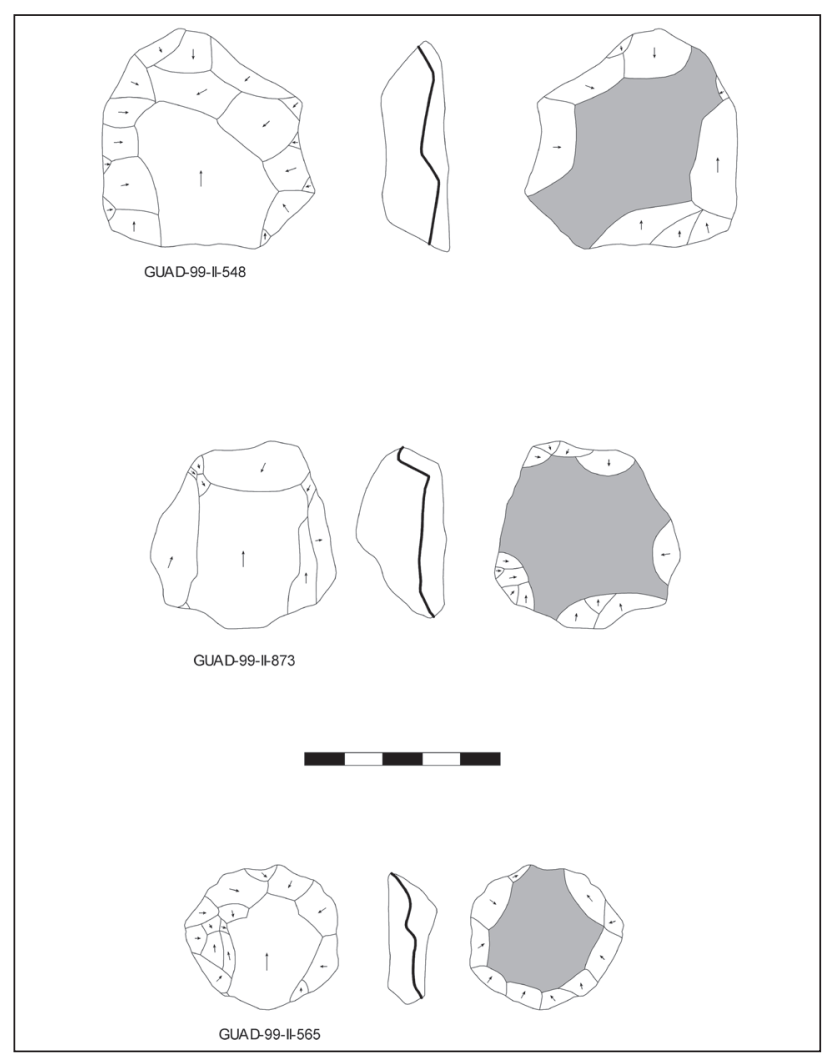

\ Figura 13. Bases negativas de Explotación bifaciales multipolares, centrípetas de lasca preferente. 


\begin{tabular}{|c|c|c|c|c|c|c|c|c|c|c|c|c|c|c|c|c|c|c|c|c|c|c|c|c|c|c|c|}
\hline \multirow{3}{*}{\multicolumn{2}{|c|}{ CRITERIOS ANALITICOS }} & \multicolumn{24}{|c|}{ MATERIA PRIMA } & \multirow{2}{*}{\multicolumn{2}{|c|}{$\begin{array}{l}\text { TOTAL } \\
\text { BP }\end{array}$}} \\
\hline & & \multicolumn{2}{|c|}{ AMF } & \multicolumn{2}{|c|}{$\mathrm{AF}$} & \multicolumn{2}{|c|}{ AM } & \multicolumn{2}{|c|}{$A G$} & \multicolumn{2}{|c|}{ AMG } & \multicolumn{2}{|c|}{ MT } & \multicolumn{2}{|c|}{$\mathrm{RD}$} & \multicolumn{2}{|c|}{ RI } & \multicolumn{2}{|c|}{$\begin{array}{c}\mathrm{SA} / \mathrm{SB} / \mathrm{S} \\
\mathrm{BB} / \mathrm{SH}\end{array}$} & \multicolumn{2}{|c|}{ SMO } & \multicolumn{2}{|c|}{ SMT } & \multicolumn{2}{|c|}{ SO } & & \\
\hline & & $\mathrm{N} .^{\circ}$ & $\%$ & $\mathrm{~N} .^{\circ}$ & $\%$ & N. ${ }^{\circ}$ & $\%$ & N. ${ }^{\circ}$ & $\%$ & $\mathrm{~N} .^{\circ}$ & $\%$ & $\mathrm{~N} .^{\circ}$ & $\%$ & N. ${ }^{\circ}$ & $\%$ & N. ${ }^{\circ}$ & $\%$ & $\mathrm{~N} .^{\circ}$ & $\%$ & N. ${ }^{\circ}$ & $\%$ & $\mathrm{~N} .^{\circ}$ & $\%$ & N. ${ }^{\circ}$ & $\%$ & $\mathrm{~N} .^{\circ}$ & $\%$ \\
\hline \multirow{3}{*}{ VOLUMEN } & ESPESA/PLANA & 32 & 38,6 & 54 & 36,2 & 132 & 43,1 & 68 & 42,5 & 6 & 42,9 & 3 & 60,0 & 1 & 50,0 & 0 & 0,0 & 4 & 100 & 8 & 34,8 & 5 & 83,3 & 6 & 42,9 & 319 & 41,6 \\
\hline & LARGA/PLANA & 51 & 61,4 & 95 & 63,8 & 174 & 56,9 & 92 & 57,5 & 8 & 57,1 & 2 & 40,0 & 1 & 50,0 & 0 & 0,0 & 0 & 0,0 & 15 & 65,2 & 1 & 16,7 & 8 & 57,1 & 447 & 58,4 \\
\hline & TOTAL & 83 & 100 & 149 & 100 & 306 & 100 & 160 & 100 & 14 & 100 & 5 & 100 & 2 & 100 & 0 & 0,0 & 4 & 100 & 23 & 100 & 6 & 100 & 14 & 100 & 766 & 100 \\
\hline \multirow{3}{*}{ BULBO } & MARCADO & 17 & 19,1 & 33 & 23,2 & 67 & 21,8 & 49 & 30,8 & 2 & 18,2 & 1 & 20,0 & 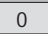 & 0,0 & 0 & 0,0 & 2 & 50,0 & 5 & 20,8 & 2 & 28,6 & 2 & 12,5 & 180 & 23,5 \\
\hline & DIFUSO & 72 & 80,9 & 109 & 76,8 & 241 & 78,2 & 110 & 69,2 & 9 & 81,8 & 4 & 80,0 & 1 & 100 & 1 & 100 & 2 & 50,0 & 19 & 79,2 & 5 & 71,4 & 14 & 87,5 & 587 & 76,5 \\
\hline & TOTAL & 89 & 100 & 142 & 100 & 308 & 100 & 159 & 100 & 11 & 100 & 5 & 100 & 1 & 100 & 1 & 100 & 4 & 100 & 24 & 100 & 7 & 100 & 16 & 100 & 767 & 100 \\
\hline \multirow{5}{*}{$\begin{array}{c}\text { DELINEACIÓN } \\
\text { CARA } \\
\text { VENTRAL }\end{array}$} & CONVEXA & 8 & 7,3 & 7 & 3,8 & 30 & 7,8 & 23 & 12,5 & 0 & 0,0 & 0 & 0,0 & 0 & 0,0 & 0 & 0,0 & 0 & 0,0 & 1 & 3,4 & 2 & 22,2 & 2 & 10,0 & 73 & 7,7 \\
\hline & RECTA & 61 & 56,0 & 106 & 57,9 & 207 & 54,0 & 92 & 50,0 & 6 & 42,9 & 0 & 0,0 & 0 & 0,0 & 1 & 100 & 2 & 50,0 & 17 & 58,6 & 4 & 44,4 & 8 & 40,0 & 504 & 53,4 \\
\hline & CÓNCAVA & 24 & 22,0 & 54 & 29,5 & \begin{tabular}{|l|}
107 \\
\end{tabular} & 27,9 & 50 & 27,2 & 6 & 42,9 & 3 & 60,0 & 1 & 50,0 & 0 & 0,0 & 1 & 25,0 & 7 & 24,1 & 2 & 22,2 & 6 & 30,0 & 261 & 27,7 \\
\hline & SINUOSA & 16 & 14,7 & 16 & 8,7 & 39 & 10,2 & 19 & 10,3 & 2 & 14,3 & 2 & 40,0 & 1 & 50,0 & 0 & 0,0 & 1 & 25,0 & 4 & 13,8 & 1 & 11,1 & 4 & 20,0 & 105 & 11,1 \\
\hline & TOTAL & 109 & 100 & 183 & 100 & \begin{tabular}{|l|}
383 \\
\end{tabular} & 100 & 184 & 100 & 14 & 100 & 5 & 100 & 2 & 100 & 1 & 100 & 4 & 100 & 29 & 100 & 9 & 100 & 20 & 100 & 943 & 100 \\
\hline & $\mathrm{CO}$ & 8 & 7,3 & 12 & 6,6 & \begin{tabular}{|l|}
12 \\
\end{tabular} & 3,1 & 4 & 2,2 & 0 & 0,0 & 0 & 0,0 & 0 & 0,0 & 0 & 0,0 & 0 & 0,0 & 0 & 0,0 & 0 & 0,0 & 1 & 5,0 & 37 & 3,9 \\
\hline & CO/NCO & 20 & 18,3 & 18 & 9,8 & 29 & 7,6 & 19 & 10,3 & 3 & 21,4 & 0 & 0,0 & 0 & 0,0 & 0 & 0,0 & 0 & 0,0 & 0 & 0,0 & 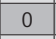 & 0,0 & 0 &, 0 & 89 & 94 \\
\hline & $\mathrm{NCO} / \mathrm{CO}$ & 24 & 22,0 & 44 & 24,0 & 69 & 18,0 & 33 & 17,9 & 2 & 14,3 & 1 & 20,0 & 0 & 0,0 & 0 & 0,0 & 1 & 25,0 & 6 & 20,7 & 3 & 33,3 & 1 & 5,0 & 184 & 19,5 \\
\hline & $\mathrm{NCO}$ & 57 & 52,3 & 109 & 59,6 & \begin{tabular}{|l|}
273 \\
\end{tabular} & 71,3 & 128 & 69,6 & 9 & 64,3 & 4 & 80,0 & 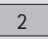 & 100 & 1 & 100 & 3 & 75,0 & 23 & \begin{tabular}{|l|}
79,3 \\
\end{tabular} & 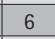 & 66,7 & 18 & 90,0 & 633 & 67,1 \\
\hline & TOTAL & 109 & 100 & 183 & \begin{tabular}{|l|}
100 \\
\end{tabular} & 383 & 100 & 184 & 100 & 14 & 100 & 5 & 100 & 2 & 100 & 1 & 100 & 4 & 100 & 29 & 100 & 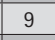 & 100 & 20 & 100 & 943 & 100 \\
\hline & DESCORT. & 8 & 7,3 & 12 & 6,6 & 12 & 3,1 & 4 & 2,2 & 0 & 0,0 & 0 & 0,0 & 0 & 0,0 & 0 & 0,0 & 0 & 0,0 & 0 & 0,0 & 0 & 0,0 & 1 & 5,0 & 37 & 3,9 \\
\hline & SEMIDESC. & 40 & 36,7 & 56 & 30,6 & 90 & 23,5 & 48 & 26,1 & 4 & 28,6 & 1 & 20,0 & 0 & 0,0 & 0 & 0,0 & 1 & 25,0 & 6 & 20,7 & 3 & 33,3 & 0 & 0,0 & 249 & 26,4 \\
\hline TIPO BP & INTERNA & 30 & 27,5 & 74 & 40,4 & 204 & 53,3 & 82 & 44,6 & 3 & 21,4 & 3 & 60,0 & 2 & 100 & 1 & 100 & 2 & 50,0 & 17 & 58,6 & 4 & 44,4 & 15 & 75,0 & 437 & 46,3 \\
\hline & LEVALLOIS & 31 & 28,4 & 41 & 22,4 & \begin{tabular}{|l|}
77 \\
\end{tabular} & 20,1 & 50 & 27,2 & 7 & 50,0 & 1 & 20,0 & 0 & 0,0 & 0 & 0,0 & 1 & 25,0 & 6 & 20,7 & 2 & 22,2 & 4 & 20,0 & 220 & 23,3 \\
\hline & TOTAL & 109 & 100 & 183 & 100 & 383 & 100 & 184 & 100 & 14 & 100 & 5 & 100 & 2 & 100 & 1 & 100 & 4 & 100 & 29 & 100 & 9 & 100 & 20 & 100 & 943 & 100 \\
\hline & $\leq 2$ & 40 & 36,7 & 74 & 40,4 & 132 & 34,5 & 59 & 32,1 & 3 & 21,4 & 2 & 40,0 & 1 & 50,0 & 1 & 100 & 0 & 0,0 & 6 & 20,7 & 3 & 33,3 & 6 & 30,0 & 327 & 34,7 \\
\hline N. ${ }^{\circ}$ LEVANT. & $\geq 3-\geq 5$ & 62 & 56,9 & 100 & 54,6 & \begin{tabular}{|l|}
232 \\
\end{tabular} & 60,6 & 109 & 59,2 & 8 & 57,1 & 3 & 60,0 & 1 & 50,0 & 0 & 0,0 & 3 & 75,0 & 22 & 75,9 & 6 & 66,7 & 14 & 70,0 & 560 & 59,4 \\
\hline CARA DORSAL & $\geq 6$ & 7 & 6,4 & 9 & 4,9 & 19 & 5,0 & 16 & 8,7 & 3 & 21,4 & 0 & 0,0 & 0 & 0,0 & 0 & 0,0 & 1 & 25,0 & 1 & 3,4 & 0 & 0,0 & 0 & 0,0 & 56 & 5,9 \\
\hline & TOTAL & 109 & 100 & 183 & 100 & \begin{tabular}{|l|}
383 \\
\end{tabular} & 100 & 184 & 100 & 14 & 100 & 5 & 100 & 2 & 100 & 1 & 100 & 4 & 100 & 29 & 100 & 9 & 100 & 20 & 100 & 943 & 100 \\
\hline & 1. ${ }^{2}$ & 3 & 2,8 & 9 & 4,9 & 31 & 8,1 & 8 & 4,3 & 0 & 0,0 & 1 & 20,0 & 0 & 0,0 & 1 & 100 & 0 & 0,0 & 1 & 3,4 & 1 & 11,1 & 0 & 0,0 & 55 & 5,8 \\
\hline & 2. ${ }^{a}$ & 1 & 0,9 & 4 & 2,2 & 3 & 0,8 & 0 & 0,0 & 1 & 7,1 & 0 & 0,0 & 0 & 0,0 & 0 & 0,0 & 0 & 0,0 & 0 & 0,0 & 0 & 0,0 & 0 & 0,0 & 9 & 1,0 \\
\hline & RECTA & 47 & 43,1 & 77 & 42,1 & 180 & 47,0 & 91 & 49,5 & 5 & 35,7 & 2 & 40,0 & 1 & 50,0 & 0 & 0,0 & 2 & 50,0 & 12 & 41,4 & 4 & 44,4 & 10 & 50,0 & 431 & 45,7 \\
\hline ACIUN & CONVEXA & 50 & 45,9 & 70 & 38,3 & 114 & 29,8 & 59 & 32,1 & 6 & 42,9 & 1 & 20,0 & 0 & 0,0 & 0 & 0,0 & 0 & 0,0 & 10 & 34,5 & 3 & 33,3 & 4 & 20,0 & 317 & 33,6 \\
\hline & CÓNCAVA & 3 & 2,8 & 5 & 2,7 & 10 & 2,6 & 6 & 3,3 & 0 & 0,0 & 0 & 0,0 & 0 & 0,0 & 0 & 0,0 & 0 & 0,0 & 1 & 3,4 & 0 & 0,0 & 1 & 5,0 & 26 & 2,8 \\
\hline & SINUOSA & 5 & 4,6 & 18 & 9,8 & 45 & 11,7 & 20 & 10,9 & 2 & 14,3 & 1 & 20,0 & 1 & 50,0 & 0 & 0,0 & 2 & 50,0 & 5 & 17,2 & 1 & 11,1 & 5 & 25,0 & 105 & 11,1 \\
\hline & TOTAL & 109 & 100 & 183 & 100 & 383 & 100 & 184 & 100 & 14 & 100 & 5 & 100 & 2 & 100 & 1 & 100 & 4 & 100 & 29 & 100 & 9 & 100 & 20 & 100 & 943 & 100 \\
\hline
\end{tabular}

A Tabla 4. Criterios analíticos de las Bases Positivas.

Los valores tipométricos medios arrojados por las muescas son de $46 \times 35 \times 12 \mathrm{~mm}$, mientras que los denticulados suponen $51 \times 42 \times 19 \mathrm{~mm}$, por lo que resulta que para las muescas se han seleccionado soportes con dimensiones similares a las raederas, a excepción del espesor, ya que las raederas presentan los índices más planos de toda la serie, mientras que sobre las BP de mayores dimensiones se han configurado los denticulados.

El índice de carenado confirma patrones vistos para todo el conjunto, donde ninguna muesca se puede considerar espesa y tan sólo 3 denticulados reúnen los criterios necesarios, lo que representa un 1,3\% de todas las BN2GC.

Las 52 muescas y 48 denticulados suman un total de 100 herramientas líticas, que analizados sus filos suponen un total de 129 segmentos retocados o filos configurados, estando el lateral izquierdo retocado en 54 ocasiones, el lateral derecho en 51 y el extremo distal en 24, además 104 filos presentan retoques simples, 17 retoques semiabruptos y 8 retoques abruptos, en cuanto a la amplitud dominan los retoques profundos en un 99\%, en relación con el tipo de útil descrito, la dirección del retoque es directa en 93 segmentos, inversa en 30 y alternante en 6 , con retoques continuos denticulados y enconché y con morfología en la arista sobre la que se sitúa el reto- que, cóncavas ( $n=66)$, sinuosas $(n=46)$, rectas $(n=12)$ y convexas $(n=5)$.

La presencia de otros grupos es testimonial, ya que se han identificado 3 raspadores, que supone el 1,3\% del total de BN2GC y se corresponden con $1 \mathrm{G} 11$ (raspador frontal simple), 1 G12 (raspador frontal con retoque lateral) y 1 G312 (raspador carenado con retoque lateral).

Igualmente se han localizado 3 buriles, el 1,3\% del total de BN2GC, que se corresponden con 1 B12 (buril sobre fractura) y 2 B32 (buril con paños laterotransversales).

\section{CONTEXTUALIZACIÓN HISTÓRICA EN EL ÁMBITO GEOGRÁFICO DEL ESTRECHO DE GIBRALTAR Y SUR DE LA PENÍNSULA IBÉRICA}

Siendo consecuentes con nuestra posición teórico-metodológica de partida, consideramos imprescindible realizar una contextualización con los sitios sincrónicos del ámbito geográfico del Estrecho de Gibraltar y sur peninsular, pues aspiramos a explicar la sociedad como totalidad histórica, pero en este apartado nos centraremos de manera exclusiva en los datos tecnológicos que ha aportado el análisis de los conjuntos líticos en los distintos yacimientos. 


\begin{tabular}{|c|c|c|c|c|c|c|c|c|c|c|c|c|c|c|c|c|c|c|c|c|c|}
\hline \multirow{3}{*}{\multicolumn{2}{|c|}{$\begin{array}{l}\text { MATERIA } \\
\text { PRIMA }\end{array}$}} & \multicolumn{20}{|c|}{ CRITERIOS ANALÍTICOS SUPERFICIE TALONAR BP } \\
\hline & & \multicolumn{4}{|c|}{ CORTICALIDAD } & \multicolumn{7}{|c|}{ DELINEACIÓN } & \multicolumn{5}{|c|}{ GRADO DE FACETADO } & \multicolumn{4}{|c|}{ TIPO } \\
\hline & & $\mathrm{CO}$ & $\begin{array}{l}\mathrm{CO} / \\
\mathrm{NCO}\end{array}$ & NCO & $\pi$ & $1^{\mathrm{a}}$ & $2^{\mathrm{a}}$ & RT & $\mathrm{cx}$ & CC & SIN & $\Pi$ & NF & UF & $\mathrm{BF}$ & MF & $\pi$ & LIN & PLAT & PUNT & $\pi$ \\
\hline \multirow{2}{*}{ AMF } & N. ${ }^{\circ}$ & 19 & 1 & 69 & 89 & 8 & 0 & 56 & 19 & 2 & 4 & 89 & 18 & 53 & 13 & 5 & 89 & 9 & 79 & 1 & 89 \\
\hline & $\%$ & 21,3 & 1,1 & 77,5 & 100 & 9,0 & 0,0 & 62,9 & 21,3 & 2,2 & 4,5 & 100 & 20,2 & 59,6 & 14,6 & 5,6 & 100 & 10,1 & 88,8 & 1,1 & 100 \\
\hline \multirow{2}{*}{$\mathrm{AF}$} & N. ${ }^{\circ}$ & 23 & 1 & 118 & 142 & 12 & 0 & 85 & 25 & 12 & 8 & 142 & 22 & 94 & 19 & 7 & 142 & 9 & 133 & 0 & 142 \\
\hline & $\%$ & 16,2 & 0,7 & 83,1 & 100 & 8,5 & 0,0 & 59,9 & 17,6 & 8,5 & 5,6 & 100 & 15,5 & 66,2 & 13,4 & 4,9 & 100 & 6,3 & 93,7 & 0,0 & 100 \\
\hline \multirow{2}{*}{ AM } & N. ${ }^{\circ}$ & 26 & 1 & 281 & 308 & 21 & 1 & 212 & 39 & 13 & 22 & 308 & 24 & 230 & 45 & 9 & 308 & 6 & 298 & 4 & 308 \\
\hline & $\%$ & 8,4 & 0,3 & 91,2 & 100 & 6,8 & 0,3 & 68,8 & 12,7 & 4,2 & 7,1 & 100 & 7,8 & 74,7 & 14,6 & 2,9 & 100 & 1,9 & 96,8 & 1,3 & 100 \\
\hline \multirow{2}{*}{ AG } & N. ${ }^{\circ}$ & 18 & 0 & 141 & 159 & 15 & 1 & 106 & 23 & 4 & 10 & 159 & 17 & 104 & 31 & 7 & 159 & 4 & 155 & 0 & 159 \\
\hline & $\%$ & 11,3 & 0,0 & 88,7 & 100 & 9,4 & 0,6 & 66,7 & 14,5 & 2,5 & 6,3 & 100 & 10,7 & 65,4 & 19,5 & 4,4 & 100 & 2,5 & 97,5 & 0,0 & 100 \\
\hline \multirow{2}{*}{ AMG } & N. ${ }^{\circ}$ & 1 & 0 & 10 & 11 & 1 & 0 & 9 & 0 & 0 & 1 & 11 & 1 & 8 & 1 & 1 & 11 & 0 & 11 & 0 & 11 \\
\hline & $\%$ & 9,1 & 0,0 & 90,9 & 100 & 9,1 & 0,0 & 81,8 & 0,0 & 0,0 & 9,1 & 100 & 9,1 & 72,7 & 9,1 & 9,1 & 100 & 0,0 & 100 & 0,0 & 100 \\
\hline \multirow{2}{*}{ MT } & N. ${ }^{\circ}$ & 0 & 0 & 5 & 5 & 1 & 0 & 3 & 1 & 0 & 0 & 5 & 0 & 3 & 1 & 1 & 5 & 0 & 4 & 1 & 5 \\
\hline & $\%$ & 0,0 & 0,0 & 100 & 100 & 20,0 & 0,0 & 60,0 & 20,0 & 0,0 & 0,0 & 100 & 0,0 & 60,0 & 20,0 & 20,0 & 100 & 0,0 & 80,0 & 20,0 & 100 \\
\hline \multirow{2}{*}{ RD } & N. ${ }^{\circ}$ & 0 & 0 & 1 & 1 & 0 & 0 & 1 & 0 & 0 & 0 & 1 & 0 & 1 & 0 & 0 & 1 & 1 & 0 & 0 & 1 \\
\hline & $\%$ & 0,0 & 0,0 & 100 & 100 & 0,0 & 0,0 & 100 & 0,0 & 0,0 & 0,0 & 100 & 0,0 & 100 & 0,0 & 0,0 & 100 & 100 & 0,0 & 0,0 & 100 \\
\hline \multirow{2}{*}{ RI } & N. ${ }^{\circ}$ & 0 & 0 & 1 & 1 & 1 & 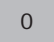 & 0 & 0 & 0 & 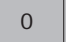 & 1 & 0 & 0 & 1 & 0 & 1 & 0 & 1 & 0 & 1 \\
\hline & $\%$ & 0,0 & 0,0 & 100 & 100 & 100 & 0,0 & 0,0 & 0,0 & 0,0 & 0,0 & 100 & 0,0 & 0,0 & 100 & 0,0 & 100 & 0,0 & 100 & 0,0 & 100 \\
\hline \multirow{2}{*}{$\mathrm{SA} / \mathrm{SB} / \mathrm{SBB} / \mathrm{SII}$} & N. ${ }^{\circ}$ & 0 & 0 & 4 & 4 & 1 & 0 & 2 & 0 & 0 & 1 & 4 & 0 & 3 & 1 & 0 & 4 & 0 & 4 & 0 & 4 \\
\hline & $\%$ & 0,0 & 0,0 & 100 & 100 & 25,0 & 0,0 & 50,0 & 0,0 & 0,0 & 25,0 & 100 & 0,0 & 75,0 & 25,0 & 0,0 & 100 & 0,0 & 100 & 0,0 & 100 \\
\hline \multirow{2}{*}{ SMO } & N. ${ }^{\circ}$ & 2 & 0 & 22 & 24 & 3 & 0 & 18 & 1 & 0 & 2 & 24 & 1 & 16 & 3 & 4 & 24 & 2 & 20 & 2 & 24 \\
\hline & $\%$ & 8,3 & 0,0 & 91,7 & 100 & 12,5 & 0,0 & 75,0 & 4,2 & 0,0 & 8,3 & 100 & 4,2 & 66,7 & 12,5 & 16,7 & 100 & 8,3 & 83,3 & 8,3 & 100 \\
\hline \multirow{2}{*}{ SMT } & N. ${ }^{\circ}$ & 0 & 0 & 7 & 7 & 0 & 0 & 5 & 1 & 0 & 1 & 7 & 0 & 5 & 1 & 1 & 7 & 1 & 5 & 1 & 7 \\
\hline & $\%$ & 0,0 & 0,0 & 100 & 100 & 0,0 & 0,0 & 71,4 & 14,3 & 0,0 & 14,3 & 100 & 0,0 & 71,4 & 14,3 & 14,3 & 100 & 14,3 & 71,4 & 14,3 & 100 \\
\hline \multirow{2}{*}{ so } & N. ${ }^{\circ}$ & 2 & 0 & 14 & 16 & 1 & 1 & 10 & 3 & 0 & 1 & 16 & 2 & 10 & 2 & 2 & 16 & 0 & 16 & 0 & 16 \\
\hline & $\%$ & 12,5 & 0,0 & 87,5 & 100 & 6,3 & 6,3 & 62,5 & 18,8 & 0,0 & 6,3 & 100 & 12,5 & 62,5 & 12,5 & 12,5 & 100 & 0,0 & 100 & 0,0 & 100 \\
\hline \multirow{2}{*}{ TOTAL } & N. ${ }^{\circ}$ & 91 & 3 & 673 & 767 & 64 & 3 & 507 & 112 & 31 & 50 & 767 & 85 & 527 & 118 & 37 & 767 & 32 & 726 & 9 & 767 \\
\hline & $\%$ & 11,9 & 0,4 & 87,7 & 100 & 8,3 & 0,4 & 66,1 & 14,6 & 4,0 & 6,5 & 100 & 11,1 & 68,7 & 15,4 & 4,8 & 100 & 4,2 & 94,7 & 1,2 & 100 \\
\hline
\end{tabular}

\ TABLA 5. Análisis de la superficie talonar de las Bases Positivas.

\section{Abrigo de Benzú}

El Abrigo de Benzú (Ramos et al. 2003), está situado en el acceso oriental del Estrecho de Gibraltar, en la costa norte de África, en la parte más occidental de la Ciudad Autónoma de Ceuta y a una altitud de 63 m.s.n.m.

En él se han identificado diez niveles, enumerados del 0 al 9 de base a techo, de los que presentan indicios de ocupación humana los estratos 1 al 7.

Los resultados obtenidos tras las dataciones absolutas indican que toda la secuencia es anterior a $70 \mathrm{Ka}$ con base cronológica en los $254 \pm 17 \mathrm{Ka}$ del estrato 3 , evidenciándose períodos de intensa ocupación en los estratos 4 y 5 formados entre $173 \pm 10$ Ka y $168 \pm 11$ Ka (Ramos et al. 2007 y 2008).

Para valorar la tecnología lítica contamos con reseñas en los artículos publicados hasta el momento, entre ellos (Ramos et al. 2005, 2007 y 2008). Supone una excepción el análisis técnico de los artefactos líticos recuperados en la campaña del año 2002 de los estratos 7 y 4 (Herrero et al. 2003).

Con más de 10.000 artefactos líticos recuperados entre los estratos 7, 4, 3 y 2, sus autores plantean algunas conclusiones tecnológicas que resumimos a continuación, aunque consideramos que éstas deberían hacerse por estratos, debido al lapso temporal que existe entre ellos:

- La materia prima seleccionada para la configuración de los objetos ha sido principalmente sílex y arenisca, junto con radiolaritas, procedentes del entorno inmediato al yacimiento, por lo tanto su adquisición por parte de los paleopobladores fue local.

- Escasa representación de BN1GE, identificando estrategias de talla unipolar, levallois y centrípetos multipolares.

- Las BP se corresponden en su mayoría con lascas internas y levallois, con escaso número de BP con presencia de cortex y algún artefacto lítico laminar.

- Representación de elementos líticos de desecho que clasifican como otros restos de talla, esquirlas y desechos propiamente dichos.

- En cuanto a las BN2GC constatan selección de materia prima, método de talla y tipometría de BP para su posterior configuración, identificando los tipos propios de modo 3 como raederas, tanto marginales como profundas, laterales y transversales, puntas musterienses, muescas y denticulados. 


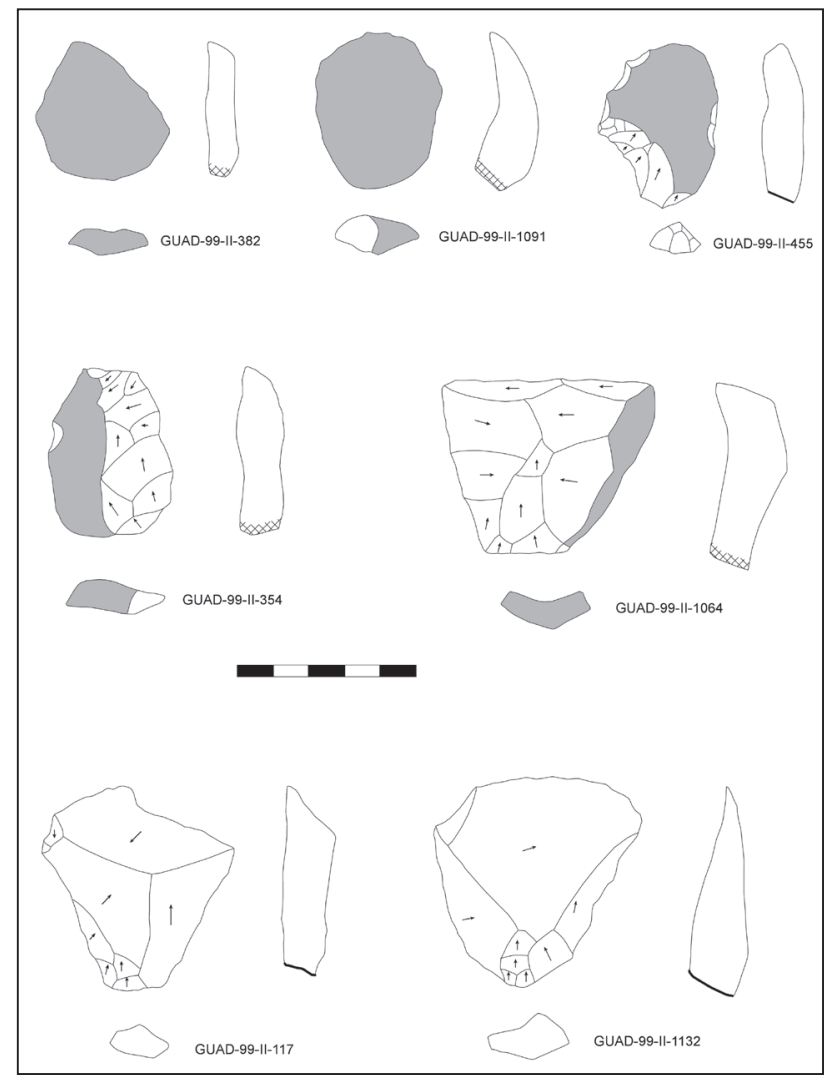

A Figura 14. Bases positivas, secuencia operativa de completamente corticales a no corticales.

Es un tema recurrente para estos autores valorar las similitudes tecnológicas desde el modo 2 y la selección de materias primas, entre ambas orillas del Estrecho de Gibraltar (Ramos et al. 2003, 2005 y 2007), retoman con ello el antiguo debate de los posibles contactos entre Europa y África vía Estrecho de Gibraltar, dejando abierta la identificación antropológica de los autores con tecnología de modo 3 en el norte de África (Ramos 2006).

Últimamente plantean la posibilidad de que las similitudes tecnológicas tengan un origen común en el Próximo Oriente, desde donde habría Ilegado a la Península Ibérica, en lugar de hacerlo directamente a través del Estrecho de Gibraltar, toman como núcleo central de defensa de la hipótesis del Estrecho de Gibraltar como vía de paso el análisis de las materias primas (Ramos et al. 2008).

Tenemos conocimiento de que pronto verá la luz una sintesis que recogerá los resultados de las sucesivas campañas de excavación, llevadas a cabo desde el año 2002, así como de los diferentes estudios analíticos y funcionales.

\section{Cuevas de Gibraltar}

Gibraltar se ha erigido en un lugar excepcional donde analizar la tardía desaparición de los neandertales en el sur de la Península Ibérica, así como el medio natural en el que

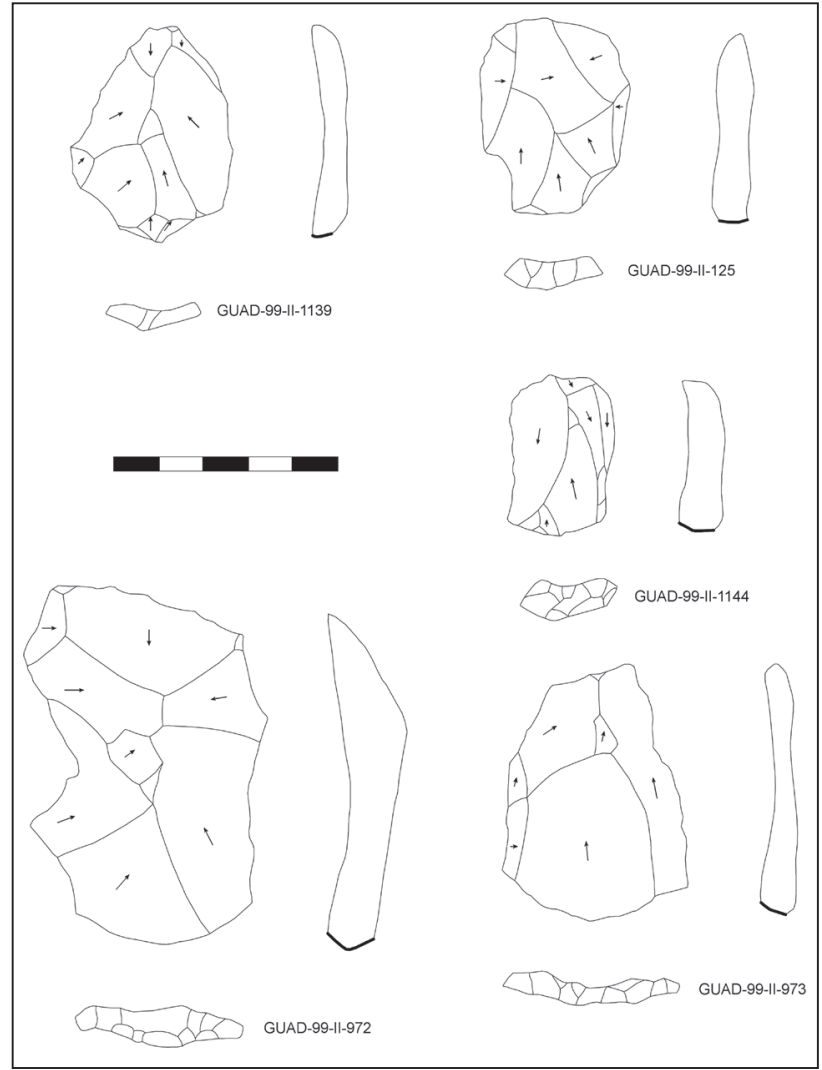

A Figura 15. Bases positivas procedentes de métodos de talla predeterminados (levallois).

desarrollaron su modo de vida estas sociedades y la variabilidad tecnológica asociada al modo 3 y 4.

En Gibraltar se han identificado varias cuevas con niveles musterienses entre las que cabe citar: Gorham's Cave, Forbe's Quarry, Genista, Devil's Tower, Vanguard, Ibex y Beefsteak Cave.

Gorham's Cave es hasta el momento la cueva mejor estudiada, en ella se ha establecido una importante serie de dataciones absolutas desde J. D'A Waechter (1951), a las que habría que añadir las dataciones recientes (Petit y Bailey 2000; Volterra et al. 2000; Rink et al. 2000). En Gorham's Cave se retomaron las excavaciones recientes en los años noventa del siglo pasado, momento en el que se atribuye el nivel IV al OIS 3, con tecnología lítica Musteriense, donde los patrones técnicos se caracterizan por una exigua representación de temas operativos técnicos directos $(n=2)$, una limitada variedad de temas operativos técnicos indirectos, representada por los tipos recurrentes centrípetos, bipolares opuestos y unipolares ortogonales y BN2GC como raederas, muescas y denticulados (Giles et al. 2001 y 2011).

\section{Río Palmones}

En el seno del proyecto de investigación Las bandas de cazadores-recolectores en el Campo de Gibraltar, se prospectó en el año 2001 la cuenca fluvial del río Palmones, 


\begin{tabular}{|c|c|c|c|c|c|c|c|c|c|c|c|c|c|c|c|c|c|c|c|c|c|c|c|}
\hline \multirow{3}{*}{\multicolumn{2}{|c|}{$\begin{array}{l}\text { CRITERIOS ANALÍTICOS } \\
\text { DEL RETOQUE EN LAS BN2GC }\end{array}$}} & \multicolumn{20}{|c|}{ MATERIA PRIMA } & \multirow{2}{*}{\multicolumn{2}{|c|}{\begin{tabular}{|c|} 
TOTAL \\
SEGMENTOS \\
RETOCADOS \\
\end{tabular}}} \\
\hline & & \multicolumn{2}{|c|}{ AMF } & \multicolumn{2}{|c|}{$\mathrm{AF}$} & \multicolumn{2}{|c|}{ AM } & \multicolumn{2}{|c|}{ AG } & \multicolumn{2}{|c|}{ AMG } & \multicolumn{2}{|c|}{ MT } & \multicolumn{2}{|c|}{$\mathrm{SH} / \mathrm{SB}$} & \multicolumn{2}{|c|}{ SMO } & \multicolumn{2}{|c|}{ SMT } & \multicolumn{2}{|c|}{ SO } & & \\
\hline & & $\mathrm{N} .^{\circ}$ & $\%$ & N. ${ }^{\circ}$ & $\%$ & N. ${ }^{\circ}$ & $\%$ & N. ${ }^{\circ}$ & $\%$ & N. ${ }^{\circ}$ & $\%$ & $\mathrm{~N} .^{\circ}$ & $\%$ & $\mathrm{~N} .{ }^{\circ}$ & $\%$ & N. ${ }^{\circ}$ & $\%$ & N. ${ }^{\circ}$ & $\%$ & N. ${ }^{\circ}$ & $\%$ & $\mathrm{~N} .^{\circ}$ & $\%$ \\
\hline \multirow{4}{*}{ LOCALIZACIÓN } & LAT. IZQUIERDO & 16 & 43,2 & 25 & 43,1 & 36 & 36,4 & 23 & 39,0 & 1 & 20,0 & 1 & 100 & 1 & 50,0 & 5 & 42 & 1 & 50,0 & 4 & 44,4 & 113 & 39,8 \\
\hline & EXT. DISTAL & 10 & 27,0 & 12 & 20,7 & 15 & 15,2 & 16 & 27,1 & 0 & 0,0 & 0 & 0,0 & 0 & 0,0 & 2 & 16,7 & 0 & 0,0 & 2 & 22,2 & 57 & 20,1 \\
\hline & LAT. DERECHO & 11 & 29,7 & 21 & 36,2 & 48 & 48,5 & 20 & 33,9 & 4 & 80,0 & 0 & 0,0 & 1 & 50,0 & 5 & 41,7 & 1 & 50,0 & 3 & 33,3 & 114 & 40,1 \\
\hline & TOTAL & 37 & 100 & 58 & 100 & 99 & 100 & 59 & 100 & 5 & 100 & 1 & 100 & 2 & 100 & 12 & 100 & 2 & 100 & 9 & 100 & 284 & 100 \\
\hline \multirow{4}{*}{ MODO } & ABRUPTO & 2 & 5,4 & 2 & 3,4 & 2 & 2,0 & 1 & 1,7 & 0 & 0,0 & 0 & 0,0 & 0 & 0,0 & 0 & 0 & 0 & 0,0 & 1 & 11,1 & 8 & 2,8 \\
\hline & SIMPLE & 33 & 89,2 & 52 & 89,7 & 89 & 89,9 & 53 & 89,8 & 5 & 100 & 1 & 100 & 2 & 100 & 11 & \begin{tabular}{|l|l|}
91,7 \\
\end{tabular} & 2 & \begin{tabular}{|l|}
100 \\
\end{tabular} & 6 & 66,7 & 254 & 89,4 \\
\hline & SEMIABRUPTO & 2 & 5,4 & 4 & 6,9 & 8 & 8,1 & 5 & 8,5 & 0 & 0,0 & 0 & 0,0 & 0 & 0,0 & 1 & 8,3 & 0 & 0,0 & 2 & 22,2 & 22 & 7,7 \\
\hline & TOTAL & 37 & 100 & 58 & 100 & 99 & 100 & 59 & 100 & 5 & 100 & 1 & 100 & 2 & 100 & 12 & 100 & 2 & 100 & 9 & 100 & 284 & 100 \\
\hline \multirow{3}{*}{ AMPLITUD } & MARGINAL & 11 & 29,7 & 10 & 17,2 & 19 & 19,2 & 10 & 16,9 & 0 & 0,0 & 0 & 0,0 & 0 & 0,0 & 0 & 0,0 & 0 & 0 & 2 & 22,2 & 52 & 18,3 \\
\hline & PROFUNDO & 26 & 70,3 & 48 & 82,8 & 80 & \begin{tabular}{|l|}
80,8 \\
\end{tabular} & 49 & 83,1 & 5 & 100 & 1 & 100 & 2 & 100 & 12 & 100 & 2 & 100 & 7 & 77,8 & 232 & 81,7 \\
\hline & TOTAL & 37 & 100 & 58 & 100 & 99 & 100 & 59 & 100 & 5 & 100 & 1 & 100 & 2 & 100 & 12 & 100 & 2 & 100 & 9 & 100 & 284 & 100 \\
\hline \multirow{4}{*}{ DIRECCIÓN } & DIRECTO & 27 & 73,0 & 43 & 74,1 & 74 & 74,7 & 48 & 81,4 & 5 & 100 & 1 & 100 & 2 & 100 & 11 & \begin{tabular}{|l|l|}
91,7 \\
\end{tabular} & 1 & 50,0 & 8 & 88,9 & 220 & 77,5 \\
\hline & INVERSO & 8 & 21,6 & 14 & 24,1 & 21 & 21,2 & 10 & 16,9 & 0 & 0,0 & 0 & 0,0 & 0 & 0,0 & 1 & 8 & 1 & 50,0 & 1 & 11,1 & 56 & 19,7 \\
\hline & ALTERNO & 2 & 5,4 & 1 & 1,7 & 4 & 4,0 & 1 & 1,7 & 0 & 0,0 & 0 & 0,0 & 0 & 0,0 & 0 & 0,0 & 0 & 0,0 & 0 & 0,0 & 8 & 2,8 \\
\hline & TOTAL & 37 & 100 & 58 & 100 & 99 & 100 & 59 & 100 & 5 & 100 & 1 & 100 & 2 & 100 & 12 & 100 & 2 & 100 & 9 & 100 & 284 & 100 \\
\hline \multirow{4}{*}{ DELINEACIÓN } & CONTINUO & 26 & 70,3 & 35 & 60,3 & 62 & 62,6 & 28 & 47,5 & 2 & 40,0 & 1 & 100 & 2 & 100 & 6 & 50,0 & 2 & 100 & 3 & 33,3 & 167 & 58,8 \\
\hline & DENTICULADO & 4 & 10,8 & 13 & 22,4 & 13 & 13,1 & 15 & 25,4 & 3 & 60,0 & 0 & 0,0 & 0 & 0,0 & 4 & 33,3 & 0 & 0,0 & 2 & 22,2 & 54 & 19,0 \\
\hline & MUESCA & 7 & 18,9 & 10 & 17,2 & 24 & 24,2 & 16 & 27,1 & 0 & 0,0 & 0 & 0,0 & 0 & 0 & 2 & 17 & 0 & \begin{tabular}{|l|}
0,0 \\
\end{tabular} & 4 & 44,4 & 63 & 22,2 \\
\hline & TOTAL & 37 & 100 & 58 & 100 & 99 & 100 & 59 & 100 & 5 & 100 & 1 & 100 & 2 & 100 & 12 & 100 & 2 & 100 & 9 & 100 & 284 & 100 \\
\hline \multirow{5}{*}{ MORFOLOGIAA } & RECTO & 15 & 40,5 & 25 & 43,1 & 37 & 37,4 & 19 & 32,2 & 1 & 20,0 & 1 & 100 & 1 & 50,0 & 5 & 41,7 & 0 & \begin{tabular}{|l|}
0,0 \\
\end{tabular} & 4 & 44,4 & 108 & 38,0 \\
\hline & CONVEXO & 11 & 29,7 & 9 & 15,5 & 23 & 23,2 & 12 & 20,3 & 1 & 20,0 & 0 & 0,0 & 1 & 50,0 & 1 & 8,3 & 1 & 50,0 & 2 & 22,2 & 61 & 21,5 \\
\hline & CÓNCAVO & 7 & 18,9 & 11 & 19,0 & 27 & 27,3 & 15 & 25,4 & 0 & 0,0 & 0 & 0,0 & 0 & 0 & 2 & 17 & 0 & \begin{tabular}{|l|}
0,0 \\
\end{tabular} & 3 & 33,3 & 65 & 22,9 \\
\hline & SINUOSOS & 4 & 10,8 & 13 & 22,4 & \begin{tabular}{|l|}
12 \\
\end{tabular} & 12,1 & 13 & 22,0 & 3 & 60,0 & 0 & 0,0 & 0 & 0,0 & 4 & 33,3 & 1 & 50,0 & 0 & 0,0 & 50 & 17,6 \\
\hline & TOTAL & 37 & 100 & 58 & 100 & 99 & 100 & 59 & 100 & 5 & 100 & 1 & 100 & 2 & 100 & 12 & 100 & 2 & 100 & 9 & 100 & 284 & 100 \\
\hline \multirow{6}{*}{$\begin{array}{l}\text { TIPO DE } \\
\text { OBJETO } \\
\text { RETOCADO }\end{array}$} & RAEDERA & 22 & 66,7 & 29 & 60,4 & 43 & 53,8 & 19 & 41,3 & 2 & 50,0 & 1 & 100 & 2 & 100 & 4 & 44 & 2 & 100 & 3 & 37,5 & 127 & 54,5 \\
\hline & MUESCA & 6 & 18,2 & 9 & 18,8 & 20 & 25,0 & 12 & 26,1 & 0 & 0,0 & 0 & 0,0 & 0 & 0,0 & 2 & 22,2 & 0 & \begin{tabular}{|l|}
0,0 \\
\end{tabular} & 3 & 37,5 & 52 & 22,3 \\
\hline & DENTICULADO & 4 & 12,1 & 10 & 20,8 & 14 & 17,5 & 13 & 28,3 & 2 & 50,0 & 0 & 0,0 & 0 & 0,0 & 3 & 33,3 & 0 & \begin{tabular}{|l|}
0,0 \\
\end{tabular} & 2 & 25,0 & 48 & 20,6 \\
\hline & RASPADOR & 1 & 3,0 & 0 & 0,0 & 1 & 1,3 & 1 & 2,2 & 0 & 0,0 & 0 & 0,0 & 0 & 0,0 & 0 & 0,0 & 0 & 0,0 & 0 & 0,0 & 3 & 1,3 \\
\hline & BURIL & 0 & 0,0 & 0 & 0,0 & 2 & 2,5 & 1 & 2,2 & 0 & 0,0 & 0 & 0,0 & 0 & 0,0 & 0 & 0,0 & 0 & 0,0 & 0 & 0,0 & 3 & 1,3 \\
\hline & TOTAL & 33 & 100 & 48 & 100 & 80 & 100 & 46 & 100 & 4 & 100 & 1 & 100 & 2 & 100 & 9 & 100 & 2 & 100 & 8 & 100 & 233 & 100 \\
\hline
\end{tabular}

\ Tabla 6. Criterios analíticos del retoque en las Bases Negativas de Segunda Generación de Configuración.

donde se localiza en una terraza de su margen izquierda (T2) el sitio de Garganta del Cura 2, en la cola del pantano de Charco Redondo, en el término municipal de Los Barrios (Cádiz) (Castañeda 2008).

Garganta del Cura 2 es un sitio de superficie que proporcionó un total de 132 artefactos ( $n=11$ BN1GE, $n=95$ BP y $n=26$ BN2GC), del que se pueden extraer las siguientes conclusiones:

- La materia prima seleccionada para su elaboración fue el silex en un 50\%, la arenisca en un $46,97 \%$, radiolaritas con un $2,28 \%$ y cuarcita con un $0,75 \%$.

- La estrategia de talla (BNE) dominante es la multipolar, con más de un 50\% de multipolares centrípetos, predeterminados recurrentes, con dos superficies jerarquizadas, la cara horizontal superior de explotación y la cara horizontal inferior de preparación, donde permanece cortex residual hasta la fase terminal de explotación.

- Estos sistemas de explotación van dirigidos a la producción de bases positivas (BP), en general planas o muy planas, con talones lisos y facetados, propios de los métodos de talla empleados.

- Las BN2GC se corresponden con 10 raederas, en su mayoría laterales directas e inversas y presencia de raederas dobles, 4 muescas, 9 denticulados y 3 retoques de uso.

A pesar del escaso número de artefactos identificados, en Garganta del Cura 2, observamos una serie de patrones comunes y marcadas diferencias con el sitio de la desembocadura del río Guadalmesí.

- En primer lugar, los porcentajes de materia prima seleccionada, con un incremento importante en la utilización del silex, cuyos autores relacionan con la mayor movilidad de las bandas de cazadoresrecolectores neandertales.

- En segundo lugar, la práctica ausencia de BP corticales nos hace pensar en la posibilidad de una ruptura de la cadena operativa como consecuencia de que el silex haya sido aportado al lugar previamente desbastado.

- Únicamente se han identificado temas operativos técnicos indirectos (TOTI), dirigidos a la obtención de $B P$, estando ausente del registro los tipos de gran formato (bifaces, hendedores, cantos tallados), que si están profusamente representados en los sitios de modo técnico 2 de la cuenca fluvial del río Palmones. 


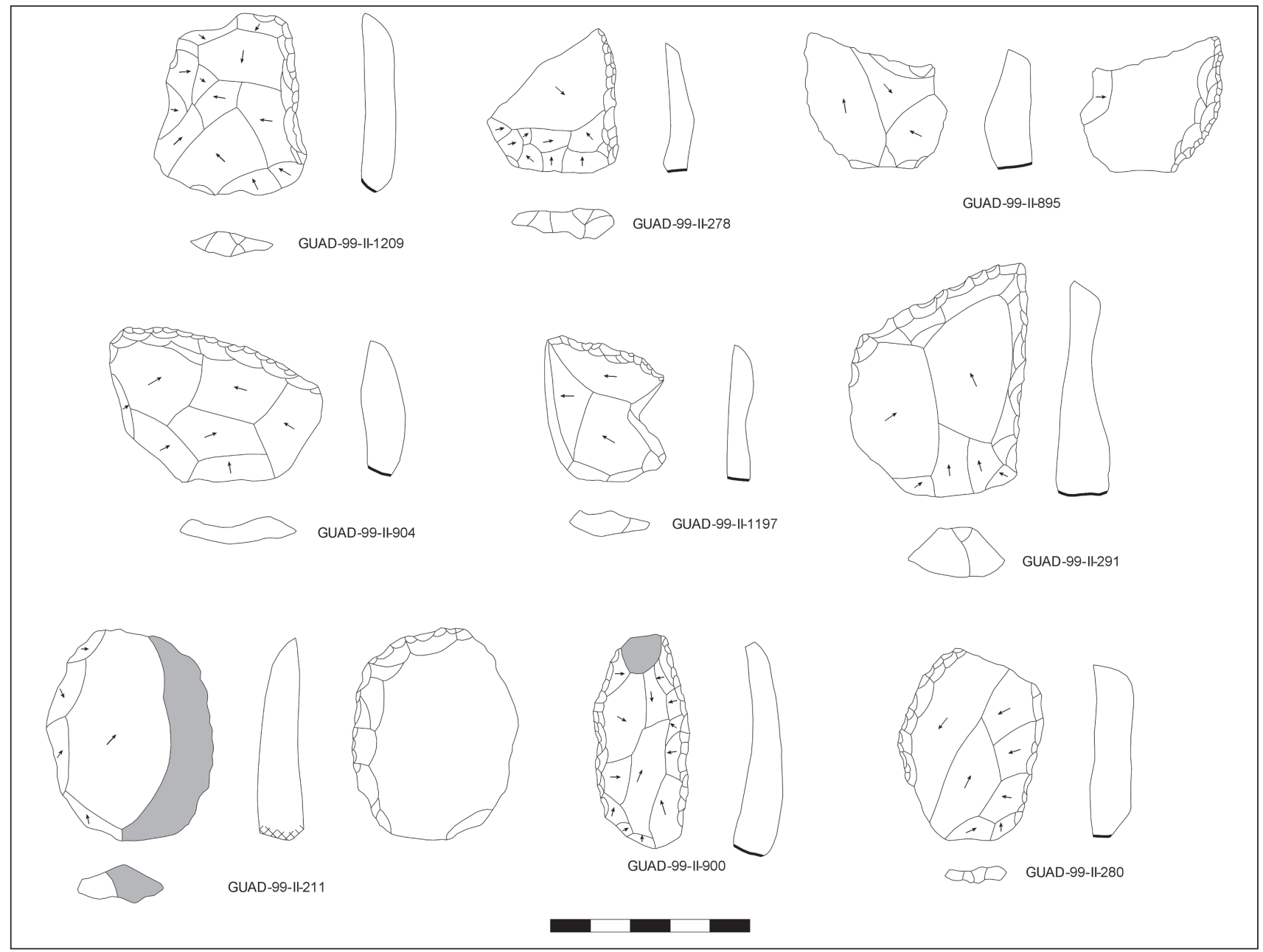

\ Figura 16. Bases negativas de Segunda Generación de Configuración. Raederas.

Consideramos que los sitios de estas características encajan perfectamente en los patrones de movilidad de grupos cazadores-recolectores neandertales que utilizan los valles fluviales como vía natural de comunicación, en este caso concreto uniendo el espacio que existe entre la Bahía de Algeciras y la Laguna de la Janda.

De estos valles fluviales, como el río Palmones, no sólo tienen acceso a la materia prima empleada en la elaboración de los artefactos líticos, sino también a los recursos alimenticios, agua potable...

\section{Sitios de la antigua Laguna de la Janda}

La Laguna de la Janda fue la zona del Campo de Gibraltar que gozó de mayor dinamismo en cuanto a la atención y presencia de investigadores durante buena parte del primer tercio del siglo XX. Estos estudios fueron abandonados hasta el año 1978 cuando se revitaliza el panorama investigador, tanto con trabajos puntuales como formando parte de proyectos de investigación.

De los estudios clásicos se citan los sitios de Venta de la Pasada de Gibraltar (Musteriense muy dudoso) y los De- rramaderos localizados por E. Hernández-Pacheco y Juan Cabré (1913), ya que el resto de localizaciones se corresponden con estaciones chelenses y achelenses (HernándezPacheco 1915).

En el seno del proyecto de investigación codirigido por D. Juan Ramón Ramírez, D. Carlos Fernández-Llebrez

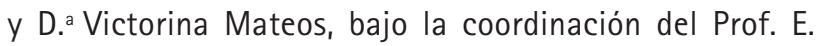
Vallespi, "El Paleolítico en la antigua Laguna de la Janda" (Fernández-Llebrez et al. 1988; Ramírez et al. 1989; Mateos et al. 1990 y Mateos et al. 1995), se identifican dos momentos de ocupación, uno de ellos se correspondería con lo que normativamente se conoce como Achelense Medio o Achelense lbérico, y el otro se correspondería con momentos adscritos a la Prehistoria Reciente. Tan sólo en algunos trabajos (Ramírez et al. 1989) mencionan la existencia de "algunas piezas...muy claras...parecen abogar a favor de la existencia de un Musteriense aún no caracterizado estadísticamente", planteando a la vez la posibilidad de que algunos sitios clásicos como la Venta de la Pasada de Gibraltar se corresponda con un conjunto post-paleolítico. En otro trabajo (Fernández-Llebrez et al. 1988) mencionan la existencia de un "Musteriense aún no bien definido". 
Con motivo del proyecto de investigación "La ocupación prehistórica de la campiña litoral y banda atlántica de Cádiz", el cual contaba con la dirección y responsabilidad del Prof. J. Ramos (Universidad de Cádiz), se realizó en el año 1999 la prospección del término municipal de Tarifa, se localizó entre otros, el yacimiento de la desembocadura del río Guadalmesí, cuyos materiales líticos han permanecido inéditos hasta la elaboración de este trabajo.

De las sierras que bordean la laguna de la Janda y en el seno del mencionado proyecto de investigación, se estudian materiales líticos de superficie que habían sido cedidos por Juan Ramón Ramírez y que procedian de su proyecto de investigación, como son: Cortijo de Tapatanilla (conocido en la bibliografía clásica como Loma de los Derramaderos), Cortijo de Tahivilla-Arroyo del Machorro (conocido como Loma del Machorro), Cerro de la Venta, Cortijo del Aciscar, Cortijo de los Caserones-Arraez, Casa del Espinazuelo, Cerro de las Campanillas, Embalse del Almodóvar y Facinas (Ramos 2008).

Aunque algunos yacimientos como son Cortijo de Tapatanilla y Cerro de la Venta presentan elementos líticos que indican perduración como lugares de ocupación en momentos adscritos a la prehistoria reciente, nosotros nos limitaremos a analizar lo que se corresponde con el modo técnico 3 .

Se trata de artefactos líticos realizados sobre sílex, areniscas y cuarcitas, en los que se observan una serie de patrones comunes en cuanto al índice de rodamiento alto, presencia de la secuencia de explotación completa, estrategias de talla centrípetas y discoides, tendentes a la obtención de BP procedentes de métodos de talla estandarizados que serán transformadas en BN2GC. Dominan los tipos R21, R22 y R23 en las raederas, las muescas D21 y los denticulados D23 que realmente se corresponden con raederas denticuladas, lo que junto a la escasa o nula presencia de artefactos de gran formato asociados a los conjuntos de modo 3 , nos sitúa en la línea de las características generales vistas al analizar el conjunto lítico del yacimiento de la desembocadura del río Guadalmesí.

\section{Cueva de la Carihuela}

La cueva de la Carihuela (Piñar, Granada), situada en un relieve de sierras bajas y campiñas, a 1020 m.s.n.m., fue objeto de excavación en los años 1954 y 1955 por J. Ch. Spahni, en 1959 y 1960 por Manuel Pellicer y en 1969, 1970 y 1971 por H. T. Irwin y R. Fryxell. A partir de esta última fecha no se retomarán los trabajos hasta el proyecto de investigación Carihuela (1980-1986), donde se realizan obras de acondicionamiento en 1980, saneamiento de la visera en 1981 y nuevo cierre en 1981 y 1982. Se establece una secuencia estratigráfica y cultural a partir de los materiales de las excavaciones de H. T. Irwin y R. Fryxell y de los materiales procedentes de la limpieza de los testigos y perfiles entre los años 1983-1985 (Vega 1988).

Estos trabajos de campo y los posteriores de laboratorio permitieron la obtención de una de las secuencias estratigráficas más completas que vertebran el tránsito Plesitoceno Medio-Final, Plesitoceno Superior y Holoceno en el sur peninsular. La secuencia estratigráfica está formada por doce

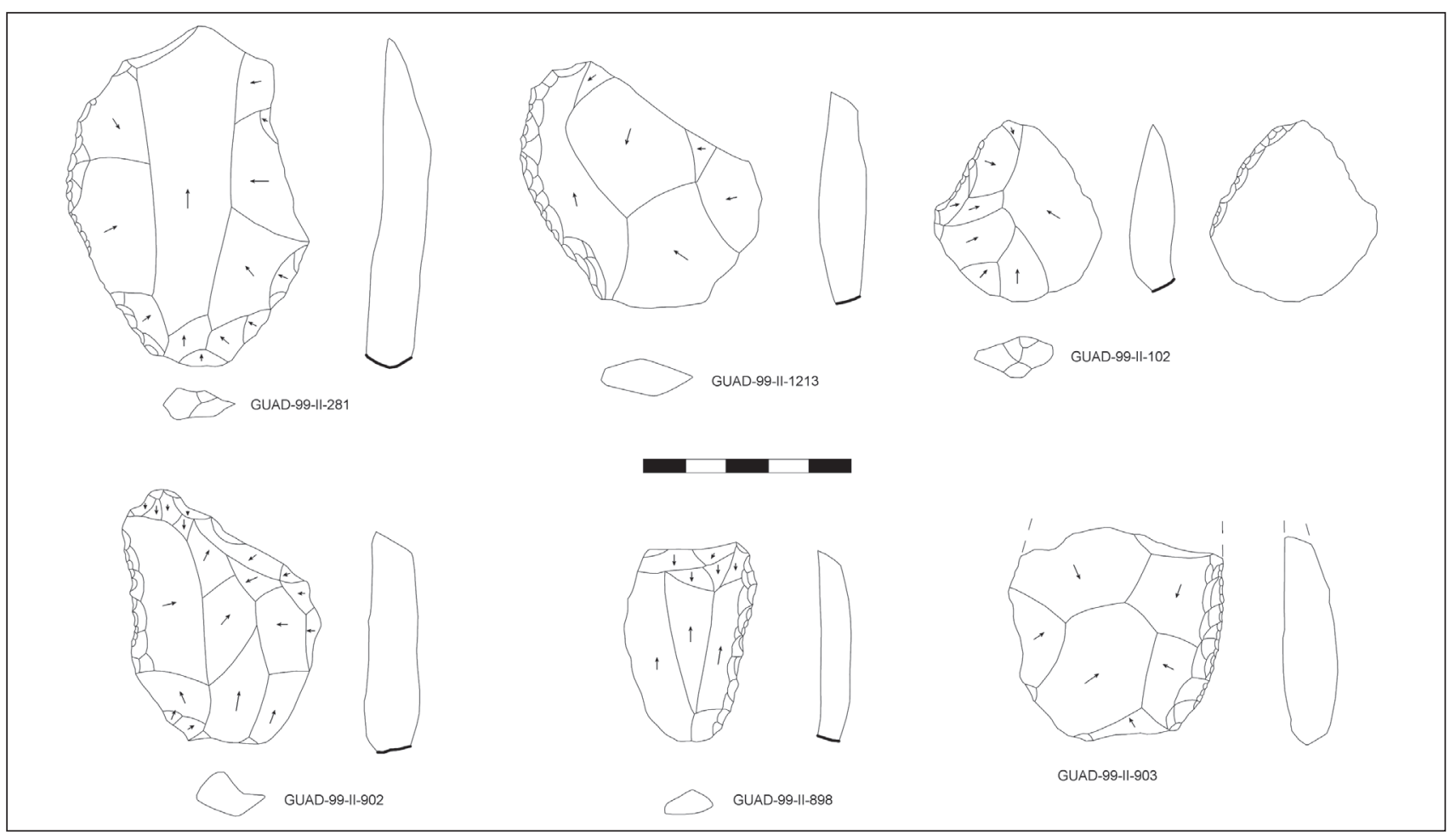

A Figura 17. Bases negativas de Segunda Generación de Configuración. Raederas. 


\begin{tabular}{|c|c|c|c|c|c|c|c|c|c|c|c|c|c|c|}
\hline \multirow{3}{*}{$\begin{array}{l}\text { MATERIA } \\
\text { PRIMA }\end{array}$} & \multicolumn{12}{|c|}{ TIPO DE RAEDERA (G. LAPLACE 1972) } & \multirow{2}{*}{\multicolumn{2}{|c|}{$\begin{array}{c}\text { TOTAL } \\
\text { RAEDERAS }\end{array}$}} \\
\hline & \multicolumn{2}{|c|}{ R11 } & \multicolumn{2}{|c|}{ R12 } & \multicolumn{2}{|c|}{ R13 } & \multicolumn{2}{|c|}{ R21 } & \multicolumn{2}{|c|}{ R22 } & \multicolumn{2}{|c|}{ R23 } & & \\
\hline & $\mathrm{N} .^{\circ}$ & $\%$ & $\mathrm{~N} .^{\circ}$ & $\%$ & $\mathrm{~N} .^{\circ}$ & $\%$ & N. ${ }^{\circ}$ & $\%$ & $\mathrm{~N} .^{\circ}$ & $\%$ & N. ${ }^{\circ}$ & $\%$ & $\mathrm{~N} .^{\circ}$ & $\%$ \\
\hline AMF & 8 & 36,4 & 3 & 13,6 & 0 & 0,0 & 8 & 36,4 & 1 & 4,5 & 2 & 9,1 & 22 & 17,3 \\
\hline $\mathrm{AF}$ & 7 & 24,1 & 2 & 6,9 & 0 & 0,0 & 15 & 51,7 & 2 & 6,9 & 3 & 10,3 & 29 & 22,8 \\
\hline AM & 16 & 37,2 & 0 & 0,0 & 1 & 2,3 & 19 & 44,2 & 3 & 7,0 & 4 & 9,3 & 43 & 33,9 \\
\hline$A G$ & 4 & 21,1 & 3 & 15,8 & 0 & 0,0 & 8 & 42,1 & 2 & 10,5 & 2 & 10,5 & 19 & 15,0 \\
\hline AMG & 0 & 0,0 & 0 & 0,0 & 0 & 0,0 & 2 & 100 & 0 & 0,0 & 0 & 0,0 & 2 & 1,6 \\
\hline MT & 0 & 0,0 & 0 & 0,0 & 0 & 0,0 & 1 & 100 & 0 & 0,0 & 0 & 0,0 & 1 & 0,8 \\
\hline $\mathrm{SB} / \mathrm{SH}$ & 0 & 0,0 & 0 & 0,0 & 0 & 0,0 & 2 & 100 & 0 & 0,0 & 0 & 0,0 & 2 & 1,6 \\
\hline SMO & 0 & 0,0 & 0 & 0,0 & 0 & 0,0 & 3 & 75 & 1 & 25,0 & 0 & 0,0 & 4 & 3,1 \\
\hline SMT & 0 & 0,0 & 0 & 0,0 & 0 & 0,0 & 2 & 100 & 0 & 0,0 & 0 & 0,0 & 2 & 1,6 \\
\hline so & 1 & 33,3 & 0 & 0,0 & 0 & 0,0 & 1 & 33 & 1 & 33,3 & 0 & 0,0 & 3 & 2,4 \\
\hline TOTAL & 36 & 28,3 & 8 & 6,3 & 1 & 0,8 & 61 & 48,0 & 10 & 7,9 & 11 & 8,7 & 127 & 100 \\
\hline
\end{tabular}

A TABLA 7. Clasificación por grupo de raederas.

unidades, constituidas a su vez por un centenar de niveles (Vega 1988), correspondiéndose el muro de dicha secuencia con un conjunto adscrito al Musteriense Típico, datado entre el subestadio isotópico 5a y el OIS $4(117.000 \pm 41.000 \mathrm{BP})$ y habiéndose erigido como uno de los últimos reductos del $H$. neanderthalensis en el sur de la Península lbérica, datado entre el 28.440 y 21.430 años BP (Fernández et al. 2007), con lo que se une a la cueva del Boquete de Zafarraya, cueva Bajondillo o Gorham's Cave, entre otras, para atestiguar la presencia tardía de los neandertales en el sur peninsular.

A nivel tecnológico, que es la base de este trabajo, se identifica un Musteriense Típico, que divide en los subtipos $0,1,2$ y 3, observable en 28 niveles, un Musteriense Charentiense de tipo Zájara, identificable en 4 niveles y un Musteriense de Denticulados, con índices por encima del 50\%, reconocible en dos niveles. Es el Musteriense Típico y concretamente el tipo 1, o rico en raederas, caracterizado por un índice de raederas entre el 41 y $54 \%$ el mejor representado en toda la secuencia, siendo la materia prima utilizada para la elaboración de los artefactos líticos el sílex local, sobre el que los gestos técnicos han ido encaminados a la obtención de bases positivas procedentes de métodos con extracciones centrípetas, concretamente discoides (Vega 1988 y 1993).

\section{Cueva del Boquete de Zafarraya}

La cueva del Boquete de Zafarraya (Alcaucín, Málaga), situada a 1.022 m.s.n.m., en un escarpe de la sierra de Al- hama, ha sido identificada como un alto ocasional de caza, se trata de uno de los pocos yacimientos afortunados del sur peninsular que dispone de una secuencia excepcional para analizar el modo de vida de los grupos de cazadoresrecolectores adscritos normativamente al Paleolítico Medio y al Paleolítico Superior, así como examinar las causas de la tardía desaparición de los neandertales en el extremo sur de Europa. Para ello disponemos de una amplia memoria de la excavación que analiza el sitio desde un punto de vista multidisciplinar (Barroso 2003) y de una extensísima monografía (Barroso y Lumley 2006).

Esta cueva fue objeto de excavaciones sistemáticas entre los años 1981 a 1983 y de 1990 a 1994 y los resultados científicos obtenidos (dataciones absolutas, estudio de restos de $H$. neanderthalensis, palinología, antracología, malacología, macrofauna, microfauna, avifauna, anfibios...), exceden con creces los objetivos que nos planteamos en este trabajo.

El conjunto lítico de los niveles con tecnología de modo técnico 3, ha sido identificado por sus autores como "Musteriense Típico", que encaja perfectamente en la variedad musteriense de la Península Ibérica (Barroso et al. 2006: 1497).

El material lítico lo componen un total de 813 piezas, realizadas mayoritariamente en sílex (excepto 4 en gres cuarcítico) de origen local o semilocal, pues los afloramientos más lejanos se han identificado a una distancia de $12 \mathrm{Km}$.

El primer elemento que Ilama la atención es el escaso porcentaje de BNE con un 2,8\%, lo que marca claras diferencias con el sitio de Guadalmesí donde las BNE suponen un 
$10 \%$ del total y llega a un $11 \%$ si incluimos los fracturados, esto se debe fundamentalmente a la distinta funcionalidad de los sitios, ya que en Zafarraya los soportes han sido introducidos en la cueva previamente desbastados.

El método de talla mejor representado es el levallois recurrente centrípeto, lo que si se sitúa en la línea de Guadalmesí, donde este tipo de método de explotación representa el $65,1 \%$ de las BNE con dos superficies jerarquizadas.

Las bases positivas incluyen un porcentaje levallois alto en Zafarraya, con un 36,5\%, respecto a Guadalmesí, donde suponen el 23,3\%, que asciende al 47,2\% en las BN2GC en Guadalmesí y al $40,3 \%$ en Zafarraya y al $61,4 \%$ en el caso de las raederas para Guadalmesí.

Zafarraya presenta un índice laminar medio del 8,1\%, situándose en Guadalmesí en un 5,30\% si descartamos las
BP que presentan fractura y un 9,07\% si incluimos estas últimas, siempre teniendo en cuenta las apreciaciones vistas de que la mayoría de los casos tipométricamente se correspondian con láminas, pero no realmente al no proceder de sistemas de explotación laminares.

En cuanto a las BN2GC son más elevados los índices para los grupos de raederas, muescas y denticulados en Guadalmesí e inferiores los indices de raspadores y buriles, no teniendo representación en Guadalmesí los picos, perforadores, truncaduras y diversos.

\section{Cueva Bajondillo}

Cueva Bajondillo (Torremolinos, Málaga), situada a una altitud de entre 10 y 20 m.s.n.m., a algo más de 200 m de la

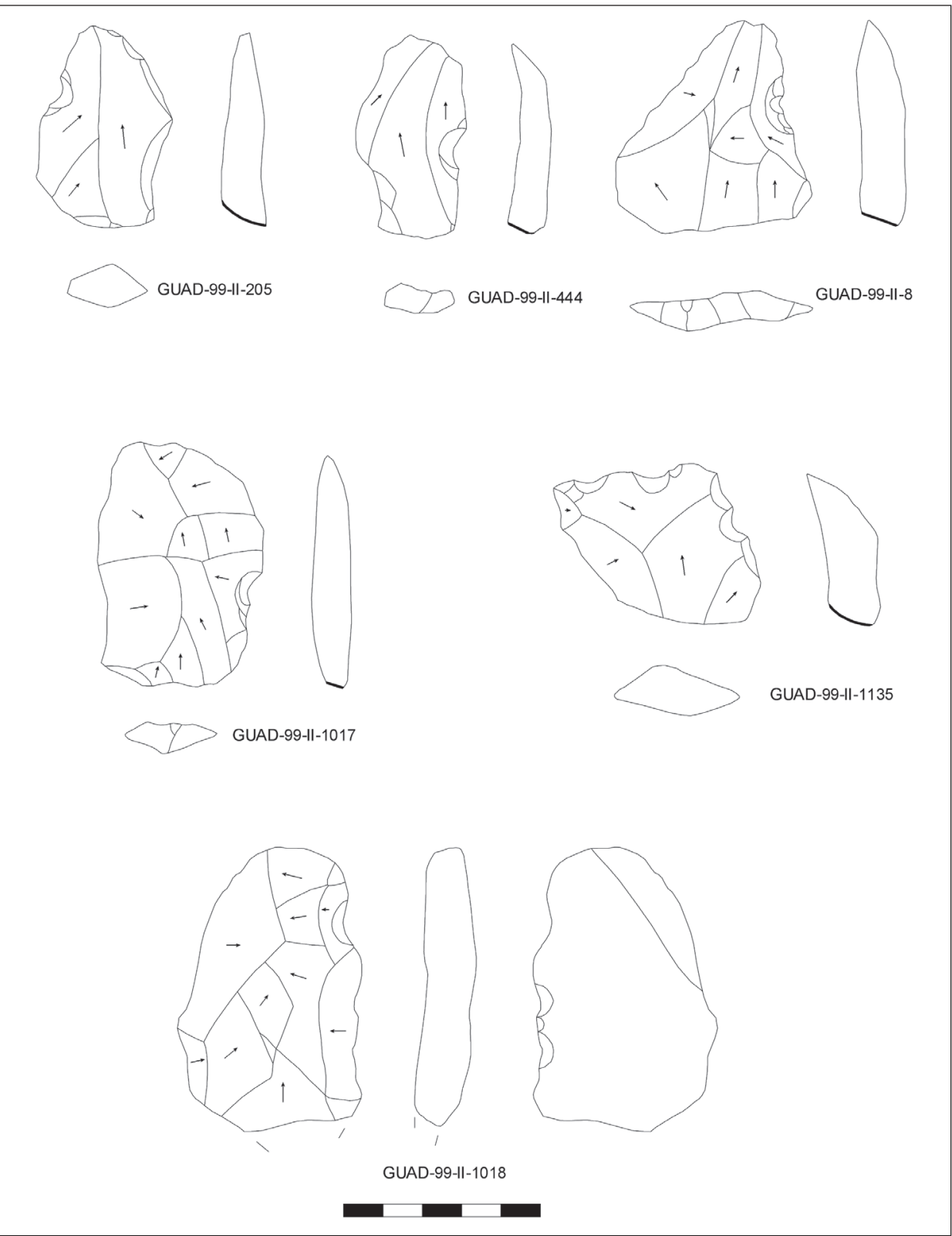

A Figura 18. Bases negativas de Segunda Generación de Configuración. Muescas y denticulados. 


\begin{tabular}{|c|c|c|c|c|c|c|c|c|c|c|c|c|c|c|}
\hline \multirow{3}{*}{$\begin{array}{c}\text { MATERIA } \\
\text { PRIMA }\end{array}$} & \multicolumn{12}{|c|}{ MUESCAS Y DENTICULADOS (G. LAPLACE 1972) } & \multirow{2}{*}{\multicolumn{2}{|c|}{$\begin{array}{l}\text { TOTAL } \\
\text { MUESCA } \\
\text { DENTIC. }\end{array}$}} \\
\hline & \multicolumn{2}{|c|}{ D21 } & \multicolumn{2}{|c|}{ D22 } & \multicolumn{2}{|c|}{ D23 } & \multicolumn{2}{|c|}{ D24 } & \multicolumn{2}{|c|}{ D25 } & \multicolumn{2}{|c|}{ D32 } & & \\
\hline & N. ${ }^{\circ}$ & $\%$ & N. ${ }^{\circ}$ & $\%$ & N. ${ }^{\circ}$ & $\%$ & N. ${ }^{\circ}$ & $\%$ & N. ${ }^{\circ}$ & $\%$ & N. ${ }^{\circ}$ & $\%$ & N. ${ }^{\circ}$ & $\%$ \\
\hline AMF & 6 & 60,0 & 3 & 30,0 & 1 & 10,0 & 0 & 0,0 & 0 & 0,0 & 0 & 0,0 & 10 & 10,0 \\
\hline $\mathrm{AF}$ & 9 & 47,4 & 6 & 31,6 & 3 & 15,8 & 1 & 5,3 & 0 & 0,0 & 0 & 0,0 & 19 & 19,0 \\
\hline AM & 20 & 58,8 & 9 & 26,5 & 3 & 8,8 & 0 & 0,0 & 1 & 2,9 & 1 & 2,9 & 34 & 34,0 \\
\hline$A G$ & 12 & 48,0 & 6 & 24,0 & 5 & 20,0 & 0 & 0,0 & 0 & 0,0 & 2 & 8,0 & 25 & 25,0 \\
\hline AMG & 0 & 0,0 & 1 & 50,0 & 0 & 0,0 & 1 & 50,0 & 0 & 0,0 & 0 & 0,0 & 2 & 2,0 \\
\hline SMO & 2 & 33,3 & 0 & 0,0 & 3 & 50,0 & 1 & 16,7 & 0 & 0,0 & 0 & 0,0 & 6 & 6,0 \\
\hline So & 3 & 75,0 & 1 & 25 & 0 & 0,0 & 0 & 0,0 & 0 & 0,0 & 0 & 0,0 & 4 & 4,0 \\
\hline TOTAL & 52 & 52,0 & 26 & 26,0 & 15 & 15,0 & 3 & 3,0 & 1 & 1,0 & 3 & 3,0 & 100 & 100 \\
\hline
\end{tabular}

A TABla 8. Clasificación por grupo de muescas y denticulados.

línea de costa actual, en las fases de travertinos de Torremolinos (Cortés 2007). Se trata de un yacimiento que sufrió las agresiones derivadas del desarrollo urbanístico galopante y carente de todo control que caracterizó a España a finales del siglo XX y principios del XXI y de manera muy específica a la Costa del Sol. A pesar de ello se pudieron realizar diversas intervenciones en los años 1989, 2000 y 2002.

Como resultado de estas intervenciones el yacimiento fue dado a conocer en varios congresos nacionales e internacionales, formó parte importante de la tesis doctoral del Prof. Miguel Cortés (Universidad de Sevilla) en el año 2002, de la que se publicó posteriormente una monografía (Cortés 2007) y los resultados de las diferentes intervenciones vieron finalmente la luz en una extensa monografía (Cortés 2007).

La serie estratigráfica la forman 20 niveles, enumerados del 1 al 20 de techo a muro, de donde se tomaron muestras para 27 dataciones absolutas que abarca una horquilla cronológica de finales del OIS 5 al Holoceno, por lo que nos encontramos ante una de las escasas secuencias del sur peninsular en las que se puede analizar la variabilidad tecnológica diacrónica del Paleolítico Medio y Superior.

En este trabajo nos interesan especialmente los estratos arqueológicos de Bajondillo 19 a Bajondillo 14 (Bj/19-Bj/14), aunque nos centraremos de manera específica en $\mathrm{Bj} / 17 \mathrm{y}$ $\mathrm{Bj} / 16$, ya que son los niveles que paralelizables a los valores tecnológicos de la desembocadura del río Guadalmesí, donde carecemos de otro tipo de estudios o analíticas para su correlación.

En Bj/19 ( $n=3)$ mencionamos una BN1GC (canto tallado) y en $\mathrm{Bj} / 18(\mathrm{n}=60)$, marcamos la presencia del sílex como materia prima dominante, talones obtenidos con percutor duro y facetados, las piezas levallois proceden de esquemas operativos recurrentes centripetos, aunque existe representación de esquemas operativos discoides.

En los niveles de $\mathrm{Bj} / 17$ a $\mathrm{Bj} / 14$ el sílex jerarquiza las estrategias y métodos de talla con índices superiores al 90\%.

Con la intención de no resultar repetitivos, presentaremos los datos más relevantes de $\mathrm{Bj} / 17$ y $\mathrm{Bj} / 16$, sin realizar el cotejo de cada uno con los índices estadísticos de Guadalmesí, derivando al lector al epígrafe 5 para su contrastación.

En BJ/17 ( $n=4682)$, se describe un musteriense de esquema operativo levallois, con BNE donde dominan los métodos de talla levallois y se reconocen 22 ejemplares de lasca recurrente y 16 de lasca preferente de un total de 47 identificables. Estas BNE presentan, como sucede en Guadalmesí un grado de explotación que los hace inviable para continuar la talla. Las BP son piezas de pequeño tamaño (entre 20-40 $\mathrm{mm}$ ) y formas planas, con índices levallois del 22,2\% que unido a las lascas desbordantes y puntas pseudolevallois supone un $48,5 \%$, con talones lisos $26,5 \%$ facetados $23,9 \%$, rotos $17,5 \%$, corticales $15 \%$, diedros $11,5 \%$, lineales $0,5 \%$, resaltando la incidencia de talones puntiformes y lineales como accidental. El índice laminar del 2,8\% carece de esquemas operativos leptolíticos. Para la configuración de BN2G se han utilizado especialmente lascas levallois como soportes de raederas en un 63\%, lo que supone en Guadalmesí un 61,4\%.

En $B j / 16$ ( $n=1593)$ los esquemas operativos se corresponden con un levallois recurrente muy normalizado, donde los núcleos presentan cortex hasta la fase final de explotación y de las 18 BNE clasificables, 16 son levallois, siendo diez para lascas levallois recurrentes y seis para lascas preferentes. El sílex como materia prima supone el 95\%, el índice levallois del $39,7 \%$ y valores tipométricos entre $20-40 \mathrm{~mm}$. El índice laminar con un 2,6\% sin vinculación a sistemas de 
explotación leptolíticos. Los talones son facetados $(23,7 \%)$, lisos $(20,6 \%)$, diedros $(11,1 \%)$, puntiformes $(10 \%)$, rotos $(19,4 \%)$ y lineales $(0,3 \%)$. Los lineales se asocian a lascas muy planas, mientras que los puntiformes se corresponden en realidad a la destrucción de la parte proximal a causa de la percusión. Como sucedía en $\mathrm{Bj} / 17$ y en Guadalmesí los soportes levallois son seleccionados para la configuración de raederas en un 59,2\%.

Tras comparar los datos estadísticos de Bj/15 (Musteriense Típico con valores bajos de raederas) y Bj/14 (Musteriense rico en muescas y denticulados) decidimos no presentarlos en este trabajo, ya que se alejan de lo visto para la desembocadura del río Guadalmesí en el epígrafe 6. Se observa entre otros parámetros una pérdida gradual de importancia de los métodos de talla levallois recurrente centrípeto y preferente, en beneficio de métodos de talla discoides, aunque para Bj/14 existe una contradicción en la secuencia, explicada por sus autores por un cambio en la funcionalidad (Cortés 2007:87), así como un descenso de las raederas y el consiguiente aumento de muescas y denticulados.

Tras presentar brevemente los datos tecnológicos de $\mathrm{Bj} / 17$ y $\mathrm{Bj} / 16$, clasificado por sus autores como Musteriense Típico rico en raederas y contrastarlos con lo aportado para la desembocadura del río Guadalmesí, observamos numerosas coincidencias en conceptos claves, como son: las estrategias y métodos de talla empleados en las BNE; la tipometría y espesor de las BP, teniendo en cuenta que se han seleccionado diferente materia prima en su configuración; los índices de talones diedros y facetados; así como los escasísimos puntiformes y lineales; los índices levallois, tanto del conjunto de BP, como las que fueron seleccionadas para su posterior configuración en raederas; los índices de las BN2GC, concretamente de raederas, muescas y denticulados y específicamente los distintos tipos de raederas. Por todo ello y con la precaución de que estamos atendiendo a un criterio exclusivamente tecnológico planteamos la posibilidad de que la desembocadura del río Guadalmesí se sitúe en la línea tecnológica de $\mathrm{Bj} / 17$ y $\mathrm{Bj} / 16$, donde contamos con una datación absoluta por TL para $\mathrm{Bj} / 17$ con una cronología de $64500 \pm 6300$ y dos dataciones absolutas por TL para $\mathrm{Bj} / 16$ con $39983 \pm 2710$ y $39183 \pm 4620$.

\section{Higueral de Valleja}

La cueva de Higueral de Valleja se encuentra en la sierra norte de Cádiz, a 190 m.s.n.m. ha sido objeto de excavaciones entre los años 1979-1982, 2000 y 2001 (Giles 1979 y Giles et al. 2003). Se trata de un enclave desde el que se están aportando datos sobre la transición del Paleolítico Medio al Superior en el sur peninsular, así como la tardía desaparición del $H$. neanderthalensis.

A nivel tecnológico el número de artefactos líticos de los niveles musterienses es escaso (capas X-V), aunque si ad- quieren un valor cualitativo importante al ser analizados, ya que son claramente diagnósticos de la tecnología de modo técnico 3.

Se mencionan en los últimos estudios el uso de la técnica Levallois, núcleos discoides y BP procedentes de estos sistemas de talla, se cita igualmente un denticulado sobre lámina en el nivel $V$, dos muescas en el nivel $V 1$ y un denticulado en el nivel X (Jennings et al. 2009).

\section{Terrazas medias y bajas de la depresión inferior del río Guadalquivir}

El Bajo Guadalquivir es una de las zonas privilegiadas que cuenta con una importante tradición investigadora en yacimientos prehistóricos del sur peninsular. Fue objeto del proyecto desarrollado entre los años 1985 y 1993 "Formaciones Cuaternarias y Secuencia Paleolítica del Bajo Guadalquivir", que contó con la responsabilidad del Prof. E. Vallespí (Universidad de Sevilla), en cuyo seno se redactaron las tesis doctorales de R. Baena (1993), Juan José Fernández Caro (1998) y de José Antonio Caro Gómez (1999) (Vallespí 2006).

Estos estudios posibilitaron la interpretación de los distintos niveles de terrazas y los conjuntos líticos asociados a ellas, estableciendo una secuencia de sitios al aire libre desde Pleistoceno Inferior al Holoceno en el sur de la Península lbérica.

El elemento identificador de la materia prima utilizada en los conjuntos líticos del Bajo Guadalquivir será el uso de la cuarcita y su continuidad temporal durante el Pleistoceno Medio y Superior, aun disponiendo a partir de las terrazas medias de cantos de sílex que habrian permitido la elaboración de útiles de gran formato, lo que consideramos que se encuentra "más en función de un legado cultural propio de la larga tradición de las industrias de las graveras" (Caro 2006:1547).

En este trabajo nos interesa el complejo de terrazas medias, con una cronología de $300 \mathrm{Ka}$ a $80 \mathrm{Ka}$ (Caro 2000) y de terrazas bajas, concretamente la T13.

La primera de las terrazas medias ha sido descrita como T10 (+45-55m), se trata de la más alta de las terrazas medias del tramo bajo del citado río, ha sido identificada con el momento de desarrollo del Achelense Pleno, donde los sistemas bifaciales aumentan considerablemente, con ejemplos en Harinera o el Saltillo (Caro 2006). Este Achelense Pleno tendrá su continuidad en la T11 (+35-40m) con un descenso cuantitativo de las herramientas líticas de gran formato, aumento de los índices levallois y mayor porcentaje de sílex (Caro 2000) y la T12 (+26-29m) donde aparece un Achelense final transicional, con peculiaridades tecnológicas próximas al Paleolítico Medio, en Alcolea, Las Jarillas o Pionner 1, que se caracterizan por la modificación en las estrategias de selección de materias primas, lo que supone un incremento importante del sílex, extensión del método de talla levallois y aumento de los tipos propios musterienses 
como las raederas (Vallespí 1990). En la T12 y de manera paralela a los cambios desarrollados, existen otros conjuntos perfectamente equiparables o más cercanos a las características vistas para la T11 (Caro 2000).

La primera de las terrazas bajas se identifica como T13 $(+13 \mathrm{~m})$, con ejemplos en Brenes y Toruño, donde se describe un Paleolítico Medio de aspecto post-Achelense (Vallespí 1992), también Ilamado Paleolítico Medio de ámbitos fluviales (Caro 2000), donde destaca Tarazona II, junto a otras localizaciones menores, que se describen como un Paleolítico Medio de aspecto post-Achelense (Díaz del Olmo et al. 1993), al que le siguen las series musterienses del bajo Guadalquivir que aparecen a continuación del Achelense final transicional, y se caracterizan de un lado por la modificación en las estrategias de selección de materias primas, lo que supone un incremento importante del sílex, extensión del método de talla levallois y aumento de los tipos musterienses como raederas dobles, convergentes y transversales (Vallespí 1990).

En definitiva el Prof. E. Vallespí realiza un modelo dual de ocupación del territorio para el Musteriense del centro y sur peninsular, de un lado identifica una fase transicional de Paleolítico Inferior avanzado-final al Paleolítico Medio, al que denomina "Paleolítico Medio postachelense de corte no clásico", originado por la "tradición de las graveras" en aquellas áreas en las que se reconoció un Achelense Pleno Ibérico, con sitios al aire libre, principalmente en las cuencas fluviales de los grandes ríos y fuerte presencia de elementos técnicos del substrato y una segunda fase, plenamente Musteriense, con las características técnicas propias del Musteriense clásico, identificada en las periferias y zonas montañosas del interior, lo que generaría impactos tecnológicos recíprocos (Vallespi 1992 y 1999).

\section{Banda Atlántica de Cádiz}

Los sitios de la banda atlántica de Cádiz que se encuentran en las inmediaciones de la antigua Laguna de la Janda han sido descritos en su apartado específico, hemos optado por este desarrollo por dos motivos principalmente; en primer lugar por su proximidad al yacimiento de la desembocadura del río Guadalmesí, lo que lo sitúa en plena área de influencia del Estrecho de Gibraltar y en segundo lugar al considerar que se trata de una zona con entidad suficiente como para ser analizada de manera específica, en parte debido al peso historiográfico.

El proyecto de investigación "La ocupación prehistórica de la campiña litoral y banda atlántica de Cádiz", que hemos mencionado anteriormente, supuso una transformación cuantitativa y cualitativa en el conocimiento de los sitios prehistóricos de la banda atlántica de Cádiz y concretamente de los yacimientos adscritos al Paleolítico Medio.

En el seno de este proyecto fueron prospectados los términos municipales de San Fernando, Chiclana de la Frontera,
Conil de la Frontera, Medina Sidonia, Vejer de la Frontera, Barbate y Tarifa, todos ellos de la provincia de Cádiz, y sus conclusiones finales se publicaron en una monografía de Arqueología de la Junta de Andalucía (Ramos 2008).

Con ocasión de este proyecto se localizaron e identificaron un total de 43 yacimientos con tecnología de modo 3, de los que nueve de ellos han sido analizados en el epígrafe de la Laguna de la Janda. Nos Ilama la atención en primer lugar que 20 de estas localizaciones se encuentran en el término municipal de Tarifa, aunque somos conscientes de que las divisiones administrativas actuales nada tiene que ver con la ocupación social de territorio que realizaron estos grupos de cazadores-recolectores, por lo que ante esta situación nos planteamos varias explicaciones; en primer lugar se trata de una zona que ha sido prospectada desde principios del siglo $X X$, en segundo lugar, gran parte de lo que conocemos como la antigua Laguna de la Janda se encuentra en el mencionado término municipal de Tarifa y en tercer lugar, aunque no pretendemos situarnos del lado de posiciones procesuales, nos encontramos con una variedad de biotopos susceptibles de ser ocupados por estas sociedades y donde la conservación de sus depósitos geológicos han permitido la identificación del registro arqueológico, tales como terrazas marinas a lo largo de la línea de costa, terrazas y valles fluviales de entidad, que conectan por el interior el mar Mediterráneo y el océano Atlántico, en definitiva la Bahía de Algeciras/Gibraltar con la banda atlántica, relieves suaves que bordeaban la Laguna de la Janda, es decir se dan las circunstancias favorables en cuanto a movilidad y acceso a la materia prima, y demás recursos necesarios para la subsistencia del grupo.

En el T.M. de Chiclana de la Frontera destacamos Playa de la Barrosa, con un total de cinco zonas, situadas de manera relativa en un Achelense Superior y Paleolítico Medio, donde se identifican unos conjuntos líticos que representan la secuencia operativa completa, la cual se encuentra jerarquizada por estrategias de talla multipolares centripetas que se complementan con otros sistemas de explotación, como unipolares o bipolares, la presencia de BP predeterminadas es importante en aquellos sitios que cuentan con un número suficiente para su análisis, como el 17,6\% de Playa de La Barrosa general, el 35\% de Playa de la Barrosa 0, el 29, 8\% de Playa de la Barrosa 2 y el 27,4\% de Playa de la Barrosa 3.

En el término de Conil de la Frontera nos interesan las zonas I, II, III, V y VI de Cerro Jándila; en Medina Sidonia se identificaron cuatro lugares con testimonios de tecnología de modo 3, pero la exigua cantidad no permite ningún tipo de análisis comparativo; sucede lo mismo en Vejer de la Frontera con el sitio de Playa del Palmar; del T. M. de Barbate mencionamos Caños de Meca con un total de 149 artefactos líticos, donde no tenemos representadas las estrategias de talla multipolares centrípetas y los índices levallois descienden drásticamente.

Finalmente es el T. M. de Tarifa el que se reveló más productivo cuantitativa y cualitativamente en yacimientos 
de tecnología de modo 3 y a nivel tecnológico resulta imposible detenerse en cada uno de los yacimientos de manera pormenorizada, por lo que indicaremos los patrones comunes a todos ellos, como son la somera presencia de temas operativos técnicos directos, concretados en cantos tallados, hendedores y bifaces, el empleo de sistemas expeditivos multipolares centripetos recurrentes (levallois), para la obtención de BP predeterminadas, con talones en plataforma y facetados que serán transformados en BN2GC, concretamente raederas, muescas, denticulados, puntas y algunos raspadores.

Se valora por parte de sus autores la continuidad histórica, con base tecnológica del modo 2 al modo 3, circunstancia que como tuvimos ocasión de ver se daba en los registros del bajo Guadalquivir, así como la variedad de espacios ocupados, contrastando los registros de modo 3 del sur peninsular con los del norte de África, destacando la similitud tecnológica que existe entre ambas orillas (Ramos 2007-2008).

\section{Terrazas del río Guadalete}

En el seno de los proyectos de investigación "Prospecciones arqueológicas superficiales en la cuenca del río Guadalete. Análisis geocronológicos y sedimentológicos" y "Secuencia fluvial y paleolítica del río Guadalete", los cuales contaban con la dirección de F. Giles, se identifica en la T-6 (+5-10m) diferentes estaciones al aire libre, adscritas al $\mathrm{Pa}-$ leolítico Medio (Giles et al. 2003).

Son sitios caracterizados por estrategias de talla multipolares centripetas (levallois), de talla unifacial y bifacial, escasamente representada la multifacial, sobre sílex local, tendentes a la obtención de BP predeterminadas con talones espesos y facetados, donde podemos mencionar algunos ejemplos en el tramo superior de Majarromaque (Jerez de la Frontera, Cádiz), las Arenosas (San José del Valle, Cádiz), la Escalera (Arcos de la Frontera, Cádiz) (Giles et al. 1993), así como en el curso medio-alto de la cuenca del río Guadalete, donde se localizan conjuntos líticos adscritos tecnológicamente al modo 3 en la terraza T-3 (+20-35m), con repetición de los sistemas operativos vistos anteriormente.

En resumen somos conscientes de que apenas hemos esbozado la situación de los conjuntos líticos de modo técnico 3 en el sur peninsular, pero tras su análisis observamos como la variabilidad es la característica común asociada a estos grupos de cazadores-recolectores:

- Variabilidad en cuanto a la articulación y uso que realizan del espacio los grupos de $\mathrm{H}$. neanderthalensis, ocupando una variedad de biotopos (costa, valle y montaña), como elemento identificador del control que tienen del medio.

- Variabilidad en cuanto a la selección y aprovisionamiento de materia prima utilizada en la confección del conjunto lítico, ya que hemos visto yacimientos donde la arenisca supone más del 90\%, como en Guadalmesí, a diferencia de otros donde el sílex supone más del 90\% como Bajondillo o Zafarraya. La materia prima ha sido seleccionada en un ámbito eminentemente local, reduciéndose a un radio de unos $10 \mathrm{Km}$, transformando aquella que tienen a su alcance más o menos inmediato, independientemente de que se trate de sílex, arenisca, cuarcita.

- Variabilidad de estrategias y métodos de talla, evidenciándose en general y en aquellos sitios en los que disponemos de un estudio morfotécnico el empleo recurrente de estrategias de explotación bipolares y multipolares centripetas, con métodos de talla de lasca preferente y recurrente predeterminado, como el levallois, para la obtención de BP procedentes de sistemas de explotación predeterminados, que serán utilizadas como soporte de raederas, así como la utilización de una estrategia de explotación menos exigente, como es la multipolar centrípeta, con método de talla discoide para la obtención de BP que serán utilizadas como soporte de muescas y denticulados principalmente.

En general y con las excepciones vistas para BajondiIlo, Zafarraya y Carihuela, carecemos de criterios suficientes para realizar la contrastación tecnológica con Guadalmesí, pues en los trabajos publicados echamos en falta estudios que aborden desde una perspectiva tecnológica interna los sitios adscritos tecno-tipológicamente al modo técnico 3, pues serán éstos los que nos aportarán la información necesaria para identificar las distintas estrategias y métodos de talla, que a la vez nos ayudará a plantear la variabilidad técnica tanto sincrónica como diacrónica. En este sentido estamos en la línea de las afirmaciones que cuestionan el modelo tradicional de transición basado exclusivamente en los objetos finales (Castañeda 2011).

\section{SÍNTESIS Y CONCLUSIONES}

Nuestro objetivo último consistía en explicar la sociedad como totalidad histórica concreta y somos conscientes de que con el sitio de la desembocadura del río Guadalmesí esta explicación ha resultado parcial, ya que sería precisa una excavación arqueológica, planteada desde un posicionamiento concreto y aplicando una metodología determinada que posibilite la realización de otro tipo de analíticas.

A pesar de ello presentamos las siguientes conclusiones:

\subsection{Síntesis litológica}

Basándonos en las analíticas realizadas sobre el tipo de roca con el que se elaboraron los artefactos líticos, así como 
localizando las áreas de aprovisionamiento y selección de materias primas, hemos identificado la articulación del territorio y uso del espacio, en definitiva la movilidad, de estos grupos cazadores-recolectores y concluimos que:

1. La selección de la materia prima lítica fue realizada mediante una explotación directa e inmediata del territorio, usando el sistema de "laboreo superficial", concretamente los cantos rodados de arenisca del Aljibe aportados por el propio río. Esta movilidad (frecuentación cíclica) debemos valorarla en dirección este-oeste a lo largo de la línea de costa, en función de su proximidad o lejanía.

2. Consideramos que la movilidad está relacionada con la captación de materias primas, explotación de los recursos marinos costeros y la apertura hacia el oeste de un espacio abierto que posibilita el acceso a los recursos necesarios para la subsistencia, donde la historiografía nos ha demostrado que nos encontramos ante una zona privilegiada para estudiar desde las primeras ocupaciones humanas hasta la prehistoria más reciente (Breuil 1914 y 1917; Breuil y Burkitt 1929; Hernández-Pacheco 1915; Obermaier 1925).

3. La adquisición y transformación de la materia prima tuvo lugar de manera inmediata para el caso de la arenisca, en el mismo yacimiento o las inmediaciones, mientras que para el escaso aporte de sílex, se obtuvo de un radio de pocos kilómetros, que en ningún caso supera los $20 \mathrm{Km}$, resulta un origen local o semilocal para todos los tipos de roca representados.

4. La secuencia de producción está claramente jerarquizada por la arenisca, mientras que la cadena operativa aparece muy fragmentada para otro tipo de rocas como el sílex o la metacuarcita, sirviendo de complemento a la materia prima principal.

5. La arenisca más compacta, que había sido previamente seleccionada de entre la gran variedad que aparece en el entorno, fue introducida en el yacimiento en forma de canto redondeado, ya que, hemos analizado la secuencia operativa completa. No sucede lo mismo con el resto de rocas, como el sílex, que su aporte fue previamente desbastado, con el ahorro energético que supone su transporte desde el lugar de aprovisionamiento para las paleocomunidades.

6. Los porcentajes de arenisca, superiores al 90\%, nos indica que en los sitios en los que no se dispone de sílex, estos grupos cazadores-recolectores hacen uso de la materia prima que tienen a su alcance, pero siempre seleccionando la que mejores resultados le aportan tras el proceso de talla, realizando los gestos técnicos que reproducen las distintas estrategias y métodos de talla necesarios para desarrollar sus actividades e interactuar con el medio, hecho que nos enlaza con el concepto de "variabilidad".

7. Los análisis granulométricos realizados a las areniscas confirman la disminución del tamaño de grano durante este periodo, con selección de una arenisca de grano muy fino, fino y grano medio frente a las areniscas de grano grueso, poco presentes, y muy grueso prácticamente anecdótica, que sí habian tenido un peso cuantitativamente importante en los sitios de modo 2 del Campo de Gibraltar (Castañeda et al. 2010b).

8. Esta selección puede estar relacionada con un cambio en las necesidades del grupo, al abandonarse progresivamente los útiles de gran formato y sustituirse los métodos de talla hacia la producción sistemática de BP, con sistemas estandarizados y predeterminados, junto a otros que le sirven de complemento.

\subsection{Síntesis tecnológica}

Basándonos en el análisis de los conceptos explicativos, el análisis morfotécnico del conjunto lítico nos ha permitido plantear una serie de conclusiones tecnológicas específicas:

1. Los valores tipométricos nos han aportado una valiosa información, tanto desde un punto de vista sincrónico como diacrónico, ya que a nivel interno hemos constatado la selección de las BP de mayor tamaño para su posterior configuración y a nivel diacrónico se evidencia una disminución del tamaño de todas las categorías estructurales con respecto a los sitios de modo 2 en el Campo de Gibraltar, como Algetares (Algeciras) (Castañeda et al. 2009) y de tránsito de modo 2 a modo 3, como Cortijo Carrasco (San Roque-La Línea de la Concepción), Los Partichuelos, Guadalquitón-Borondo 1 (San Roque), Guadalquitón-Borondo 4 (San Roque), Torre Nueva (La Línea de la Concepción), Punta Mala (San Roque) (Castañeda et al. 2010a y b).

2. No se han identificado temas operativos técnicos directos (TOTD), lo que nos sitúa en la línea del paulatino abandono de artefactos líticos de gran formato (bifaces, hendedores, cantos tallados) que ha tenido lugar en esta zona desde el OIS 5 (Castañeda et al. 2010a).

3. Si existe una variedad de temas operativos técnicos indirectos (TOTI), representados por distintas estrategias de talla, entre las que se encuentran:

- Los unifaciales unipolares como los longitudinales $(n=5)$, donde la explotación se realiza sobre un 
plano de la BNE. Los unifaciales bipolares, representados por opuestos $(n=2)$ y ortogonales $(n=3)$. Los unifaciales multipolares, representado por 1 centrípeto sin preparación.

- Los bifaciales unipolares con 2 BNE circulares. Los bifaciales bipolares, representados por 7 ortogonales. Los bifaciales multipolares, representados por 108 centrípetos, correspondientes a distintos métodos de talla que desarrollaremos a continuación.

- Los trifaciales, representados por 3 unipolares circulares y por 1 multipolar.

4. La estrategia de talla dominante es la bifacial multipolar centripeta donde se encuentran representados diferentes métodos de talla, como son:

- Estrategia de talla bifacial multipolar centrípeta, con método de talla discoide $(n=15)$, en su mayoría con dos superficies no jerarquizadas simétricas.

- Estrategia de talla bifacial multipolar centrípeta, con método de talla predeterminado de lasca preferente $(n=15)$, con dos superficies jerarquizadas asimétricas.

- Estrategia de talla bifacial multipolar centrípeta, con método de talla predeterminado recurrente $(n=71)$, con dos superficies jerarquizadas asimétricas.

5. Podemos concluir tras el análisis de las diferentes estrategias y métodos de talla que las secuencias operativas se dirigen a la producción exclusiva de $\mathrm{BP}$, utilizando para ello métodos de talla predeterminados (levallois) y estandarizados (discoides) junto a otros que le sirven de complemento.

6. Cabe preguntarse al analizar las secuencias de explotación el motivo que llevó al tallador a agotar las BNE a tamaños tan reducidos, como por ejemplo $30 \times 20 \times 15 \mathrm{~mm}$, que tras tomar medidas de los negativos dejados por las BP extraídas, inferiores a $1 \mathrm{~cm}$, éstas en ningún caso han podido ser configuradas en $2^{\text {a }}$ generación, cuando además se observó justo lo contrario al analizar las BN2GC, es decir, se seleccionaron las BP de mayor tamaño. Por ello planteamos: ¿Cuál es el motivo del grado de explotación terminal que presentan las $B N E$, cuando los artefactos líticos finales no han sido utilizados para configurar herramientas líticas retocadas en segunda generación?, si además la materia prima empleada se encuentra de manera natural y abundante en el propio yacimiento. Este hecho ya fue observado por L. G. Vega Toscano (1988: 498-499). Hasta el momento y teniendo en cuenta las características propias del yacimiento, nos situamos en la línea explicativa de E. Boëda (1991) que la justifica en base a la tradición técnica y cultural tan arraigada en estos grupos cazadores-recolectores.

7. En los sistemas de explotación evidenciamos una selección técnica en los métodos de talla levallois, tendentes a la obtención de BP que serán transformadas en BN2GC (raederas), mientras que de un método de talla menos exigente técnicamente, como el discoide, resultarán BP que serán transformadas en muescas y denticulados principalmente.

8. Algunas BNE con estrategia de talla bifacial multipolar centrípeta y método de talla discoide, en su etapa final de producción se asemejan morfológicamente a BNE bifaciales multipolares centrípetas predeterminadas recurrentes, esto es debido a que ciertos soportes pueden sobrepasar la cúspide del núcleo, presentando un plano de explotación plano (Slimak 1998-1999).

9. Las Bases Positivas (lascas), son la categoría estructural mejor representada, por lo que el objetivo de los sistemas de explotación ha sido su producción. Se trata de un conjunto de lascas planas o muy planas que son el resultado de las distintas estrategias y métodos de talla desarrollados anteriormente, concretamente bifaciales multipolares centrípetos (recurrentes, de lasca preferente y discoide). Existen numerosas BP no corticales, procedentes de métodos de talla predeterminados (levallois) que presentan filos activos susceptibles de ser utilizados y algunos con trazas de utilización. Este hecho nos enlaza con el concepto de "útil", y que entendemos por útil, y de las limitaciones que suponen los estudios tecnológicos sin su complementariedad traceológica. Las piezas descritas como láminas lo son tipométricamente, pero no tecnológicamente, es decir, no proceden de sistemas de explotación prismáticos ni para hojas.

10. Fueron las raederas las BN2GC a las que se dirigieron los gestos técnicos más específicos y desarrollados. Se ha demostrado una selección de materia prima más compacta y de menor tamaño de grano, así como la utilización de los soportes de mayores dimensiones.

11. En definitiva, los miembros del grupo utilizan para la elaboración de los artefactos líticos la estrategia de talla bifacial multipolar centripeta recurrente y el método de talla levallois, resultando soportes predeterminados que serán transformados en raederas, con indices superiores al 50\%, concretamente un $54,5 \%$, que se incrementa hasta el 60,9\% si incluimos las raederas denticuladas, con índice levallois alto de modo genérico y muy alto si analizamos los soportes sobre los que se materializaron las raederas con un $61,4 \%$, con índices de muescas y denticula- 
dos medios con un 22,3 y $20,6 \%$ respectivamente, reduciéndose el índice de denticulados al 14,2\% si no tenemos en cuenta las raederas denticuladas.

\subsection{Conclusiones generales}

El estudio geológico y geomorfológico, el análisis morfotécnico del conjunto lítico y las distintas analíticas realizadas a la variedad litológica nos ha permitido plantear una serie de conclusiones generales:

1. Barajamos la posibilidad de que el yacimiento se encuentre mínimamente desplazado, prácticamente "in situ", en base a:

- Los nulos índices de rodamiento en todas las categorias estructurales, la frescura que presenta la talla, con filos activos aún en la actualidad.

- La presencia de la secuencia de producción completa, desde los primeros gestos técnicos encaminados a la explotación hasta la configuración, donde el porcentaje de cortex en la cara dorsal de las BP es del $32,8 \%$.

- La nula selección que ha sufrido el material por los distintos agentes erosivos, pues hemos localizado tanto esquirlas con medidas inferiores a $1 \mathrm{~cm}$ como BNE con medidas que llegan a los $15 \mathrm{~cm}$.

A pesar de ello somos conscientes de que no podemos afirmar que el yacimiento se encuentre en posición primaria, al tratarse de un sitio de superficie que no ha sido excavado.

2. En el conjunto lítico analizado y huyendo de posiciones teóricas deterministas, carecemos de elementos indicadores de tránsito, ya sea del modo 2 al 3 (total ausencia de Temas Operativos Técnicos Directos) o del modo 3 al 4, como puede ser el indice laminar que cuando aparece es de manera accidental y no como consecuencia de un método de talla determinado tendente a la obtención de este tipo de soportes, las dimensiones generales del conjunto analizado, asi como las de los soportes transformados en segunda generación por medio del retoque, no marcan ningún indicio de tendencia a formatos pequeños o muy pequeños, propios de modos técnicos posteriores, es decir no existe ningún indicador de tendencia a la microlitización ni leptolitización, así como el conjunto de artefactos característicos de lo que normativamente conocemos como Paleolítico Superior es muy bajo, con un indice del 2,6\% de las BN2GC y un $0,45 \%$ del total.

3. Por ello y visto lo expuesto a lo largo de este trabajo tras el planteamiento geológico, tecnológico y lito- lógico realizado, consideramos que podemos situar el yacimiento de la desembocadura del río Guadalmesí, de manera relativa en un genérico Pleistoceno Superior, adscrito normativamente a lo que conocemos como Musteriense Típico, de Tipo 1 o rico en raederas (Vega 1988) y tecnológicamente, como se analizó en la contextualización histórica, en la línea de los niveles de Bajondillo/17 y BajondiIlo/16, donde contamos con una datación absoluta por TL para Bj/17 de $64500 \pm 6300$ y dos dataciones absolutas por TL para Bj/16 de $39983 \pm 2710$ y $39183 \pm 4620$.

4. En cuanto a la funcionalidad del sitio planteamos la hipótesis, a validar o refutar con posibles excavaciones o analíticas posteriores, de que el yacimiento de la desembocadura del río Guadalmesí es un lugar de selección, aprovisionamiento y transformación de materias primas, así como de aprovechamiento de los recursos marinos costeros.

Recursos marinos costeros que en el caso del sur peninsular y concretamente en el espacio físico del Estrecho de Gibraltar se definen, según el registro arqueológico, en moluscos como los mejillones, mamiferos marinos, como focas y delfines, incluso peces $y$ tortugas. Aprovechamiento que tiene lugar en los momentos de frecuentación cíclica de la zona que realizan estas sociedades en determinadas épocas del año (Stringer 2008).

Consideramos que con el yacimiento de la desembocadura del río Guadalmesí nos encontramos ante un lugar de referencia, debido a la importancia cualitativa y cuantitativa del conjunto, a la localización en las inmediaciones de sitios de similar tecnología y adscripción geomorfológica, pero secundarios respecto a este, el acceso inmediato a la materia prima utilizada en la elaboración del conjunto lítico, la cercanía del agua dulce, no sólo el propio río Guadalmesí, sino los arroyos próximos como Alhelíes o arroyo de la Viña, así como la posibilidad de acceso inmediato tanto a recursos biológicos terrestres como costeros.

5. El yacimiento de la desembocadura del río Guadalmesí es un sitio de ocupación del espacio al aire libre, lo que no es ajeno a esta región con ejemplos vistos en el valle del Guadalquivir, valle del Guadalete, valle del Palmones, banda atlántica de Cádiz, y Laguna de la Janda (Tarifa), aunque existen ocupaciones en cuevas y abrigos, como las cuevas de Gibraltar (R.U.) o Abrigo de Benzú (Ceuta).

Estos sitios al aire libre son posibles gracias a la benignidad del clima en el sur peninsular (Ruiz 1991, 1997), incluso durante las etapas más frías, siendo considerado por algunos autores como refugio gla- 
cial para muchas especies durante el Cuaternario (Finlayson et al. 2006).

6. La variabilidad demostrada por estas sociedades en cuanto a materia prima, estrategias y métodos de talla, aprovechamiento de recursos (caza y recolección), diversidad de asentamientos y ocupación del territorio, es muy amplia. Entendemos esta variabilidad como la capacidad del H. neanderthalensis de "transformar" el medio (Ramos 1999), valoramos a los neandertales con capacidad suficiente para superar el medio que en ningún caso les sitúa en la línea de argumentos caducos y superados.

7. Creemos necesario estar atentos a los distintos parámetros indicadores del cambio y no sólo desde un punto de vista unilineal como plantean los modelos tipologicistas y ambientalistas, sino proponiendo la necesidad del trabajo interdisciplinar que nos permita comprender la dinámica interna de estos grupos sociales, el peso de la trasmisión cultural y el desarrollo tecnológico desde bases locales, más cercanas al concepto de continuum que al de ruptura.

\section{AGRADECIMIENTOS}

Este trabajo ha sido desarrollado en el marco del grupo de investigación Primeras ocupaciones humanas y sus inferencias socioeconómicas en el Extremo Sur de la Península Ibérica (PAI HUM-831), autorizado y subvencionado por la Consejería de Innovación, Ciencia y Empresa de la Junta de Andalucia y que cuenta con la dirección y responsabilidad del Prof. Vicente Castañeda (Universidad de Cádiz).
Es una satisfacción recordar a las personas que sufrieron la redacción de la memoria de investigación, por ello deseo expresar mi agradecimiento, a mi profesor y amigo Vicente Castañeda, codirector del trabajo, gracias por tu apoyo, por estar ahí en los momentos de debilidad, por creer en mis posibilidades, por los comentarios realizados a cada capítulo y por tu calidad humana. Al Prof. Martí Mas, de quién he sentido el apoyo y la libertad que se precisa, tanto formal como metodológica, para la redacción del trabajo. A mi amigo Francisco Luis Torres, por tu paciencia ante mis insistentes consultas, pues mi formación como historiador adolece de falta de conocimientos geológicos y litológicos que has sabido transmitir y dirigir, gracias igualmente por la identificación litológica del conjunto analizado. Al Prof. Eudald Carbonell que amablemente dio respuesta a las dudas que me planteaba aplicar el Sistema Lógico Analítico al conjunto estudiado. Al Prof. José Ramos, quién despertó en mí el interés por la tecnología lítica y me enseñó a valorar en su extensión a las sociedades cazadoras-recolectoras. A Yolanda Costela, por tus palabras de apoyo y el interés mostrado, así como por los dibujos de las piezas a partir de los que se han montado las figuras, a mi amigo José María Tomassetti, porque tu ironía me anima en momentos de debilidad, gracias por digitalizar las imágenes de las figuras que aparecen en este artículo. A Juan Carlos, un amigo con el que siempre puedo contar, gracias por acercar a esta comarca la bibliografía específica necesaria para la redacción de este trabajo. A Silvia Ros por la traducción del resumen al inglés. Como no, a María del Mar y Daniel, porque sin vuestro apoyo y comprensión no habría sido posible. •

\section{BIBLIOGRAFÍA}

ARTEAgA, O. 1992: "Tribalización, Jerarquización y Estado en el territorio de El Argar". Spal 1: 179-208.

Barroso, C. (Coord.) 2003: El Pleistoceno Superior de la cueva del Boquete de Zafarraya. Serie monografias de Arqueología Junta de Andalucía. Sevilla.

BarRoso, C. y Lumley, H. (Dir.) 2006: La Grotte du Boquete de Zafarraya, Málaga, Andalousie. 4 volúmenes. Consejería de Cultura de la Junta de Andalucía. Sevilla.

Barroso, C., Medina, F., Boutié, P. y Barsky, D. 2006: "Les industries moustériennes de la grotte du Boquete de Zafarraya". En Barroso, C. y Lumley, H. (Dir.): La Grotte du Boquete de Zafarraya, Málaga, Andalousie. Tomo III. Consejería de Cultura de la Junta de Andalucía. Sevilla: 1497-1586

BATE, L. F. 1998: El proceso de investigacion en arqueología. Editorial Crítica. Barcelona.

BINFORD, L. 1962: "Archeology as anthropology". American Antiquity 28: 217-225.

BoËDA, E. 1988: "Le concept levallois et evaluation de son champ d'application". L'Homme de Néandertal, Vol. 4, La Technique, Liége: 13-26.

- 1990: "De la surface su volume, analyse des conceptions des débitages levallois et laminaire". Paleolithique moyen récent et Paleolithi- que supérieur ancien en Europe. Colloque international de Nemours, 9-11 mai 1988. Mémoires du musée de Préhistoire d'ille-de-France, 3: 63-68.

- 1993: "Le débitage discoïde et le débitage levallois récurrent centripète". Bulletin de la Société Préhistorique Francaise 90: 392404.

- 1994: Le concept levallois: variabilité des méthodes. Monographie du Cra 9. CNRS Editions. Paris.

- 1995: "Levallois: A volumetric construction, methods, a technique". En H. L. Dibble y 0. Bar-Yosef (Eds.): The definition and interpretation of levallois technology. Monograps in world Archaeology, 23, Wisconsin: 41-68.

BoRDES, F. 1961: Typologie du Paleolithique ancien et moyen. Publications de I'Institut de Préhistorie de I'Université de Bordeaux, 1. Burdeos.

BREUIL, H. 1914: "Stations Chelléennes de la provincie de Cadix". Institut Français d'Anthropologie, 2: 67-79.

- 1917: "Observations sur les terres noires de la Laguna de la Janda". L'Anthropologie 28: 235-240.

BREUIL, H. y BURKIT, M. 1929: Rock Paintings of southern Andalusia. A description of a Neolithic and Cooper Age art group. Clarendon Press. Oxford.

CarbonelL, E. (Coord.) 2005: Homínidos: Las primeras ocupaciones de los continentes. Ed. Ariel. 
Carbonell, E., Guilbaud, M. y Mora, R. 1983: "Utilización de la lógica analítica para el estudio de tecno-complejos a cantos tallados". Cahier Noir 1: 3-64.

Carbonell, E., Márouez, B., Mosouera, M., Olle, A., Rodríguez, X. P., Sala, R. y Verges, J. M. 1999: "El modo 2 en Galería. Análisis de la industria lítica y sus procesos técnicos". En Carbonell, E., Rosas, A. y Diez, J.C. (Eds.): Atapuerca: ocupaciones humanas y paleoecología del yacimiento de Galería: 299-352.

Carbonell, E., Olle, A., Rodriguez, X. P., Sala, R. y Verges, J. M. 1997: "Instrumentos de los homínidos de Atapuerca". Mundo Científico 175: 54-59.

Carbonell, E., Rodríguez, X. P., Mosquera, M., Olle, A., Sala, R., Vaquero, M. y VERGES, J. M. 2006: "El Sistema Lógico Analítico: una herramienta para el estudio de la tecnología prehistórica". Dialektikê. Cahiers de Typologie Analytique 2006 Hommage a Georges Laplace: 44-62.

Carbonell, E., Rodríguez, X. P., Sala, R. y Vaquero, M. 1992: "New elements of the logical analytic system", Cahier Noir 6: 3-59.

CARO, J. A. 2000: "Evolución de las industrias achelenses en las terrazas fluviales del bajo Guadalquivir (780.000-40.000 B. P.): episodios geomorfológicos y secuencia Paleolítica". SPAL 9: 189-207.

- 2006: "Yacimientos e industrias Achelenses en las terrazas fluviales de la depresión del bajo Guadalquivir (Andalucia, España). Secuencia estratigráfica, caracterización tecnocultural y cronología". CAREL 4: 1423-1605

CASTAÑEDA, V. 2011: "Algunas reflexiones sobre la transición en el Paleolítico. El paso del modo tecnológico 2 al 3 en el Campo de Gibraltar (sur de España)". Homenaje al Profesor Antonio Caro Bellido, Vol. I: Prehistoria y Protohistoria de Andalucía y Levante. Servicio de Publicaciones de la Universidad de Cádiz.

- (Coord.) 2008: Las primeras ocupaciones humanas de los Barrios (Cádiz). El ejemplo proporcionado por el río Palmones. Servicio de Publicaciones de la Universidad de Cádiz e Ilmo. Ayuntamiento de la Villa de Los Barrios. Cádiz.

Castañeda, V., Costela, Y., Torres, F. y Pérez, L. 2011: "Ventorrillo de la Trocha 1 y 2 (Algeciras, Cádiz). La consolidación de la economía de producción en el Campo de Gibraltar durante el IV y el III milenio a.n.e.". II Jornadas de Prehistoria y Arqueología en el Campo de Gibraltar. Los Barrios 5, 6 y 7 de junio de 2009. Cádiz.

Castañeda, V., Pérez, L., Torres, F., Costela, Y., Jiménez-Camino, R. y TomasSETTI, J. M. 2009: "Los modelos de reducción lítica en Algetares (AIgeciras, Cádiz) durante el modo 2 y su contextualización histórica en el ámbito del Estrecho de Gibraltar". Espacio, Tiempo y Forma. Serie I, Prehistoria y Arqueología, Nueva Época 2.

Castañeda, V., Torres, F., Pérez, L. y Costela, Y. 2010a: "La tenue línea de separación entre los modos 2 y 3 en el Campo de Gibraltar (Sur de la Península Ibérica, España). Una propuesta histórica". SPAL.

- 2010b: "Geología, materias primas, áreas de captación y tecnología de las sociedades de finales del Achelense en el Campo de Gibraltar". VIII Congreso Ibérico de Arqueometría. 19, 20 y 21 de octubre de 2009. Teruel.

CHAcón, M. G. 2009: El paleolítico medio en el suroeste europeo: Abric Romani (Capellades, Barcelona, España), Payre (Rompón, Ardèche, Francia) y Tournal (Bize, Aude, Francia). Análisis comparativo de los conjuntos líticos y los comportamientos humanos. Tesis Doctoral en cotutela Universitat Rovira i Virgili (Dept. d'Història i Història de I'Art) y Muséum National D'Histoire Naturelle. Tarragona.

ClARKE, D. L. 1984: Arqueología analítica. Ed. Bellaterra. Barcelona.

CORTÉs, M. 2002: El Paleolítico Medio y Superior en el sector central de Andalucía (Córdoba y Málaga). Tesis doctoral. Universidad de Córdoba.

- 2007: El Paleolítico Medio y Superior en el sector central de Andalucía (Córdoba y Málaga). Monografías Museo de Altamira, 22.

- (Ed.) 2007: Cueva Bajondillo (Torremolinos). Secuencia cronocultural y paleoambiental del Cuaternario reciente en la Bahía de Málaga. Servicio de Publicaciones, Centro de Ediciones de la Diputación de Málaga. Málaga.

Díaz del Olmo, F., Vallespi, E. y BaenA, R. 1993: "Formaciones Cuaternarias y Secuencia Paleolítica del Bajo Guadalquivir". VI Jornadas de
Arqueología Andaluza. Investigaciones Arqueológicas en Andalucía 1985-1992. Proyectos, Huelva: 193-210.

Fernández, S., Fuentes, N., Carrión, J. S., González-Sampériz, P., Montoya, E., GIL, G., Vega, G. y Riquelme, J. A. 2007: "The Holocene and Upper Pleistocene pollen sequence of Carihuela Cave, southern Spain". Geobios 40: 75-90.

Fernádez-Llebrez, C., Mateos, V. y RamíreZ, J. R. 1988: "Los yacimientos paleolíticos de la depresión de la Janda (Provincia de Cádiz)". Actas del I Congreso Internacional el Estrecho de Gibraltar, Ceuta - Noviembre de 1987. Tomo I, UNED. Madrid: 87-96.

Finlayson, C., Giles, P., Rodriguez-Vidal, J., FA, D., Gutiérrez, J. M., Santiago, A., Finlayson, G., Aluue, E., Baena, J., Cáceres, I., Carrión, J., Fernández, Y., Gleed-OWen, C., Jiménez, F. J., López, P., López, J. A., RIQuelme, J. A., SÁnChez, A., Giles, F., Brown, K., Fuentes, N., Valarino, C., Villalpando, A., Stringer, C. B., Martinez, F. y Sakamoto, T. 2006: "Late survival of Neanderthals at the southernmost extreme of Europe". Nature 443.

GÁNDARA, M. 1993: "El análisis de las posiciones teóricas: aplicaciones a la arqueología social". Boletín de Antropología Americana 27: 5-20.

GARCíA, J. 2005: Tecnología lítica i variabilitat de les indústries del Pleistocè mitjà i superior inicial del nord-est de la península lbèrica i sud-est de Franca: nivel G de la Caune de L'Arago, la Selva i conques del Roselló, Ter i lacustre de Banyoles. Ph. D. Thesis, Universitat Rovira i Virgili de Tarragona (Dept. d'Història, Història de l'Art i Geografia).

Gavala, J. 1924: "Mapa Geológico de la provincia de Cádiz, escala 1:200.000". I.G.M.E.

GENESTE, J. M. 1992: "L'approvisionnement en matières premières dans les systemes de production lithique: la dimension spatiale de la technologie". En Mora, R., et al:: Tecnologia y cadenas operativas líticas. Treballs D'Arqueologia, 1.

GILES, F. 1979: "Cueva del Higueral". Arqueología 79.

Giles, F., Finlayson, C., Gutiérrez, J. M., Santiago, A., Finlayson, G., RelNOSO y C., GILES GUZMÁN, F. 2001: "Investigaciones arqueológicas en Gorham's Cave (Gibraltar): resultados preliminares de las campañas de 1997 a 1999". Almoraima 25: 49-64.

Giles, F., Giles, F. J., Gutiérrez, J. M., Santiago, A., Finlayson, C., RodríguezVIDAL, J., FINLAYSON, G. y FA, D. A. 2011: "The tools of the last Neanderthals: Morphotechnical characterisation of the lithic industry at level IV of Gorham's Cave, Gibraltar" Quaternary International.

Giles, F., Gutiérrez, J. M., Mata, E., Santiago, A. y Gracia, F. J. 1993: "Prospecciones arqueológicas y análisis geocronológicos y sedimentológicos en la cuenca del río Guadalete. Secuencia fluvial y paleolítica del río Guadalete (Cádiz). Resultados de las investigaciones hasta 1993". VI Jornadas de Arqueología Andaluza. Investigaciones Arqueológicas en Andalucía 1985-1992. Proyectos, Huelva: 211-227.

Giles, F., Santiago, A., Aguilera, L., Gutiérrez, J. M. y Finlayson, C. 2003 : "Paleolitico Inferior y Medio en la sierra de Cádiz. Evidencias de grupos cazadores-recolectores del Pleistoceno Medio y Superior". Almajar 1: 8-35.

HeRnÁndeZ-PACHeCO, E. 1915: "Las tierras negras del extremo sur de España y sus yacimientos paleolíticos". Trabajos del Museo Nacional de Ciencias Naturales, serie geológica, 13. Madrid.

Herrero, N., Ramos, J., Castañeda, V., Bernal, D., Vijande, E., Castañeda, A., Moncayo, F. y SÁnchez, P. 2003: "Avance al estudio de los productos arqueológicos del Abrigo de Benzú". En Ramos, J., Bernal, D. y Castañeda, V. (eds.). El Abrigo y la Cueva de Benzú en la Prehistoria de Ceuta. Aproximación al estudio de las sociedades cazadorasrecolectoras y tribales comunitarias en el ámbito norteafricano del Estrecho de Gibraltar. Universidad Nacional de Educación a Distancia de Ceuta y Universidad de Cádiz. Cádiz: 293-323.

Jennings, R. P., Giles, F., Barton, R.N.E., Collcutt, S. N., Gale, R., GleedOWen, C.P., Gutiérrez, J.M., Higham, T. F. G., PARker, A., Price, C., RhOdes, E., Santiago, A., Schwenninger, J. L. y Turner, E. 2009: "New dates palaeoenvironmental evidence for the Middle to Upper Palaeolithic 
occupation of Higueral de Valleja Cave, southern Spain". Quaternary Science Reviews 28: 830-839.

LAPLACE, G. 1972: "La typologie analityque et structurale. Base rationelle d'étude des industries lithiques et osseusses". Banques de données archéologiques 932: 91-143.

Mateos, V., Fernández, C. y Ramírez, J. R. 1990: "Nuevas investigaciones sobre el Cuaternario y la Prehistoria de la Janda". II Congreso Internacional el Estrecho de Gibraltar. Noviembre de 1990. Ceuta.

Mateos, V., Ramírez, J. R. y Fernández, C. 1995: "Hábitat y poblamiento prehistórico en la Comarca de la Janda-Barbate (Cádiz)". III Jornadas de Historia del Campo de Gibraltar, 7-9 octubre 1994. Revista de Estudios campogibraltareños. Almoraima, 13: 23-31.

LUMBRERAS, L. 1974: La Arqueología como ciencia social. Histar. Lima.

MANGADO, J. 2006: "El aprovisionamiento en materias primas líticas: hacia una caracterización paleocultural de los comportamientos paleoeconómicos". Trabajos de Prehistoria 63: 79-91.

MesíAs, D. 2009: Tecnocomplejos del Pleistoceno en la Cuenca MediaBaja del Tajo. El yacimiento Vendimia en la penillanura del Salor, zona y afluente integrados. Tesis Doctoral. Universitat Rovira i Virgili. Tarragona.

MenÉnDEZ, D. L. 2009: La transición del modo 2 al modo 3 vista a través de la industria lítica de Gran Dolina TD10 (Atapuerca, Burgos) y Orgnac 3 (Ardéche, Francia). Desarrollo tecnológico y posibles implicaciones ocupacionales de los conjuntos. Tesis Doctoral. Universitat Rovira i Virgili (Dept. d'Història i Geografia). Tarragona.

Mosouera, M. 1995: Procesos técnicos y variabilidad en la industria lítica del Pleistoceno medio de la meseta: Sierra de Atapuerca, Torralba, Ambrona y Áridos. Tesis Doctoral. Universidad Complutense de Madrid.

Navazo, M. 2006: Sociedades cazadoras-recolectoras en la Sierra de Atapuerca durante el Paleolítico medio: patrones de asentamiento y estrategias de movilidad. Tesis Doctoral. Universidad de Burgos.

OBermaleR, H. 1925: El Hombre Fósil. 2a edición de la memoria número 9 de la Comisión de Investigaciones Paleontológicas y Prehistóricas. Madrid.

PéreZ, L. 2010: El yacimiento de modo técnico 3 de la desembocadura del río Guadalmesí (Tarifa, Cádiz) y su contextualización histórica en el sur de la Península lbérica. Memoria de investigación para la obtención del DEA. Departamento de Prehistoria y Arqueología, UNED. Madrid.

Pérez, L. y ToRres, F. (en PRensA): "Geología, litología e identificación de áreas fuente y caracterización de las materias primas líticas del yacimiento de modo técnico 3 de la desembocadura del río Guadalmesí (Tarifa, Cádiz)". IX Congreso Ibérico de Arqueometría. 26-28 de octubre de 2011. Lisboa.

PETIIT, P. B. y BAILEy, R. M. 2000: "AMS radiocarbon and luminescencedating of Gorham's and Vanguard Caves, Gibraltar, and implications for the middle to upper Palaeolithic transition in Iberia". En Stringer, C. B., Barton, R.N.E. y Finlayson, C.: Neanderthals on the edge. Papers from a conference marking the 150th anniversary of the Forbes' Quarry discovery, Gibraltar. Oxbow Books: 155-162.

Ramirez, J. R., Fernádez-Llebrez, C. y Mateos, V. 1989: "Aproximación al estudio del Cuaternario de la Laguna de la Janda (Cádiz)". El Cuaternario en Andalucia occidental, AEQUA, monografias, 1. Sevilla: 105-111.

Ramos, J. 1999: Europa prehistórica. Cazadores y Recolectores. Ed. Silex. Madrid.

- 2006: "Las sociedades cazadoras-recolectoras en el norte de África y sur de la Península Ibérica. Reflexiones sobre relaciones y contactos desde los orígenes del poblamiento a los grupos portadores de tecnocomplejos de modo 3". En Bernal, D., Bouzzouggar, A., Raissounni, B. y Ramos, J. (eds.), Actas del I Seminario Hispano-Marroquí de espècialización en Arqueología, Universidad de Cádiz. Cádiz: 95-111.

- 2007-2008: "Novedades en el estudio de los grupos humanos portadores del tecnocomplejo Musteriense-Modo III en la banda atlántica de Cádiz, en el contexto del Estrecho de Gibraltar". Veleia 24-25: 397-414.
- (Coord.) 2008: La ocupación prehistórica de la campiña litoral y banda atlántica de Cádiz. Aproximación al estudio de las sociedades cazadoras-recolectoras, tribales-comunitarias y clasistas iniciales. Serie monografias de Arqueología Junta de Andalucía. Sevilla.

Ramos, J., Bernal, D. y CASTAÑeda, V. (eds.) 2003: El Abrigo y la Cueva de Benzú en la Prehistoria de Ceuta. Aproximación al estudio de las sociedades cazadoras-recolectoras y tribales comunitarias en el ámbito norteafricano del Estrecho de Gibraltar. Universidad Nacional de Educación a Distancia de Ceuta y Universidad de Cádiz. Cádiz.

Ramos, J., Bernal, D., Castañeda, V., Durán, J. J., Calado, D., DomínguezBella, S., Ruiz, B., GIL, M. J., JuLIÁ, R., VIJANDE, E. y ChAMORRo, S. 2005: "El abrigo de Benzú (Ceuta). Una secuencia del Pleistoceno Medio y Superior en el Norte de África". Actas do IV Congresso de Arqueología Peninsular. O Paleolítico. Faro: 239-250.

Ramos, J., Bernal, D., Dominguez-Bella, S., Calado, D., Ruiz, B., Gil, M. J., Clemente, I., Durán, J. J., ViJande, E. y Chamorro, S. 2007: "El Abrigo de Benzú (Ceuta). Frecuentaciones humanas de un yacimiento con tecnología de modo 3 en el norte de África". Zephyrus 60: 27-41.

- 2008: "The Benzú rockshelter: a Middle Palaeolithic site on the North African coast". Quaternary Science Reviews 27: 2210-2218.

Rink, W. J., ReES-Jones, J., VolterRa, V. y Schwarcz, H. P. 2000: "ESR, OSL and U-series chronology of Gorham's Cave, Gibraltar". En Stringer, C. B., Barton, R. N. E. y Finlayson, C.: Neanderthals on the edge. Papers from a conference marking the 150th anniversary of the Forbes' Quarry discovery, Gibraltar. Oxbow Books: 165-170.

Rodriguez, X. P. 1997: Los sistemas técnicos de producción lítica del Pleistoceno Inferior y Medio de la Península Ibérica: variabilidad tecnológica entre yacimientos del noreste y de la Sierra de Atapuerca. Ph. D. Thesis, Universitat Rovira i Virgili (Dept. d'Història i Geografia).

Ruiz Bustos, A. 1991: "Hacia una cronología del Cuaternario continental ibérico. Cuestiones básicas a considerar". Raña 10. I. VIII.

- 1997: "Características bioestratigráficas y paleoecológicas que implican los mamiferos en las cuencas de las Cordilleras Béticas". Cuaternario lbérico: 283-296.

SLIMAK, L. 1998-1999: "La variabilité des débitages discoïdes au Paléolithique Moyen. Diversité des Méthodes et unité d'un concept. L'exemple des gisements de la Baume Néron (Soyons, Ardèche) et du Champ Grand (Saint-Maurice-Sur-Loire, Loire)". Préhistoire Anthropologie Méditerranéennes 7-8: 75-88.

STRINGER, et al. 2008: "Neanderthal exploitation of marine mammals in Gibraltar". PNAS: 105: 14319-14324.

TERRADAS, X. 2001: "La gestión de los recursos minerales en las sociedades cazadoras-recolectoras". Treballs D'Etnoarqueología 4.

Terradillos, M. 2010: El Paleolítico inferior en la Meseta Norte. Sierra de Atapuerca, la Maya, El Basalito, San Quirce y Ambrona. Estudio tecnológico y experimental. Tesis Doctoral. Universidad de Burgos.

Thompson, E. P. 1981: Miseria de la Filosofía. Ed. Crítica. Barcelona.

Torres, F., CastañedA, V., Pérez, L. y Costela, Y. 2012: "Geología, materias primas, áreas de captación y tecnología de los sistemas técnicos de modo 2 y modo 3 en el Campo de Gibraltar (extremo sur de la Península Ibérica)". Memorial Siret, I Congreso de Prehistoria de Andalucía: La Tutela del Patrimonio Prehistórico. Consejeria de Cultura de la Junta de Andalucía.

Torres, F., García, M., Gómez, M. I. y Mariscal, D. 2003: "Aprovisionamiento de materias primas líticas en el territorio del Campo de Gibraltar durante la Prehistoria". En VII Jornadas de Historia del Campo de Gibraltar, Castellar de la Frontera 18, 19 y 20 de octubre de 2002, Almoraima 29: 59-69.

TURO, A. 1996: "L'approvisionnement en matière première lithique au Mousterien et au début du Paléolithique supérieur dans le nord est du bassin aquitain: continuité ou discontinuité?". En Carbonell, E. y Vaquero, M. (eds.): The last Neandertals, the first anatomically modern humans: a tale about the human diversity. Cultural change and human evolution: the crisis at 40 KA BP: 355-362. 
Valenzuela, J. M. 1995: "Las redes hidrográficas del Campo de Gibraltar. Distribución de sedimentos". Revista de Estudios campogibraltareños. Almoraima 14: 53-67.

VallesPi, E. 1990: "Paleolítico y Epipaleolítico". I/ Congreso Internacional El Estrecho de Gibraltar, noviembre 1990, Ceuta: 3-18.

- 1992: "Las industrias achelenses en Andalucía: ordenación y comentarios". SPAL 1: 61-78.

- 1999: "Comentario al Paleolítico lbérico: continuidad, etapas y perduraciones del proceso tecnocultural". SPAL 8: 39-46.

- 2006: "El Bajo Guadalquivir en los comienzos de su historia humana. Investigaciones del proyecto 1985-1993 y tesis doctorales de 1993, 98 y 99 (nota informativa)". En CAREL 4.

VEGA, L. G. 1988: El paleolítico Medio del sureste español y Andalucía oriental. Colección Tesis Doctoral n. ${ }^{\circ}$ 466/88. Universidad Complutense de Madrid.
- 1993: "El tránsito del Paleolítico Medio al Paleolítico Superior en el sur de la Península Ibérica". En Cabrera, V. (ed.): El origen del hombre moderno en el suroeste de Europa. Universidad Nacional de Educación a Distancia. Madrid.

VolterRa, V., Schwarcz, H. P. y Rink, W. J. 2000: "Results of the Current program of ESR dating of Gorham's Cave teeth from the Gibraltar Museum". En Stringer, C. B., Barton, R. N. E. y Finlayson, C.: Neanderthals on the edge. Papers from a conference marking the 150th anniversary of the Forbes 'Quarry discovery, Gibraltar. Oxbow Books: 163-164.

WAECHTER, J. D'A. 1951: "Excavacations of Gorham's Cave, Gibraltar, Preliminary report for the seasons 1948 and 1950". Proceedings of the Prehistoric Society 17: 83-92.

- 1964: "The excavacation of Gorham's Cave, Gibraltar, 1951-54". Bulletin of the Institute of Archaeology 4: 189-221. 